\title{
WestVirginiaUniversity
}

THE RESEARCH REPOSITORY @ WVU

Graduate Theses, Dissertations, and Problem Reports

2002

\section{Determining the effects of phosphorylation on AFAP-110 function}

\author{
Lidia Nikolayevna Cherezova \\ West Virginia University
}

Follow this and additional works at: https://researchrepository.wvu.edu/etd

\section{Recommended Citation}

Cherezova, Lidia Nikolayevna, "Determining the effects of phosphorylation on AFAP-110 function" (2002). Graduate Theses, Dissertations, and Problem Reports. 1517.

https://researchrepository.wvu.edu/etd/1517

This Thesis is protected by copyright and/or related rights. It has been brought to you by the The Research Repository @ WVU with permission from the rights-holder(s). You are free to use this Thesis in any way that is permitted by the copyright and related rights legislation that applies to your use. For other uses you must obtain permission from the rights-holder(s) directly, unless additional rights are indicated by a Creative Commons license in the record and/ or on the work itself. This Thesis has been accepted for inclusion in WVU Graduate Theses, Dissertations, and Problem Reports collection by an authorized administrator of The Research Repository @ WVU. For more information, please contact researchrepository@mail.wvu.edu. 


\title{
Determining the effects of phosphorylation on AFAP-110 function
}

\author{
Lidia Nikolayevna Cherezova
}

Thesis submitted to the School of Medicine at West Virginia University

in partial fulfillment of the requirements

for the degree of

Master of Science

in

Biological Science

Daniel Flynn, Ph.D., Chair

John Barnett, $\mathrm{PhD}$

Bing-Hua Jiang, PhD

Department of Microbiology, Immunology, and Cell Biology

Morgantown, West Virginia

2002

Key Words: “AFAP-110, PKC, phosphorylation, actin filament cross-linking, 14-3-3". 


\title{
Abstract
}

\section{Determining the effects of phosphorylation on AFAP-110 function.}

\author{
Lidia N. Cherezova
}

AFAP-110 was discovered in late eighties as a $110-\mathrm{kDa}$ protein that associates with active Src in Src transformed cells. Since then it has been determined that AFAP110 is a actin cross-linking protein with an intrinsic ability to remodel actin cytoskeleton in response to signals from active Src and PKC. AFAP-110 associates with Src via SH2 and SH3 interactions and with PKC via amino terminal PH domain. AFAP-110 binds actin filaments directly, multimerizes via carboxy-terminal leucine zipper motif and also possesses an intrinsic ability to remodel actin cytoskeleton. Therefore AFAP-110 may act as a cellular effector for Src and PKC remodeling actin filaments in response to activation of these kinases. AFAP-110 is hyperphosphorylated on serine and threonine residues in active Src expressing cells and in cells subjected to PMA treatment in PKC-dependent manner. PKC-dependent phosphorylation influences AFAP-110 multimerization mode as well as its actin-cross linking abilities. Therefore it became important to identify functional serine/threonine phosphorylation sites of AFAP-110.

As there are over twenty potential PKC phosphorylation sites in AFAP-110 structure, deletional mutagenesis was employed to determine which regions of AFAP110 are most likely to contain crucial sites for PKC phosphorylation. Our data indicate that functional PKC phosphorylation sites must be localized to the amino acid stretch 266-294 within STK region of AFAP-110. There are four PKC candidate phosphorylation sites in this region; they are being substituted by alanine residues in order to determine their significance in serine/threonine phosphorylation regulation of AFAP-110 function.

Analysis of AFAP-110 amino acid sequence has also revealed that AFAP-110 contains twelve potential 14-3-3 binding sequences. 14-3-3 proteins are a family of small acidic adaptor proteins of dimeric nature that act as molecular scaffolds and/or allosteric regulators in a number of cellular pathways. We have been interested to determine whether 14-3-3 is a binding partner for AFAP-110 in vivo. We determined that AFAP110 associates with 14-3-3 in vivo, although it still remains unknown whether this association is direct or facilitated by any of a multitude of 14-3-3 binding partners. 


\section{Table of contents}

Determining the effects of phosphorylation on AFAP-110 function ...................................................

Abstract.............................................................. ii

Acknowledgements.................................................

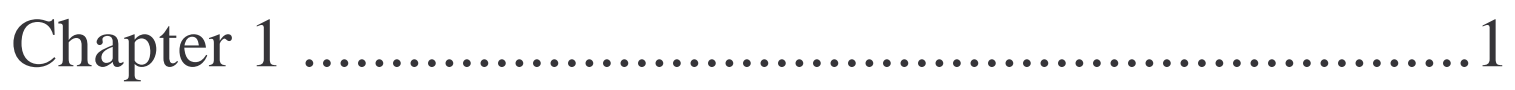

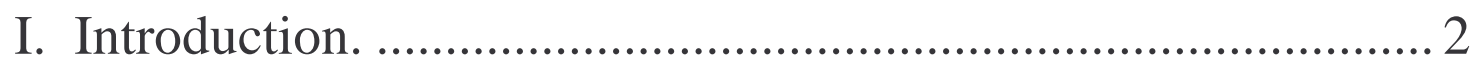

II. Indirect effects: Serine/threonine phosphorylation of another protein enables it to become a binding partner for an adaptor

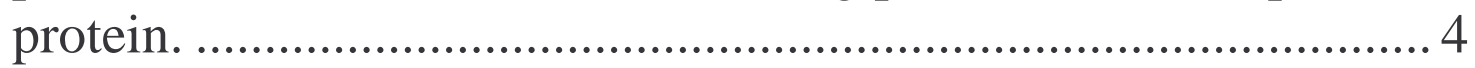

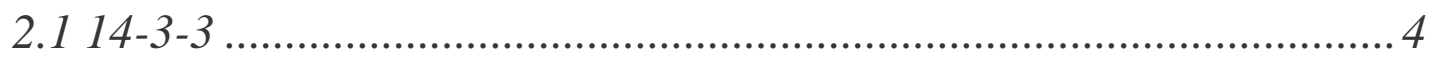

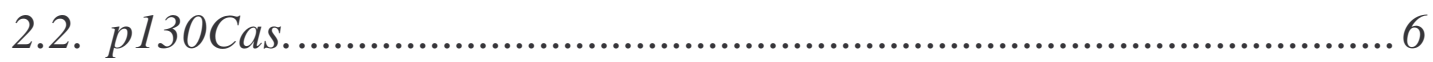

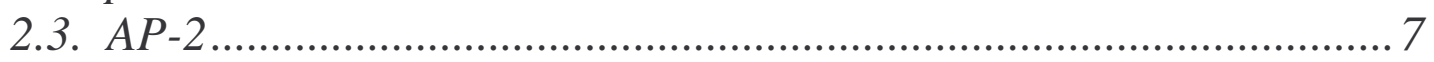

III. Adaptor proteins that are serine/threonine phosphorylated but function of phosphorylation remains to be determined........... 8

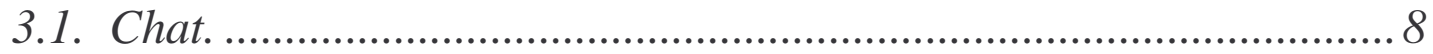

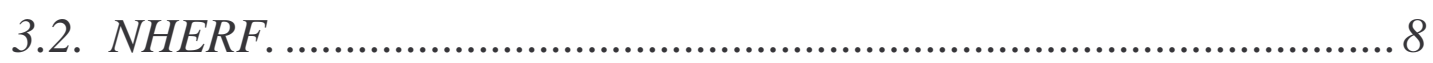

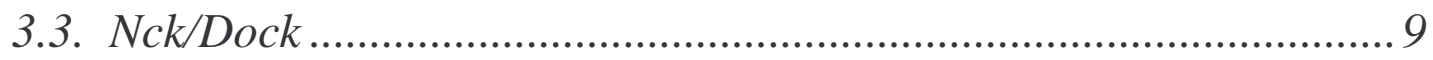

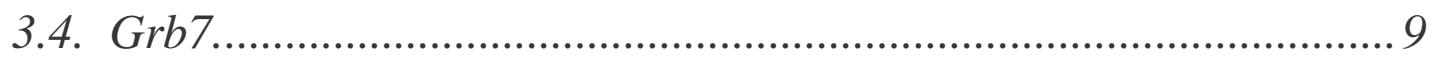

IV. Direct effects: Serine/threonine phosphorylation of an adaptor protein recruits in a binding partner for it. .................... 10

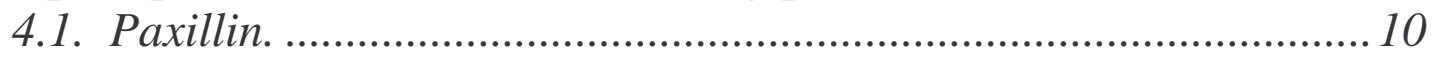

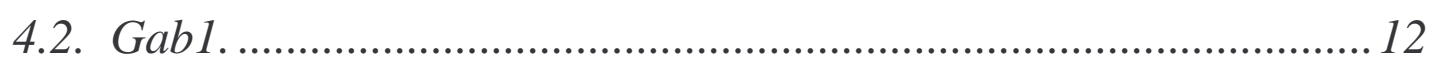

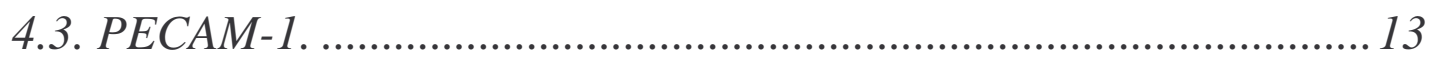

4.4. Sos.

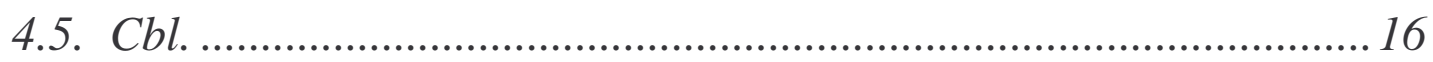

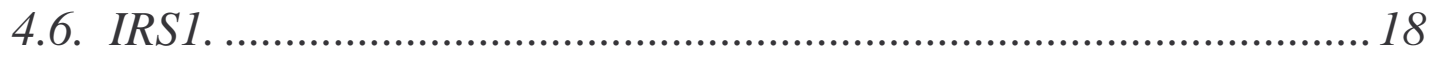

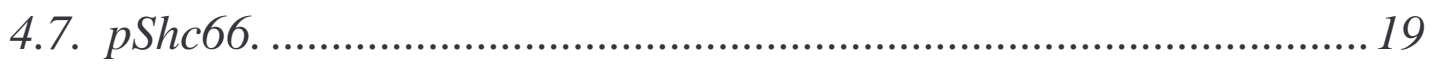

V. Direct effects: Serine/threonine phosphorylation of an adaptor protein alters its conformation and subsequent function............. 21

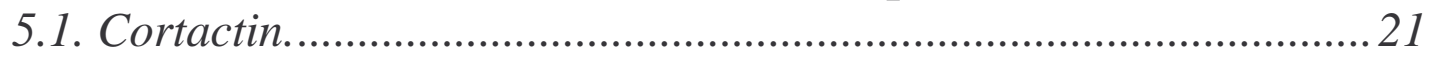

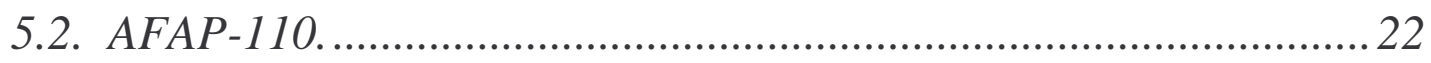

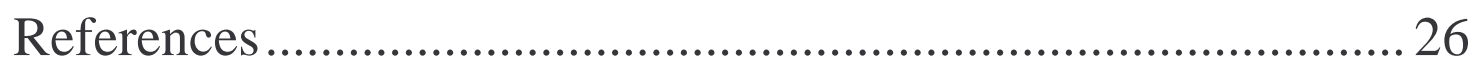


Chapter 2 ................................................................

Determining the effects of phosphorylation on AFAP-110 function. ..................................................33

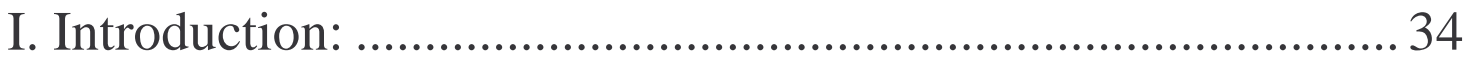

II. Materials and methods........................................................... 37

III. Results............................................................................ 44

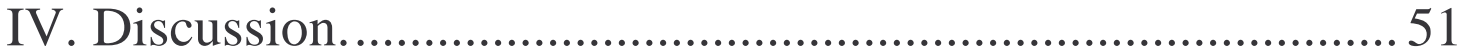

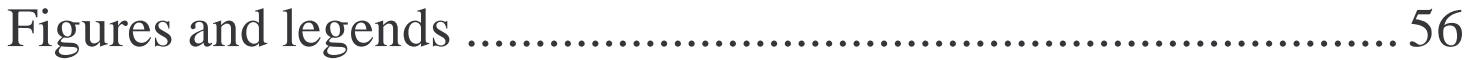

References........................................................................... 70

Chapter 3 .......................................................

Determining whether 14-3-3 is a binding partner for AFAP-110.....................................................71

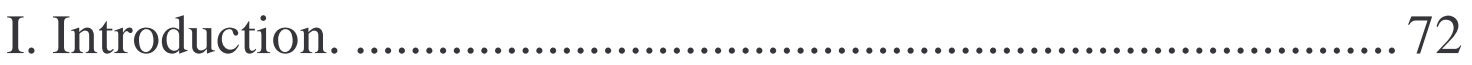

II. Materials and methods. .................................................. 75

III. Results......................................................................... 78

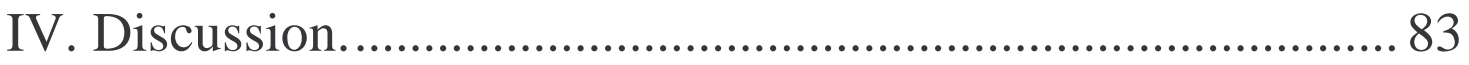

Figures and legends. ............................................................... 86

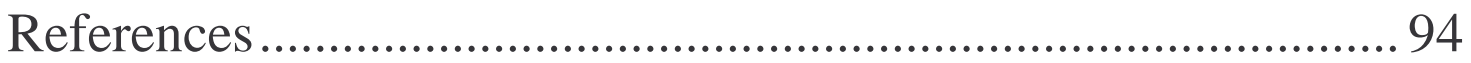

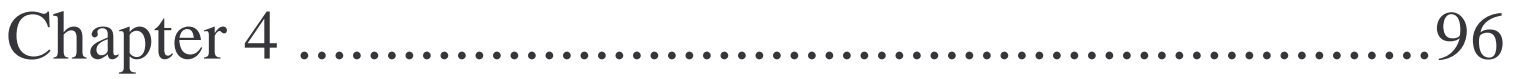

General discussion ............................................96

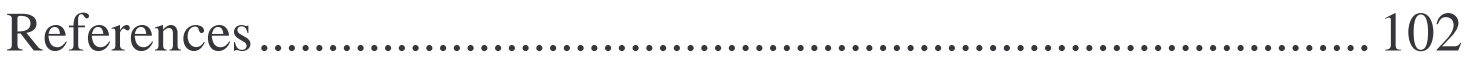

Curriculum vitae ...............................................103 


\section{Acknowledgements}

I would like to express my most profound gratitude to my advisor, Dr. Daniel C. Flynn for his support and guidance during my graduate career. By allowing me to take on a challenging project Dr. Flynn has greatly contributed to my development as a scientist. I would like to thank Dr. Flynn for his insight on ideas that I discussed with him, and for his patience in keeping me on the right path.

I would like to thank the members of my committee, past and present, including Dr. John Barnett, Dr. Bing-Hua Jiang, Dr. Peter Mathers and Dr. Michael Miller. Their advice has helped me a great deal with experimental design as well as with presentation of my data and with writing of my thesis.

I would like to thank all the members of Dr. Flynn's Lab, including Anne Guappone Koay, Dr. Yong Qian, Dr. Joseph Baisden, Dr. Justin Summy, Amanda Gatesman, Ihtishaam Qazi, Carrie Marshall, Thomas Brown, and Andy Clump. They were always there to provide me with theoretical and technical advice, and kept my lab days enjoyable.

Finally, I would like to thank all my family and friends who supported me throughout my graduate career. My special thanks are to my husband, Vladimir Sadov, for his love and understanding and for his help at the hard times during my graduate years. 


\section{Chapter 1}

\section{Serine/threonine phosphorylation of adaptor proteins}




\section{Introduction.}

Phosphorylation of proteins is a reversible form of posttranslational modification that occurs rapidly in response to cellular signals to regulate protein function. Phosphorylated proteins often display conformational changes and/or altered ability to interact with binding partners. Until recently tyrosine phosphorylation regulated proteinprotein interactions were the subject of thorough investigation while the sole consequence of serine/threonine phosphorylation were thought to be allosteric modifications. In the past few years it became apparent that serine/threonine phosphorylation regulates protein-protein interactions not only via allosteric mechanism, but also results in their ability to form complexes with phospho-serine/threonine specific binding partners. Four phospho-serine/threonine binding domains that have been identified are described below.

14-3-3 ligand binding groove was the first phospho-serine/threonine specific binding domain to be identified (1). It represents a carboxy-terminal part of the 14-3-3 molecule with highly conserved residues lining the inner surface of a concave ligandbinding groove (2). Co-crystallization studies have confirmed the phosphorylation specific nature of 14-3-3-ligand interactions (3). Most well-known consensus sequences for 14-3-3 conserved binding groove are RSXpS/TXP and RXSXpS/TXP. Arginine in -3 or -4 position relative to phosphorylated serine or threonine is required, whereas serine in -2 and proline in +2 are preferable. Serine or threonine in position 0 must be phosphorylated for 14-3-3 to bind to a target protein. Phosphorylation of serine in -2 position does not enable 14-3-3 binding (4). 14-3-3 binds to a variety of signaling and structural proteins, thus it may act as a scaffold to bring different target proteins into complexes facilitated by its ability to form saddle-shaped dimers via interaction between amino terminal parts of the two 14-3-3 molecules (2).

WW domains are relatively small 35-40 amino acid modules that bind prolinerich sequences PPXY or PPLP. Recently it became apparent that certain WW domains bind target proteins in a phosphorylation specific manner. WW domains of prolyl isomerase Pin1 and ubiquitin ligase Nedd4 have been shown to recognize pSer/Thr-Pro motifs on target proteins (5). Pin1 is a prolyl isomerase, a protein whose function is cistrans isomerization of peptidyl-prolyl bond. Pin 1 differs from other prolyl isomerases as 
it is able to catalyze isomerization of pSer/Thr-Pro bond while it is known that phosphorylation of Ser or Thr residue in Ser/Thr-Pro sequences reduces the rate of isomerization for other prolyl isomerases (6). WW domain of Pin 1 binds mitotic phosphoproteins via interactions with $\mathrm{p}$-Ser or $\mathrm{p}$-Thr. This binding occurs in a phosphorylation dependent manner for Pin 1 does not initiate binding to mitotic targets if they were dephosphorylated. The crystal structure shows that the Pin $1 \mathrm{WW}$ domain has a hydrophobic cluster formed by different strands of $\beta$ sheets (6). Co-crystallization of the WW domain of Pin 1 with a phosphopeptide substrate show the structural basis for WWPhosphorylated target interactions (7). WW domain of ubiquitin ligase Nedd4 has also been shown to associate with target proteins via phosphothreonine or phosphoserine interactions, which are responsible for presentation of proteins for ubiquitination $(5 ; 6)$.

Forkhead associated domains (FHA) are conserved 55-75 amino acid modules that were originally found in forkhead family transcription factors (8). They are present in both eucaryotes and prokaryotes. FHA domain contains three highly conserved stretches of amino acid separated by variable regions. Each conserved stretch contains invariable residues in the middle of it - a Gly for the first and third, His for the second position. The secondary structure of FHA has a $\beta$ strand structure. The majority of FHA proteins known today are nuclear proteins that fall into three categories - transcription factors, DNA repair proteins or cell cycle proteins. Yeast FHA containing DNA repair protein Rad53p is the best studied. It has two FHA domains, FHA1 and FHA2, both of which bind to target proteins in a phosphorylation dependent manner, specifically recognizing phospho-threonine $(9 ; 10)$. The FHA1 domain binds phospho-threonine containing sequences within the consensus pTXXD, whereas FHA2 binds pTXXI $(11 ; 12)$. Other FHA containing proteins display different preferences for amino acid in the +3 position though it is clear that their binding to target proteins is phospho-threonine specific. Liao and co-workers have shown that the FHA2 domain of Rad53p can also bind phosphotyrosine containing targets (9). Their data suggest that FHA domains may be dual specificity binding modules.

WD 40 motifs were originally discovered in the $\beta$ subunit of heterotrimeric $G$ proteins (13). Since then they have been found in various other proteins. WD 40 motifs represent regions of approximately forty amino acids. Their characteristic feature is that 
they always terminate with Trp-Asp (WD). WD-40 motifs are always arranged in tandem with sequence similarity among them. In the past few years a number of reports indicated that WD-40 motifs of F-box containing proteins bind their target proteins in a serine/threonine phosphorylation-dependent manner (5). F-box proteins are the ones responsible for recognizing phosphorylated substrates and linking them to E3 ubiquitin ligases. The biochemical data accumulated on F-box-protein interactions with their substrates suggests that it is WD-40 repeat regions of F-box proteins that mediate F-box protein binding to the substrate (14-17). Unlike for 14-3-3, WW and FHA domains, for WD-40 domains no experiment has been performed to provide us with structural proof that WD-40 indeed binds substrates in phospho-serine/threonine dependent manner.

\section{Indirect effects: Serine/threonine phosphorylation of another protein enables it to become a binding partner for an adaptor protein.}

\subsection{4-3-3}

14-3-3 proteins are small acidic proteins with a molecular weight around 30kDa (18). The 14-3-3 proteins are cellular components of all cells types that have been examined, and they have been found in all vertebrates, invertebrates, plants, and fungi $(19 ; 19-21)(20 ; 21)$. The 14-3-3 family of proteins includes seven unique isoforms, named by Greek letters according to their elution order after reverse-phase highperformance liquid chromatography: $\beta / \alpha, \zeta / \delta, \eta, \gamma, \tau, \sigma$ and $\varepsilon(18 ; 18 ; 22 ; 23) .14-3-3$ proteins are highly conserved among each other and across different species although they do have differences in some regions $(23 ; 23 ; 24)$. All 14-3-3 proteins are able to dimerize, with the ability to form both homo- and heterodimers in vitro and in vivo $(21 ; 21 ; 25)$. Dimerization occurs via hydrophobic interactions between highly conserved residues within amino-terminal parts of the molecules $(18 ; 18 ; 22 ; 23 ; 23)$. Carboxy-termini of two molecules brought together by dimerization create a ligand binding amphipathic groove $(4 ; 4 ; 26)$. Highly conserved residues form the inner surface of the binding groove, whereas variable residues create the outer surface. This groove may bind either two different molecules or bring together different regions of the same protein therefore serving as a scaffold or allosteric regulator $(26 ; 27)$. The variant residues of the outer 
surface of the groove may provide specific binding surfaces for different proteins. 14-3-3 proteins bind two well-defined structural motifs on target proteins. The first contains phosphoserine in the center with arginine, serine and proline in positions $-3,-2$, and +2 , respectively. Another one is defined as short amino acid sequence containing phosphoserine in the center with arginine, aromatic residue, basic residue and proline at positions $-4,-2,-1,+2$ respectively $(4 ; 4 ; 18 ; 28 ; 28)$. 14-3-3 dimers could bind to several phosphoserine-containing motifs on one protein or bring several target proteins together as a consequence of binding to conserved motifs found on different proteins. 14-3-3 dimers also may act as molecular links between proteins bound to the conserved groove and ones associated with variable outer surface, therefore performing a role of scaffolds that regulate specific protein-protein interactions (26). 14-3-3 proteins have over 60 in vivo binding partners (2). 14-3-3 proteins have been implicated in regulation of serine/threonine kinases such Raf and PKC (19;19;22;29;30;30). 14-3-3 proteins bind Raf and certain PKC isoforms directly and therefore serve to facilitate interactions between these signaling proteins (27). 14-3-3 brings Raf into proximity with Bcr as well (2). Raf is a key protein kinase in mitogen activated protein kinase cascade. Raf functions downstream of growth factor receptor and Src-family non-receptor tyrosine kinases, and Ras, and upstream of MAP kinase to transmit developmental and proliferative signals. 14-3-3 associates with Raf in vivo regardless of Raf subcellular localization or activation status $(18 ; 19 ; 31 ; 32)$. Overexpression of 14-3-3 proteins has been shown to contribute to Raf activation, although it is clear that 14-3-3 proteins are unable to activate Raf by themselves (32;32). Some other reports stated that the nature of 14-3-3 influence on Raf1 is inhibitory $(33 ; 34 ; 34)$. The data on Raf-14-3-3 interaction accumulated to date suggests the following model of Raf-14-3-3 interaction: Raf has three 14-3-3 binding sequences in its structure. 14-3-3 is bound to cytosolic Raf at amino-terminal and carboxy terminal binding sites; this association serves to keep Raf in an inactive, although activatable, state. Upon Raf activation by Ras the former undergoes translocation to the membrane. The 14-3-3 dimer is displaced from the amino terminal binding site on Raf, but it still associates with the carboxy terminal 14-3-3 binding site. Yet unidentified kinases come along and phosphorylate the serine in the center of the intermediate 14-3-3 binding site of Raf and 14-3-3 binds to it, stabilizing Raf in an active state (4;4;30). 14-3- 
3 therefore has a dual role in Raf regulation, it keeps Raf in an inactive state in the cytosol, but upon Ras-dependent Raf activation it stabilizes it in an active conformation. 14-3-3 proteins also have been shown to be both PKC substrates and regulatory proteins (35;36). 14-3-3 may bind to Raf and PKC at the same time, therefore bringing Raf to proximity with PKC to ensure phosphorylation of the former by the latter $(18 ; 18 ; 27 ; 37)$.

14-3-3 binding to a target protein often serves to keep that protein either in inactive state and/ or sequester it from binding partners. 14-3-3 binds Cdc25C phosphatase in a phosphorylation dependent manner via its RSXpSXP site -the perfect consensus for 14-3-3 binding. This interaction is responsible for keeping this protein inactive throughout G1, S and G2 phases of the cell cycle and also transports it from the nucleus to cytosol $(38 ; 39)$. 14-3-3 bind the apoptotic protein BAD in a phosphorylation dependent fashion. The function of this interaction is to sequester BAD in the cytosol and keep it from binding to Bcl2 and also possibly protecting it from phosphatases (40). 14-33 binds IRS-1 and therefore prevents its association with PI3K (41).

Dubois and colleagues show that two unidentified brain kinases phosphorylate 143-3 on the sites located at $\mathrm{C}$ terminus of 14-3-3, a region where PI3K, Raf and $\mathrm{Cbl}$ bind to 14-3-3 (42). Therefore, they speculate that phosphorylation regulates 14-3-3 interactions with binding partners. They also refer to the data of Aitken and colleagues that leads to suggestion that $14-3-3 \alpha$ and $\delta$, which are phosphoisoforms of 14-3-3 $\beta$ and $\zeta$, respectively, may influence PKC activity more strongly than their non-phosphorylated counterparts(29). Later that year they followed with another publication where they determined the identity of the brain kinase that phosphorylates Ser233 of 14-3-3 as casein kinase 1 (43). Another kinase that utilizes 14-3-3 as a substrate is sphingosine dependent protein kinase SDK1 (44). The function of 14-3-3 phosphorylation remains to be determined.

\section{2. p130Cas.}

$\underline{\text { Crk }}$ associated substrate p130Cas was discovered over a decade ago as a phosphotyrosine-containing binding partner for active Src and Crk (45). The Cas domain structure along with variety of binding partners, suggests that it acts as an adaptor protein. The domain structure from amino to carboxy terminus: SH3 domain, proline rich region, 
so-called "substrate-binding" domain that associates with adaptor proteins Crk, Nck and SHIP, serine rich motif and a carboxy-terminal region that interacts with different protein kinases and adaptor proteins (45). Cas is involved in regulation of cell motility, cytoskeleton integrity, growth regulation, apoptosis, and Src and Crk dependent transformation (45). Cas is localized to focal adhesions where it associates with Crk, Src and FAK. FAK/Cas interaction occurs via proline-rich region of FAK and SH3 domain of Cas $(46 ; 47)$. Cas forms a complex with Crk at focal adhesions; Cas/Crk complexes influence cytoskeletal rearrangements in a Rac1-dependent manner (45;48).Focal adhesions are the sites where actin stress fibers are linked to extracellular matrix. Focal adhesions are also the sites of integrin signaling (49).

The data accumulated so far suggests that Cas is involved in the regulation of cytoskeletal integrity, cell-matrix adhesion and cell motility. In Cas knockout cells actin filaments are disorganized but formation of focal adhesions remains intact (50).

Cas, as well as FAK and paxillin, is phosphorylated on serine/threonine residues in mitosis and concomitantly dephosphorylated on tyrosine residues (49). Mitosis is the stage of the cell cycle when cells display actin filament disorganization and detachment from the substratum. Mitotic phosphorylation of focal adhesion proteins must be a way of cell detachment regulation. Serine phosphorylation of Cas and FAK during mitosis promotes their dissociation from one another. Mitotic FAK is able to reassociate with interphase Cas following ser/thr phosphatase treatment, therefore FAK/Cas interaction does not depend on tyrosine phosphorylation of FAK as ser/thr dephosphorylated mitotic FAK has no tyrosine phosphorylation. These data indicate that serine/threonine phosphorylation of FAK and not its tyrosine phosphorylation regulates FAK/Cas complex formation (49). $\mathrm{Ma}$ and co-workes confirm that serine/threonine phosphorylation of FAK down-regulates its ability to form a complex with Cas (51). The physiological significance of serine/threonine phosphorylation of Cas itself remains to be determined.

\subsection{AP-2}

Adaptor protein 2 is a multisubunit adaptor protein complex associated with endocytic clathrin coated vesicles. AP2 associates with proteins like EGF receptor 
substrate Eps15 and Epsin at the membrane. This association is disrupted in mitosis when both Eps15 and Epsin are phosphorylated on ser/thr residues. Eps15 and Epsin are substrates for $\mathrm{p} 34 \mathrm{Cdc} 2$ in vitro. Ser/thr phosphorylation of epsin and Eps 15 results in dissociation of these proteins from AP2 complex. This may provide a mechanism that inhibits clathrin-mediated endocytosis in the stage of mitosis $(52 ; 53)$.

\section{Adaptor proteins that are serine/threonine phosphorylated but function of phosphorylation remains to be determined.}

\subsection{Chat.}

Chat is a Cas/HEF-1 associated adaptor protein isolated by Sakakibara and Hattori last year (54). The function of Chat itself as well as the function of its phosphorylation has not been determined. Sakakibara and Hattori show that Chat binds the adaptor protein Cas directly, and this interaction is phosphorylation-independent (in vitro binding assay). Chat has multiple serine/threonine residues, four of which comprise potential MAPK sites (PXS/TP). Phosphorylation levels of Chat increase in response to growth factor treatment, and it is not due to tyrosine phosphorylation (there is a gel shift in response to GF treatment, but pTyr Ab does not react with the upper portion). MAP kinase may be the one responsible for GF mediated phosphorylation of Chat as MAPK inhibition results in the disappearance of the slower migrating band. Overexpression, but not phosphorylation, of Chat up-regulates JNK activity in a manner similar to that of Cas. Chat is a cytoplasmic protein, but in response to GF stimulation it moves to membrane ruffles where it colocalizes with actin (54).

\subsection{NHERF.}

$\mathrm{NHERF}$ is a $\mathrm{Na}+\mathrm{K}+$ exchange regulatory factor that was discovered several years ago and since then it became apparent that this is an adaptor protein. NHERF contains two PDZ domains in tandem where the majority of NHERF binding partners associate, along with the carboxy-terminal region that binds ERM proteins. NHERF proteins are localized to the plasma membrane, where in addition to already mentioned function as $\mathrm{Na}+\mathrm{K}+$ exchange regulators they also regulate transmembrane receptors and are involved into growth factor receptor signaling (55). 
In 1995 Weinman and colleagues suggested that NHERF may be a substrate for serine/threonine phosphorylation for they found potential sites for PKA phosphorylation in the C-terninus of NHERF (56). A more recent report by Hall and co-workers shows that NHERF is constitutively phosphorylated on serine/threonine residues, and that NHERF is a binding partner and an in vitro substrate for a $G$ protein receptor coupled kinase GRK6A (57). The functional significance of NHERF phosphorylation remains to be determined.

NHERF proteins are able to dimerize. The physiological significance of this capability still remains to be determined. The ability of NHERF proteins to dimerize is greatly diminished in response to okadaic acid treatment. It seems therefore that protein phosphorylation might be responsible for regulation of the ability of NHERF proteins to self-associate, although it is not known at this point whether phosphorylation of NHERF themselves or NHERF binding partners influenced this effect (58).

\subsection{Nck/Dock}

Nck is an adaptor protein that was discovered in 1990 (59). Its domain structure suggests that it serves as an adaptor protein. Nck has three SH3 domains in tandem followed by an SH2 domain at the carboxy-terminus. Indeed, it binds a variety of target proteins such as protein kinases, adaptor and motor proteins, involved in regulation of actin filaments integrity, DNA synthesis, transcription and translation as well as protein degradation (reviewed in (60).

Two reports published in 1992 show that Nck is phosphorylated in growing cells and in response to PMA or growth factor stimulation of cultured cells $(61 ; 62)$. Phosphoamino acid analysis has demonstrated that Nck is phosphorylated predominantly on serine/threonine with one tyrosine phosphorylated peptide recovered. Neither the identity of serine/threonine kinase nor the physiological role of serine/threonine phosphorylation of Nck was determined $(61 ; 62)$.

\subsection{Grb7.}

Grb7 is a 535 amino acid protein with similarity to Grb2, Shc and Nck. Grb7 family includes Grb7, Grb10 and Grb14 proteins. Grb7 proteins contain several protein- 
protein interaction modules such as proline-rich, $\mathrm{PH}$, Ras-associating, and $\mathrm{SH} 2$ in their structure, which enable them to interact with a variety of signaling proteins and therefore serve as adaptors linking receptor activation to downstream signaling pathways (63). Grb7 is able to form homo- or heterodimers and larger complexes (64). Dimerization of the Grb7 family of proteins may serve to bring signaling proteins together into large complexes. Grb7 family of adaptors has been implicated in the regulation of cell proliferation, cell motility, apoptosis and tumorigenesis (63).

The Grb7 family of adaptor proteins is constitutively phosphorylated on serine/threonine residues, and the level of their serine/threonine phosphorylation increases in response to EGFR and heregulin receptor stimulation (65-67)). The functional significance of this phosphorylation remains to be determined.

\section{Direct effects: Serine/threonine phosphorylation of an adaptor protein recruits in a binding partner for it.}

\subsection{Paxillin.}

Paxillin was initially discovered as a tyrosine phosphorylated protein from Src transformed cells (68). Paxillin is localized to focal adhesions, where it serves as a scaffold for a wide variety of signaling and structural proteins. The ability of paxillin to bind various proteins is attributed to several protein-protein interaction domains - i.e., LD motifs and SH2 and SH3 binding motifs in the amino terminus and four LIM domains in the carboxy terminus. LD motifs are conserved eight amino acid leucine rich sequences (LDXLLXXL), serving as binding sites for a number of paxillin binding partners such as FAK, vinculin, and PYK2. LIM domains are double zinc finger motifs approximately 50 amino acids long whose function is to serve as protein-protein binding modules. LIM domains of paxillin promote its localization to the plasma membrane via association with integrins. Paxillin is crucial for embryogenesis since paxillin knockout mice die on the seventh-eighth day of embryogenesis (69). Paxillin deficient cells display an inability to spread (70).

Tyrosine phosphorylation of paxillin and its functional significance has been extensively studied for some time, while serine/threonine phosphorylation has started to draw attention only recently. Paxillin is phosphorylated on serine residues in vivo in 
response to plating of cultured cells on vitronectin or fibronectin, and also in mitosis and in MCF-7 cells in response to heregulin stimulation (49;71-73). The identity of serine/threonine kinases that phosphorylate paxillin in vivo is unknown although it is known that paxillin is serine phosphorylated in response to PKC activation following PMA treatment and treatment with a PKC inhibitor reduces paxillin serine phosphorylation (71). The fact that paxillin is phosphorylated upon adhesion of cells to ECM was confirmed by (74). Their work is cell type specific for EL4 cells, which represent murine thymoma cell line. These cells display an ability to adhere in response to PMA treatment. PMA treatment also results in serine phosphorylation of paxillin. The signaling cascade may proceed from PMA stimulation via MEK/ERK pathway to adhesion. If a specific inhibitor of MEK activation is added, there is a reduction in a number of adherent cells. ERK is one (though not only) kinase that is activated downstream of PKC in these cells. MEK/ERK inhibitor abolished PMA induced paxillin phosphorylation leading to the suggestion that the proceeds from PKC via MEK/ERK pathway to paxillin. Paxillin is a substrate for ERK2 in vitro (74). Recent data of Hashimoto and co-workers indicate that paxillin associates with PAK3 and serves as a substrate for this kinase in vitro (75).

Paxillin has four LIM domains in its carboxy terminus. GST-LIM2 and GSTLIM3 constructs were phosphorylated on threonine or serine, respectively, in vitro (whereas GST-LIM1 and GST-LIM4 were not). Site directed mutagenesis was employed to identify phosphorylation sites within LIM2 and LIM3 domains. LIM3 and LIM2 become phosphorylated during cell adhesion to fibronectin in vivo. Phosphorylations of LIM domains of paxilllin promote localization of this protein to focal adhesions. Certain site-directed mutants of paxillin, which have serine or threonine mutated to alanine or valine, respectively, do not localize to focal adhesions as efficienltly as a wild type, and as a result these cells adhere to fibronectin poorly. Serine/threonine phosphorylations of LIM domains bring paxillin to newly created focal adhesions (76).

Serine/threonine phosphorylation of paxillin also has a role in cell movement, which was described in a paper by Vadlamudi and colleagues (73). They found that MCF-7 cells invasiveness is increased in response to heregulin exposure. Along with this, in response to heregulin treatment paxillin becomes phosphorylated on serine and 
threonine residues (73) as demonstrated by SDS-PAGE mobility shift, phosphoamino acid analysis and serine/threonine phosphatase versus tyrosine phosphatase treatments; the latter does not interfere with heregulin induced phosphorylation of paxillin (73). This group of researchers found that two pools of paxillin are present in MCF-7 cells: one of them is co-localized with focal adhesions, while the other is cytoplasmic. Heregulin treatment causes relocation of paxillin from focal adhesions to perinuclear areas of the cytoplasm accompanied by changes in cell shape. Serine/threonine phosphorylation of paxillin and accompanying cell scattering are dependent upon p38MAPK rather than p42/44MAPK pathway activation, which has been demonstrated by use of specific MEK inhibitors. Overall, these data indicate that heregulin treatment leads to paxillin relocation from focal adhesions, that promotes their disassembly, which is necessary for cell movement to occur (73).

\subsection{Gab1.}

The name Gab1 stands for $\underline{\text { Grb}} 2$ associated binder $\underline{1}$. In response to insulin, cytokine or growth factor stimulation (HGF, EGF, NGF, PDGF) Gab1 becomes phosphorylated on tyrosine and binds the tyrosine-phosphorylated receptor directly, or indirectly via Grb2 in a phosphorylation dependent manner (77). Gab1 has an amino terminal PH domain that tethers Gab1 at the membrane via PIP3 interaction and carboxy terminal $\underline{\text { Met }}$ binding domain (MBD) that mediates direct interaction of Gab1 with cMet, and also has binding sites via which it interacts with SH3 domain of Grb2. There are 21 tyrosine residues in between these two regions, which upon phosphorylation serve as docking sites for a number of binding partners. The list of Gab1 binding partners includes Grb2, cMet, p85 subunit of PI3K, PLC $\gamma$, Shc, Shp2 phosphatase, Crk and CrkL (77-79).

Phosphoaminoacid analysis of Gab1 overexpressed with dominant negative or positive MEK shows that serine/threonine phosphorylation levels of Gab1 are elevated in response to co-expression with constantly active MEK. Gab1 binds phosphorylated ERK2 directly and phosphorylated by it; Gab1 also associates with phospho-Erk1 in response to MEK activation (80). Several years later this same group of authors followed with another report, which demonstrates that cMet activation results in MAPK cascade 
activation, and Gab1 becomes phosphorylated by active ERK2 followed by recruitment of PI3K to the membrane (78). Consequently, Akt activation follows in response to PI3K activation as a result of an association with Gab1. They state that Gab1 has to be phosphorylated both on threonine and tyrosine residues to ensure for PI3K association (78).

Okadaic acid treatment of cultured cells results in serine/threonine phosphorylation of Gab1 (81). One of the effects of cMet stimulation by HGF is cell scattering, which is the result of c-Met stimulated increased cell motility. Okadaic acid treatment of cultured cells prior to HGF stimulation prevents cell scattering. Under these conditions Gab1 is found to be hyper-phosphorylated on serine and threonine residues and hypo-phosphorylayed on tyrosine residues. Okadaic acid promoted decrease in tyrosine phosphorylation of Gab1 is a consequence of its elevated serine/threonine phosphorylation which by some undetermined mechanism prevents cMet form interacting with and phosphorylating Gab1 (81) .

Serine/threonine phosphorylation results in Gab1 association with 14-3-3. The functional significance of this interaction remains to be determined, as it does not seem to interfere with Gab1/Met1 interactions and therefore sequester Gab1 from the membrane. Okadaic acid activates MAPK and PKC by inhibition of serine/threonine phosphatases. Using pharmacological agents that are known to be specific inhibitors of MAPK pathway or PKC kinase, they show that for serine/threonine phosphorylation of Gab1 in response to okadaic acid treatment is $\mathrm{PKC}$ dependent. Phorbol ester treatment results in a decrease of both electrophoretic mobility and tyrosine phosphorylation levels of Gab1. Gab1 is a substrate for conventional $\mathrm{PKC}$ isozymes in vitro. $\mathrm{PKC}$ inhibitor staurosporine treatment restores cell scattering inhibited by okadaic acid (81). The authors hypothesize that serine/threonine phosphorylation alters Gab1 conformation so that tyrosine residues cannot be presented for phosphorylation; as a consequence, the docking sites for binding partners are not being created which results in Gab1 inability to associate with them (81) .

\subsection{PECAM-1.}

Platelet endothelial cell adhesion molecule 1 (PECAM-1) is a transmembrane glycoprotein belonging to immunoglobulin family of adhesion molecules that is 
expressed only in hematopoetic and vascular cells. Upon phosphorylation of tyrosines within its ITAM motif it becomes a binding partner for PI3K, PLC $\gamma$, SHP1 and 2, Stat5a, and cell-cell junction proteins catenins $\beta$ and $\gamma$ (82-84). PECAM-1 is phosphorylated not only on tyrosine but also on serine and threonine residues. The levels of serine/threonine phosphorylation of PECAM-1 are elevated in response to LPS treatment of monocytes in a PKC dependent manner, which is demonstrated by the observation that PKC inhibitor treatment downregulates LPS induced serine/threonine phosphorylation of PECAM-1 (85). Along with PECAM-1 serine/threonine phosphorylation LPS induces transendothelial migration of monocytes. Phosphorylation of PECAM-1 on serine and threonine residues appears to be connected to cell migration, this conclusion comes from the fact that PKC inhibitor treatment blocks monocyte migration through the endothelial cell layer (85). Phosphatase inhibitor treatment up-regulates both PECAM-1 serine/threonine phosphorylation and transendothelial movement of monocytes. These data suggests that PECAM-1 may be involved in the regulation of monocytes movement $(85)$.

PECAM-1 is able to associate with both $\beta$ and $\gamma$ catenins (82). Serine/threonine phosphorylation of PECAM-1 has been shown to down regulate its ability to associate with $\gamma$ catenin (83). PECAM1 is a substrate for PKC in vitro and phosphorylated on serine/threonine residues in response to $\mathrm{PKC}$ activation in vivo (83). In response to $\mathrm{PKC}$ activation by DAG a decrease in PECAM-1 interaction with $\gamma$ catenin is observed, whereas PKC inhibitor bisindolylmaleimide treatment promotes this interaction. PKC, therefore, may be the kinase responsible for serine/threonoine phosphorylation of PECAM-1 in vivo and PKC dependent serine/threonine phosphorylation of PECAM-1 may be a mechanism of regultion PECAM- $1 / \gamma$ catenin interactions. Experiments of Ilan and colleagues suggest that one of the functions of PECAM-1 may be to bring catenins to adherence junctions (83); PECAM-1 interaction with $\gamma$ catenin is thought to link PECAM-1 to the cytoskeleton via vimentin and therefore participate in transduction of signals that regulate cell migration (83). 


\subsection{Sos.}

In response to growth factor stimulation receptor tyrosine kinases will autophosphorylate on tyrosine residues, creating binding sites for the adaptor proteins Grb2 and Shc. They, in turn, recruit a protein named Son of sevenless (Sos) to the membrane. Sos protein is a guanine nucleotide exchange factor for Ras. Once at the membrane, Sos promotes GDP to GTP exchange on Ras, activating it. Sos links growth factor receptor activation to Ras stimulation (86). It was determined several years ago that Sos1 is phosphorylated in response to EGFR stimulation (87). Phospho amino acid analysis determined that Sos is phosphorylated predominantly on serine and to the lesser extent on threonine residues, while no tyrosine phosphorylation was detected (88). It was observed that the $\mathrm{C}$ terminus of Sos contains potential sites for MAPK phosphorylation. Indeed, using phosphotryptic-mapping analysis it was demonstrated that Sos is a substrate for MAP kinase both in vitro and in vivo, and the sites of phosphorylation were identified $(89 ; 90)$. Since it has been determined that Sos protein is serine/threonine phosphorylated, researchers have been trying to elucidate the functional significance of Sos phosphorylation. Rozakis-Adcock and co-workers demonstrated that serine/threonine phosphorylation of Sos downregulates Sos-Grb2 association with EGFR and Shc although does not affect Sos interaction with GST-fused Grb2 (88). Corbalan-Garcia and colleagues discovered that in response to being phosphorylated Sos dissociates from Grb2. The data accumulated by the two groups must be somewhat controversial, which might be explained by the differences in exprerimental setup and also by the fact that these groups of authors used Sos from different species (either human or murine) in their experiments. Both groups agree that MAPK dependent Sos phosphorylation serves as a feedback mechanism of Ras/MAPK pathway regulation. Sos is phosphorylated in MAPK cascade dependent manner by active MAP kinase and supposedly by other serine/threonine kinases that are activated downstream of MAPK pathway $(88 ; 89)$.

In T cells the MAPK cascade is activated in response to TCR ligation. Both TCR activation and PMA stimulation result in serine/threonine phosphorylation of Sos-1; this is demonstrated by reduced mobility of Sos-1 derived from PMA stimulated cells (91). The mobility shift is lost if phosphatase treatment has been applied to Sos- 1 from PMA 
treated cells. In T cells serine/threonine phosphorylation of Sos-1 is not MAPK cascade dependent, this conclusion comes from the observation that MEK inhibitor treatment does not result in decrease in serine/threonine phosphorylation levels of Sos-1 promoted by TCR engagement. Mutation of seven potential MAPK consensus sites does not diminish ability of Sos-1 to be phosphorylated on serine/threonine residues either (91).

It is well known that prolonged exposure to PMA results in depletion of cellular pool of PKC due to its subsequent ubiquitination $(92 ; 93)$. When cells that had undergone 16-hour PMA treatment were subjected to TCR stimulation no serine/threonine phosphorylation of Sos was detected. The same result was observed in cultured cells pretreated with specific PKC inhibitors (91). Therefore, PKC may be a Sos kinase in vivo. Phosphorylation of Sos did not lead to its uncoupling from Grb2 under described conditions, which is in agreement with previous data of Rozakis-Acock and co-workers. Zhao and colleagues did not attempt to clarify the functional significance of Sos phosphorylation (91).

\subsection{Cbl.}

$\mathrm{c}-\mathrm{Cbl}$ is an adaptor protein that is ubiquitously expressed and known to be phosphorylated on tyrosine residues (94). Cbl has several modular domains including a zinc ring finger motif, $\mathrm{SH} 2$ and $\mathrm{SH} 3$ binding motifs and leucine zipper motif. These modules facilitate the association of $\mathrm{Cbl}$ with 40 target proteins, among which are receptor and non-receptor tyrosine kinases, E2 ubiquitination enzyme, p85 subunit of PI3 kinase, and adaptor proteins such as $\mathrm{Crb} 2, \mathrm{Nck}$, and $\mathrm{Crk}$. Cbl has the ability to form dimers via its carboxy-terminal leucine zipper motif. $\mathrm{T}$ cell receptor activation leads to tyrosine phosphorylation of $\mathrm{Cbl}$ and its transient association with $\mathrm{CrkL}$ and the p85 subunit of PI3K (94;95). P85 binds Cbl directly but it cannot bind CrkL, unless it associated with $\mathrm{Cbl}$ that brings it into a close proximity with $\mathrm{CrkL}$. Cbl has to be tyrosine phosphorylated to perform this function. Cbl, therefore, act as a scaffold that brings PI3K and CrkL together (95).

Liu and co-workers found that TCR ligation leads to serine/threonine phosphorylation of $\mathrm{Cbl}$ upon which $\mathrm{Cbl}$ becomes associated with 14-3-3 (96). Cbl interaction with 14-3-3 is direct and occurs only in response to TCR (96) or CD43 (97) 
ligation; while in unstimulated cells there is no Cbl-14-3-3 complex detected. 14-3-3 displaces PI3K from Cbl. Serine/threonine phosphorylation of Cbl has also been shown to downregulate its tyrosine phosphorylation and association with another partner, the adaptor protein CrkL (96). PMA treatment promotes serine/threonine phosphorylation of $\mathrm{Cbl}$ and its consequent association with 14-3-3. Pretreatment of cells with specific PKC inhibitors prior to PMA treatment results in an inability of PMA to induce serine/threonine phosphorylation of Cbl. Cumulatively, these data suggest that $\mathrm{Cbl}$ phosphorylation may be PKC dependent $(95 ; 97 ; 98)$. PMA treatment also results in a decrease in tyrosine phosphorylation levels of $\mathrm{Cbl}$ and therefore promotes its dissociation from p85 and CrkL. Recent work of Pedraza-Alva and co-workers shows that CD43 receptor cross-linking causes $\mathrm{Cbl}$ association with Vav and $\mathrm{PI} 3 \mathrm{~K}$; the latter is activated in response to this interaction event (97). It is noteworthy that $\mathrm{Cbl}$ does not have to be phosphorylated on tyrosine residues for described CD43 induced interactions to occur, as there is no tyrosine phosphorylation of $\mathrm{Cbl}$ detectable under those conditions. PedrazaAlva and colleagues attempted to gain an insight into the functional significance of serine/threonine phosphorylation of $\mathrm{Cbl}$ (97). It has been known for some time that overexpression of $\mathrm{Cbl}$ has an inhibitory effect on receptor-mediated MAP kinase activation. PKC dependent phosphorylation of Cbl followed by its association with 14-33 is thought to block the negative effect of $\mathrm{Cbl}$ on MAP kinase cascade activation (97). Serine/threonine phosphorylation of $\mathrm{Cbl}$ also negatively regulates $\mathrm{Cbl}$ tyrosine phosphorylation and therefore hampers its interaction with PI3K, CrkL and other phosphotyrosine binding partners. All the data on $\mathrm{Cbl}$ serine/threonine phosphorylation is $\mathrm{T}$ cell specific. Cumulatively, it leads to the conclusion that adaptor protein $\mathrm{Cbl}$ is phosphorylated on tyrosine and serine/threonine via two separate receptor-signaling pathways. Phosphorylation on either tyrosine or serine/threonine residues may enable Cbl to associate with different set of binding partners and therefore be engaged in either one of the two signaling cascades descending from the $\mathrm{T}$ cell receptor. 


\subsection{IRS1.}

Insulin receptor substrate $\underline{1}$ is a $165-185 \mathrm{kDa}$ protein that associates with $\mathrm{SH} 2$ containing proteins in a phosphorylation dependent manner. IRS1 becomes phosphorylated on tyrosine residues by insulin receptor and consequently associates with PI3 kinase, activating the latter. PI3 kinase activation results in activation of Akt/PKB, which sends the signal further downstream. The physiological consequences of insulin receptor signaling are glucose uptake and glycogen synthesis. In response to PDGF (in a PI3K/Akt dependent manner) (99;100) or endothelin-1 (in a PKC and MAPK dependent manner) (100) stimulation IRS1 becomes phosphorylated on serine residues, four of which are MAPK consensus sites (101). Serine phosphorylation of IRS1 leads to the decrease in its tyrosine phosphorylation levels $(99 ; 100)$ and IRS1/PI3K complex disengagement $(100 ; 102)$ therefore inhibiting insulin receptor signaling. PDGR receptor stimulation results in inhibition of insulin receptor signaling, cased by inability of IRS-1 to be tyrosine phosphorylated and form a complex with PI3K. The IRS1 mutant, which has four serine residues substituted by alanines, retains the ability to be tyrosine phosphorylated in response to insulin treatment in the presence of PDGFR stimulation and associate with PI3K, activating it. In response to Akt activation IRS1 association with PI3K is abrogated. It is not known yet whether Akt phosphorylates IRS-1 directly or simply promotes IRS-1 phosphorylation by activating serine/threonine kinase(s) downstream of it (100). Whatever the mechanism might be, attenuation of insulinreceptor signaling by active Akt suggests a model for negative feedback loop where PI3 kinase, activated in response to insulin-receptor stimulation via IRS-1 interaction, in turn activates Akt, which comes along and phosphorylates IRS-1 causing dissociation of IRS1/PI3K complex (100).

Ogihara and colleagues (103) and Staubs and co-workers (99) observe serine/threonine phosphorylation of IRS1 in response to PI3K association promoted by insulin receptor activation. IRS1 is a substrate for PI3K in vitro $(104 ; 105)$. These data suggests that PI3 kinase itself may be responsible for an attenuation of insulin receptor signaling. Ogihara and co-workers also suggest that serine phosphorylation of IRS1 may lead to presentation of phospho tyrosines for tyrosine phosphatases therefore enabling 
attenuation of insulin signaling (103).

Decrease in tyrosine phosphorylation of IRS1 was also observed in response to PMA treatment of cultured cells (106). Activation of endogenous PKC by phorbol ester treatment inhibits insulin receptor-mediated tyrosine phosphorylation of IRS-1. It has not been demonstrated whether IRS1 is a substrate for PKC either in vitro or in vivo (106).

PKC is known to activate ERK1/2 in response to its activation. IRS1 is a substrate for ERK1/2 in vitro (107). IRS1 contains four potential MAPK sites of a consensus PXS/TP. PKC activates ERK1/2 in Raf-1 dependent manner. Both ERK1/2 and Raf activation result in decreased insulin receptor mediated tyrosine phosphorylation of IRS1 in vivo, resulting in diminished IRS1/PI3K association (107).

Both insulin and PDGF receptor activation lead to PI3 kinase activation by different mechanisms, which are responsible for different outcomes. IRS-1 is a key player in insulin receptor signaling as it activates PI3K via association with it and thereby triggers insulin-receptor mediated physiological events. PDGF receptor activates PI3 kinase via another pathway and causes PI3K dependent serine/threonine phosphorylation of IRS-1, interfering with insulin receptor signaling. Serine/threonine phosphorylation of IRS-1 was observed in response to activation of insulin receptor, which is in agreement with the statement that serine/threonine phosphorylation of IRS-1 may provide the means for a negative feedback regulation of insulin receptor signaling.

\section{7. pShc66.}

Shc is a ubiquitously expressed adaptor protein, which plays an important role in growth factor receptor signaling. Upon tyrosine phosphorylation by ligand-activated receptor tyrosine kinases Shc becomes a docking molecule for Grb2 allowing Grb2 to bring Ras-GTP Sos to the membrane. Three isoforms of Shc are known - two of them, p46 Shc and p52 Shc are synthesized from the same transcript (starting sites differ), whereas p66 Shc is a result of alternative splicing $(108 ; 109)$. The three members of Shc family may have different biological functions (109;110). p66 Shc, for example, plays a role in regulation of oxidative stress response and life span in mice (111). Shc66 knockout mice have a prolonged life span and increased resistance to oxidative stress (111). p46 Shc and p52 Shc cannot substitute for the p66 defect in p66Shc deficient 
mice. Oxidative stress response mediated by p66 Shc is serine phosphorylation dependent, which is demonstrated by the fact that non-phosphorylated p66Shc cannot revert mice to a normal phenotype (111). EGFR stimulation results in both tyrosine and serine/threonine phosphorylation of the p66Shc isoform in $\mathrm{CHO}$ cells, which is demonstrated by a mobility shift characteristic of serine/threonine phosphorylation. Moreover, p66Shc has to be phosphorylated on tyrosine prior to serine/threonine phosphorylation. Serine/threonine phosphorylation of p66Shc is /MAPK cascade dependent, although the identity of the kinase is unknown. Upon serine/threonine phosphorylation the ability of p66Shc to bind EGFR is abolished, although it is still able to associate with Grb2. p66Shc competes with p52Shc for Grb2 as the amount of Grb2 in cells is limiting. Therefore, in response to serine/threonine phosphorylation p66Shc carries Grb2 away from the EGFR. Overexpression of p66 Shc inhibits ERK activation (112). These data suggest the existence of a negative feedback regulation of EGFR signaling. EGFR ligation leads to engagement of Shc/Grb2/Sos complex via which activation of Ras/Raf/ MEK/ERK cascade occurs. Serine/threonine phosphorylation of p66Shc leads to disengagement of Shc/Grb2 complex from the EGFR leading to attenuation of the EGFR signaling (112). In mesangial cells p66Shc is serine/threonine phosphorylated in response to endothelin-1 receptor stimulation (113). p66Shc serine/threonine phosphorylation occurs in response to ERK1/2 activation although the identity of kinase that phosphorylates Shc66 under these conditions is unknown. Serine phosphorylation of p66Shc brings it into proximity with three proteins two of which remain to be identified and the third is 14-3-3 (113). Function of p66Shc association with 14-3-3 remains unknown. As 14-3-3 is known to bind a wide variety of proteins, and the 14-3-3 dimer is capable of binding two different proteins at once, it may either bring p66Shc into proximity with some yet unidentified binding partner(s) for undetermined purpose or simply to sequester p66Shc from the membrane, preventing it from competing with two other Shc isoforms for Grb2 pool.

Taxol, an antitumor agent that has already been approved for treatment of breast, lung, and ovarian carcinomas, causes serine/threonine, but not tyrosine, phosphorylation of pShc66 in human lung carcinoma cells (114). Serine/threonine phosphorylated p66Shc prevents it from interacting with Grb2. Although phosphorylation of Raf-1 and ERK1/2 
is observed simultaneously with p66Shc phosphorylation, these kinases are not responsible for serine/threonine phosphorylation of pShc66. Taxol-mediated serine phosphorylation of p66Shc is protein synthesis dependent, as cycloheximide treatment inhibits taxol-induced phosphorylation of p66Shc and Raf-1. These data lead to hypothesis that taxol-inducible p66Shc activation occurs in response to stimulation of yet unknown signaling pathway, different from the MAP kinase cascade (114).

Taxol is a microtubule-interacting agent that is capable of arresting cell in mitosis and it also has an apoptotic effect. As the serine/threonine phosphorylation of Shc reaches maximum at 9-18 hours after treatment, when cell may be in the mitotic stage, the authors speculate that Shc66 ser/thr phosphorylation may be responsible for transducing an apoptotic signal (114) referring to the fact that $\mathrm{Ser} \rightarrow$ Ala substitution of p66 Shc enhances resistance to apoptosis (111).

\section{Direct effects: Serine/threonine phosphorylation of an adaptor protein alters its conformation and subsequent function.}

\subsection{Cortactin.}

Cortactin was initially identified as a tyrosine phosphorylated substrate of active Src (115). Cortactin has an amino terminal acidic (NTA) domain followed by a region of cortactin repeats; alpha-helical domain, proline rich motif containing tyrosines, serine and threonine residues in abundance and a carboxy-terminal SH3 domain (116). Cortactin is localized to cortical actin structures. Recently it has been found that cortactin is involved in regulating cell motility (117). Cortactin's structure along with its localization and ability to bind actin, suggests that this protein may be positioned to link signaling events such as growth factor receptor activation to actin filament reorganization(118). Cortactin is found to be phosphorylated in response to growth factor receptor stimuli. Phosphorylation therefore may play a role in regulation of its function (116).

Van Damme and co-workers in 1997 have shown that in response to EGF receptor stimulation of cortactin over expressing human squamous carcinoma cell line p80 cortactin is converted into p85 cortactin and this conversion is a result of phosphorylation (119). Phosphoamino acid analysis has shown that EGF-induced 
cortactin phosphorylation occurs predominantly on serine and threonine residues. Immunofluorescence analysis indicated that upon growth factor induced phosphorylation cortactin relocates from perinuclear space to cell-matrix adhesion zone.

Campbell and colleagues show that endogenous p80 cortactin is converted into the p85 form in response to EGF stimulation, confirming van Damme and co-workers data. They also show that cortactin phosphorylation is ERK dependent since pretreatment with the specific MEK inhibitor PD98059 abolishes EGF-induced cortactin phosphorylation. Active MEK is sufficient to cause cortactin phosphorylation but insufficient to prevent basal phosphorylation of cortactin which suggests that there are ser/thr kinases other than MAPK that phosphorylate cortactin in vivo. Proline-rich region have been shown to contain phosphate acceptor sites as it can be phosphorylated by Erks when expressed on its own (120). Although the role of serine/threonine phosphorylation of cortactin still remains to be determined, from data described above it is possible that phosphorylation of cortactin may regulate its subcellular localization. Campbell and coworkers speculate that the proline-rich domain of cortactin may interact with its own SH3 domain and therefore keep cortactin in a "closed" conformation. Serine/threonine phosphorylation of a proline-rich domain will result in abrogation of this interaction resulting in cortactin transition into the "open" conformation (120). Alternatively, ser/thr phosphorylation of the proline rich region of cortactin may disrupt its interaction with SH3 binding partners. The physiological significance of cortactin serine/threonine phosphorylation as well as its impact on conformation remains to be determined.

\subsection{AFAP-110.}

AFAP-110 was first identified as a $110-\mathrm{kDa}$ protein that co-immunoprecipitated with active Src in Src-transformed cells (121). In normal cells AFAP-110 co-localizes with actin stress fibers and the cortical actin matrix, frequently identified along the leading edge of the cell. AFAP-110 has several protein-protein interaction modular domains such as WW domain, $\mathrm{SH} 2$ and $\mathrm{SH} 3$ binding motifs, serine threonine kinase interaction domain, pleckstrin homology $(\mathrm{PH})$ domains, leucine zipper motif, and carboxy terminal actin binding domains (122). AFAP-110 binds actin filaments directly via its carboxy-terminal actin binding sequences, and it associates with Src via SH2/SH3 
interactions. The amino-terminal PH domain of AFAP-110 has been shown to facilitate its interactions with PKC (Qian et al, manuscript in preparation). AFAP-110 therefore may serve as an adaptor protein linking Src and PKC kinase activation to actin cytoskeleton reorganization.

AFAP-110 has the capability to self-associate via interactions enabled by its carboxy-terminal leucine zipper motif. In non-transformed cells it exists in multiple forms including monomers, dimers, trimers, tetramers and even larger complexes. Upon co expression with active $\operatorname{Src}\left(\mathrm{Scr}^{527 \mathrm{~F}}\right)$, AFAP-110 is detected as dimers, but not in larger complexes. Moreover, AFAP-110 self-association mode is altered in response to coexpression with active Src. Normally, GST-tagged c-terminus of AFAP-110 is able to affinity absorb AFAP-110 from cell lysates; in response to co-expression with active Src this ability is diminished almost completely. These data indicate that active Src causes a conformational change in AFAP-110 responsible for alteration in leucine zipper motif mediated self-association (123). It is also known that this alteration in AFAP-110 selfassociation occurs is a result of serine/threonine phosphorylation, as AFAP- $110^{5 \mathrm{Y}}$ mutant which has five tyrosine residues, phosphorylated by Src in active Src expressing cells, changed to phenilalanine ones so this mutant can neither be phosphorylated by nor even interact with Src and yet the ability of GST-Cterm to pull down AFAP- $110^{5 \mathrm{Y}}$ is decreased in response to co-expression with active Src in a manner identical to that of wild type AFAP-110 (Baisden and Flynn, unpublished data). It has been hypothesized that Src activates serine/threonine kinases one of which may be $\mathrm{PKC}$, and these kinases come along and phosphorylate AFAP-110 on serine and threonine residues. Indeed, in response to PMA treatment the ability of GST-Cterm to pull down AFAP-110 from cell lysates decreases in time-dependent manner, and 6 hour treatment of cells co-expressing AFAP$110^{5 Y}$ and active Src with PKC inhibitor bisindolylmaleimide restores the ability of GSTCterm to affinity absorb AFAP- $110^{5 Y}$ from cell lysates (Baisden and Flynn, unpublished data).

AFAP-110 has an intrinsic ability to remodel actin filaments as its leucine zipper mutant over expression causes actin filament disruption in cultured cells. This ability depends upon conformational changes in this protein, which affect its multimerization status. AFAP-110 is hyperphosphorylated in Src transformed cells, not only on tyrosine 
but also on serine and threonine residues (124). Recent data indicates that serine/threonine and not tyrosine phosphorylation of AFAP-110 is responsible for changes in its self-association (Baisden et al, in preparation). AFAP-110 is a substrate for $\mathrm{PKC}$ in vitro and serine/threonine phosphorylated in response to $\mathrm{PKC}$ activation in vivo (Qian et al, accepted). Non-phosphorylated AFAP-110 cross-links actin filaments whereas in response to PKC phosphorylation in vitro it bundles them (Qian et al, accepted). Serine/threonine phosphorylation of AFAP-110 alters its function by induction of AFAP-110 transition from actin-filament cross-linking to bundling protein. The change in AFAP-110 function occurs in response to phosphorylation-dependent alteration in its conformation and therefore the ability to self-associate. Recent evidence indicates that the site for PKC phosphorylation that mediates this change exists in the serine/threonine kinase interaction domain of AFAP-110 (125)(Cherezova and Flynn, unpublished observation). PKC activation induces motility structure formation such as lamellipodia and filopodia along with disappearance of actin stress fibers. Inside of lamellipodia, actin exists as a network of bundles. AFAP-110 therefore may be involved in PKC-dependent motility structure formation; upon phosphorylation by PKC AFAP110 may act as a protein mediating formation of a meshwork of short actin bundles forming a skeleton of growing lamellipodia.

AFAP-110 therefore is a cellular adaptor protein regulated by serine/threonine phosphorylation. Recent data suggest that PKC dependent phosphorylation influences AFAP-110 self-association mode and actin filament cross-linking properties. Therefore it becomes important to identify AFAP-110 phosphorylation sites playing a crucial role in regulation of its function. The strategy and progress in identification of AFAP-110 functional phosphorylation sites are described in chapter two of this thesis.

AFAP-110 also contains several sequences that may enable its association with another adaptor protein described above, 14-3-3. 14-3-3 proteins are known to act as cellular scaffolds bringing signaling proteins into complexes, so if 14-3-3 interacts with AFAP-110 it could bring AFAP-110 into proximity with kinases PKC and Raf and possibly with other 14-3-3 numerous binding partners. Due to their dimeric nature 14-3-3 proteins are known to act as allosteric regulators, binding to different parts of the same protein. As AFAP-110 contains more than one potential 14-3-3 binding sequence it is 
likely that 14-3-3 may regulate AFAP-110 conformation in response to cellular signals. Chapter three of this thesis describes a strategy and data for determining whether 14-3-3 is a binding partner for AFAP-110. 


\section{References}

1. Muslin, A. J., Tanner, J. W., Allen, P. M., and Shaw, A. S. (1996) Cell 84, 889897

2. Tzivion, G., Shen, Y. H., and Zhu, J. (2001) Oncogone 6331-6338

3. Yaffe, M. B., Rittinger, K., Volinia, S., Caron, P. R., Aitken, A., Leffers, H., Gamblin, S. J., Smerdon, S. J., and Cantley, L. C. (1997) Cell 91, 961-971

4. Fu, H., Subramanian, R. R., and Masters, S. C. (2000) Annu.Rev.Pharmacol.Toxicol. 40, 617-647

5. Yaffe, M. B. and Elia, A. E. (2001) Curr.Opin.Cell Biol. 13, 131-138

6. Lu, P. J., Zhou, X. Z., Shen, M., and Lu, K. P. (1999) Science 283, 1325-1328

7. Verdecia, M. A., Bowman, M. E., Lu, K. P., Hunter, T., and Noel, J. P. (2000) Nat.Struct.Biol. 7, 639-643

8. Hofmann, K. and Bucher, P. (1995) Trends Biochem.Sci. 20, 347-349

9. Liao, H., Byeon, I. J., and Tsai, M. D. (1999) J.Mol.Biol. 294, 1041-1049

10. Wang, P., Byeon, I. J., Liao, H., Beebe, K. D., Yongkiettrakul, S., Pei, D., and Tsai, M. D. (2000) J.Mol.Biol. 302, 927-940

11. Durocher, D., Henckel, J., Fersht, A. R., and Jackson, S. P. (1999) Mol.Cell 4, 387-394

12. Durocher, D., Taylor, I. A., Sarbassova, D., Haire, L. F., Westcott, S. L., Jackson, S. P., Smerdon, S. J., and Yaffe, M. B. (2000) Mol.Cell 6, 1169-1182

13. van der Voorn L and Ploegh HL (1992) FEBS Lett. 307, 131-134

14. Fuchs, S. Y., Chen, A., Xiong, Y., Pan, Z. Q., and Ronai, Z. (1999) Oncogene 18, 2039-2046

15. Orian, A., Gonen, H., Bercovich, B., Fajerman, I., Eytan, E., Israel, A., Mercurio, F., Iwai, K., Schwartz, A. L., and Ciechanover, A. (2000) EMBO J. 19, 25802591

16. Winston, J. T., Strack, P., Beer-Romero, P., Chu, C. Y., Elledge, S. J., and Harper, J. W. (1999) Genes Dev. 13, 270-283

17. Tsvetkov, L. M., Yeh, K. H., Lee, S. J., Sun, H., and Zhang, H. (1999) Curr.Biol. 9, 661-664

18. Skoulakis, E. M. and Davis, R. L. (1998) Mol.Neurobiol. 16, 269-284 
19. Morrison, D. (1994) Science 266, 56-57

20. Burbelo, P. D. and Hall, A. (1995) Curr.Biol. 5, 95-96

21. Baldin, V. (2000) Prog.Cell Cycle Res. 4, 49-60

22. Aitken, A., Jones, D., Soneji, Y., and Howell, S. (1995) Biochem.Soc.Trans. 23, 605-611

23. Reuther, G. W. and Pendergast, A. M. (1996) Vitam.Horm. 52, 149-175

24. Aitken, A., Collinge, D. B., van Heusden, B. P., Isobe, T., Roseboom, P. H., Rosenfeld, G., and Soll, J. (1992) Trends Biochem.Sci. 17, 498-501

25. Jones, D. H., Ley, S., and Aitken, A. (1995) FEBS Lett. 368, 55-58

26. Marais, R. and Marshall, C. (1995) Structure. 3, 751-753

27. Van Der Hoeven, P. C., Van Der Wal, J. C., Ruurs, P., Van Dijk, M. C., and Van Blitterswijk, J. (2000) Biochem.J. 345 Pt 2, 297-306

28. Hausser, A., Storz, P., Link, G., Stoll, H., Liu, Y. C., Altman, A., Pfizenmaier, K., and Johannes, F. J. (1999) J.Biol.Chem. 274, 9258-9264

29. Aitken, A., Howell, S., Jones, D., Madrazo, J., Martin, H., Patel, Y., and Robinson, K. (1995) Mol.Cell Biochem. 149-150, $41-49$

30. Tzivion, G., Luo, Z., and Avruch, J. (1998) Nature 394, 88-92

31. Freed, E., Symons, M., Macdonald, S. G., McCormick, F., and Ruggieri, R. (1994) Science 265, 1713-1716

32. Freed, E., McCormick, F., and Ruggieri, R. (1994) Cold Spring Harb.Symp.Quant.Biol. 59, 187-193

33. Rommel, C., Radziwill, G., Lovric, J., Noeldeke, J., Heinicke, T., Jones, D., Aitken, A., and Moelling, K. (1996) Oncogene 12, 609-619

34. Clark, G. J., Drugan, J. K., Rossman, K. L., Carpenter, J. W., Rogers-Graham, K., Fu, H., Der, C. J., and Campbell, S. L. (1997) J.Biol.Chem. 272, 20990-20993

35. Acs, P., Szallasi, Z., Kazanietz, M. G., and Blumberg, P. M. (1995) Biochem.Biophys.Res.Commun. 216, 103-109

36. Robinson, K., Jones, D., Patel, Y., Martin, H., Madrazo, J., Martin, S., Howell, S., Elmore, M., Finnen, M. J., and Aitken, A. (1994) Biochem.J. 299 ( Pt 3), 853-861

37. Bax, B. and Jhoti, H. (1995) Curr.Biol. 5, 1119-1121 
38. Peng, C. Y., Graves, P. R., Thoma, R. S., Wu, Z., Shaw, A. S., and PiwnicaWorms, H. (1997) Science 277, 1501-1505

39. Kolch, W. (2000) Biochem.J. 351 Pt 2, 289-305

40. Zha, J., Harada, H., Yang, E., Jockel, J., and Korsmeyer, S. J. (1996) Cell 87, 619-628

41. Kosaki, A., Yamada, K., Suga, J., Otaka, A., and Kuzuya, H. (1998) J.Biol.Chem. 273, 940-944

42. Dubois, T., Howell, S., Amess, B., Kerai, P., Learmonth, M., Madrazo, J., Chaudhri, M., Rittinger, K., Scarabel, M., Soneji, Y., and Aitken, A. (1997) J.Protein Chem. 16, 513-522

43. Dubois, T., Rommel, C., Howell, S., Steinhussen, U., Soneji, Y., Morrice, N., Moelling, K., and Aitken, A. (1997) J.Biol.Chem. 272, 28882-28888

44. Megidish, T., Cooper, J., Zhang, L., Fu, H., and Hakomori, S. (1998) J.Biol.Chem. 273, 21834-21845

45. Bouton, A. H., Riggins, R. B., and Bruce-Staskal, P. J. (2001) Oncogene 20, 6448-6458

46. Polte, T. R. and Hanks, S. K. (1995) Proc.Natl.Acad.Sci.U.S.A 92, 10678-10682

47. Polte, T. R. and Hanks, S. K. (1997) J.Biol.Chem. 272, 5501-5509

48. Arai, A., Nosaka, Y., Kohsaka, H., Miyasaka, N., and Miura, O. (1999) Blood 93, 3713-3722

49. Yamakita, Y., Totsukawa, G., Yamashiro, S., Fry, D., Zhang, X., Hanks, S. K., and Matsumura, F. (1999) J.Cell Biol. 144, 315-324

50. Honda, H., Oda, H., Nakamoto, T., Honda, Z., Sakai, R., Suzuki, T., Saito, T., Nakamura, K., Nakao, K., Ishikawa, T., Katsuki, M., Yazaki, Y., and Hirai, H. (1998) Nat.Genet. 19, 361-365

51. Ma, A., Richardson, A., Schaefer, E. M., and Parsons, J. T. (2001) Mol.Biol.Cell 12, $1-12$

52. Chen, H., Slepnev, V. I., Di Fiore, P. P., and De Camilli, P. (1999) J.Biol.Chem. 274, 3257-3260

53. Kariya, K., Koyama, S., Nakashima, S., Oshiro, T., Morinaka, K., and Kikuchi, A. (2000) J.Biol.Chem. 275, 18399-18406

54. Sakakibara, A. and Hattori, S. (2000) J.Biol.Chem. 275, 6404-6410 
55. Voltz, J. W., Weinman, E. J., and Shenolikar, S. (2001) Oncogene 6309-6314

56. Weinman, E. J., Steplock, D., Wang, Y., and Shenolikar, S. (1995) J.Clin.Invest 95, 2143-2149

57. Hall, R. A., Spurney, R. F., Premont, R. T., Rahman, N., Blitzer, J. T., Pitcher, J. A., and Lefkowitz, R. J. (1999) J.Biol.Chem. 274, 24328-24334

58. Shenolikar, S., Minkoff, C. M., Steplock, D. A., Evangelista, C., Liu, M., and Weinman, E. J. (2001) FEBS Lett. 489, 233-236

59. Lehmann, J. M., Riethmuller, G., and Johnson, J. P. (1990) Nucleic Acids Res. 18, 1048

60. Li, W., Fan, J., and Woodley, D. T. (2001) Oncogene 20, 6403-6417

61. Meisenhelder, J. and Hunter, T. (1992) Mol.Cell Biol. 12, 5843-5856

62. Li, W., Hu, P., Skolnik, E. Y., Ullrich, A., and Schlessinger, J. (1992) Mol.Cell Biol. 12, 5824-5833

63. Han, D. C., Shen, T., and Guan, J. (20 A.D.) Oncogene 20, 6315-6321

64. Dong, L. Q., Porter, S., Hu, D., and Liu, F. (1998) J.Biol.Chem. 273, 1772017725

65. Ooi, J., Yajnik, V., Immanuel, D., Gordon, M., Moskow, J. J., Buchberg, A. M., and Margolis, B. (1995) Oncogene 10, 1621-1630

66. Daly, R. J., Sanderson, G. M., Janes, P. W., and Sutherland, R. L. (1996) J.Biol.Chem. 271, 12502-12510

67. Fiddes, R. J., Campbell, D. H., Janes, P. W., Sivertsen, S. P., Sasaki, H., Wallasch, C., and Daly, R. J. (1998) J.Biol.Chem. 273, 7717-7724

68. Glenney, J. R., Jr. and Zokas, L. (1989) J.Cell Biol. 108, 2401-2408

69. Turner, C. E. (2000) Nat.Cell Biol. 2, E231-E236

70. Schaller, M. D. (2001) Oncogene 20, 6459-6472

71. De Nichilo, M. O. and Yamada, K. M. (1996) J.Biol.Chem. 271, 11016-11022

72. Bellis, S. L., Perrotta, J. A., Curtis, M. S., and Turner, C. E. (1997) Biochem.J. 325 ( Pt 2), 375-381

73. Vadlamudi, R., Adam, L., Talukder, A., Mendelsohn, J., and Kumar, R. (1999) Oncogene 18, 7253-7264 
74. Ku, H. and Meier, K. E. (2000) J.Biol.Chem. 275, 11333-11340

75. Hashimoto, S., Tsubouchi, A., Mazaki, Y., and Sabe, H. (2001) J.Biol.Chem. 276, 6037-6045

76. Brown, M. C., Perrotta, J. A., and Turner, C. E. (1998) Mol.Biol.Cell 9, 18031816

77. Schaeper, U., Gehring, N. H., Fuchs, K. P., Sachs, M., Kempkes, B., and Birchmeier, W. (2000) J.Cell Biol. 149, 1419-1432

78. Yu, C. F., Roshan, B., Liu, Z. X., and Cantley, L. G. (2001) J.Biol.Chem. 276, 32552-32558

79. Furge, K. A., Zhang, Y. W., and Vande Woude, G. F. (2000) Oncogene 19, 55825589

80. Roshan, B., Kjelsberg, C., Spokes, K., Eldred, A., Crovello, C. S., and Cantley, L. G. (1999) J.Biol.Chem. 274, 36362-36368

81. Gual, P., Giordano, S., Anguissola, S., Parker, P. J., and Comoglio, P. M. (2001) Oncogene 20, 156-166

82. Ilan, N., Mahooti, S., Rimm, D. L., and Madri, J. A. (1999) J.Cell Sci. 112 Pt 18, 3005-3014

83. Ilan, N., Cheung, L., Pinter, E., and Madri, J. A. (2000) J.Biol.Chem. 275, 2143521443

84. Ilan, N., Cheung, L., Miller, S., Mohsenin, A., Tucker, A., and Madri, J. A. (2001) Dev.Biol. 232, 219-232

85. Shen, Y., Sultana, C., Arditi, M., Kim, K. S., and Kalra, V. K. (1998) Am.J.Physiol 275, E479-E486

86. Paasinen-Sohns, A. and Holtta, E. (1997) Oncogene 15, 1953-1966

87. Cherniack, A. D., Klarlund, J. K., and Czech, M. P. (1994) J.Biol.Chem. 269, 4717-4720

88. Rozakis-Adcock, M., van der, G. P., Mbamalu, G., and Pawson, T. (1995) Oncogene 11, 1417-1426

89. Corbalan-Garcia, S., Yang, S. S., Degenhardt, K. R., and Bar-Sagi, D. (1996) Mol.Cell Biol. 16, 5674-5682

90. Douville, E. and Downward, J. (1997) Oncogene 15, 373-383 
91. Zhao, H., Li, Y. Y., Fucini, R. V., Ross, S. E., Pessin, J. E., and Koretzky, G. A. (1997) J.Biol.Chem. 272, 21625-21634

92. Liu, J. P. (1996) Mol.Cell Endocrinol. 116, 1-29

93. Liu, W. S. and Heckman, C. A. (1998) Cell Signal. 10, 529-542

94. Tsygankov, A. Y., Teckchandani, A. M., Feshchenko, E. A., and Swaminathan, G. (2001) Oncogene 20, 6382-6402

95. Fernandez, B., Czech, M. P., and Meisner, H. (1999) J.Biol.Chem. 274, 2024420250

96. Liu, Y. C., Elly, C., Yoshida, H., Bonnefoy-Berard, N., and Altman, A. (1996) J.Biol.Chem. 271, 14591-14595

97. Pedraza-Alva, G., Sawasdikosol, S., Liu, Y. C., Merida, L. B., Cruz-Munoz, M. E., Oceguera-Yanez, F., Burakoff, S. J., and Rosenstein, Y. (2001) J.Biol.Chem. 276, 729-737

98. Liu, Y. C., Liu, Y., Elly, C., Yoshida, H., Lipkowitz, S., and Altman, A. (1997) J.Biol.Chem. 272, 9979-9985

99. Staubs, P. A., Nelson, J. G., Reichart, D. R., and Olefsky, J. M. (1998) J.Biol.Chem. 273, 25139-25147

100. Li, J., DeFea, K., and Roth, R. A. (1999) J.Biol.Chem. 274, 9351-9356

101. Sun, X. J., Rothenberg, P., Kahn, C. R., Backer, J. M., Araki, E., Wilden, P. A., Cahill, D. A., Goldstein, B. J., and White, M. F. (1991) Nature 352, 73-77

102. Mothe, I. and Van Obberghen, E. (1996) J.Biol.Chem. 271, 11222-11227

103. Ogihara, T., Shin, B. C., Anai, M., Katagiri, H., Inukai, K., Funaki, M., Fukushima, Y., Ishihara, H., Takata, K., Kikuchi, M., Yazaki, Y., Oka, Y., and Asano, T. (1997) J.Biol.Chem. 272, 12868-12873

104. Lam, K., Carpenter, C. L., Ruderman, N. B., Friel, J. C., and Kelly, K. L. (1994) J.Biol.Chem. 269, 20648-20652

105. Tanti, J. F., Gremeaux, T., Van Obberghen, E., and Marchand-Brustel, Y. (1994) J.Biol.Chem. 269, 6051-6057

106. De Fea, K. and Roth, R. A. (1997) Biochemistry 36, 12939-12947

107. De Fea, K. and Roth, R. A. (1997) J.Biol.Chem. 272, 31400-31406

108. Sasaoka, T. and Kobayashi, M. (2000) Endocr.J. 47, 373-381 
109. Luzi, L., Confalonieri, S., Di Fiore, P. P., and Pelicci, P. G. (2000) Curr.Opin.Genet.Dev. 10, 668-674

110. Migliaccio, E., Mele, S., Salcini, A. E., Pelicci, G., Lai, K. M., Superti-Furga, G., Pawson, T., Di Fiore, P. P., Lanfrancone, L., and Pelicci, P. G. (1997) EMBO J. 16, 706-716

111. Migliaccio, E., Giorgio, M., Mele, S., Pelicci, G., Reboldi, P., Pandolfi, P. P., Lanfrancone, L., and Pelicci, P. G. (1999) Nature 402, 309-313

112. Okada, S., Kao, A. W., Ceresa, B. P., Blaikie, P., Margolis, B., and Pessin, J. E. (1997) J.Biol.Chem. 272, 28042-28049

113. Foschi, M., Franchi, F., Han, J., La Villa, G., and Sorokin, A. (2001) J.Biol.Chem. 276, 26640-26647

114. Yang, C. P. and Horwitz, S. B. (2000) Cancer Res. 60, 5171-5178

115. Kanner, S. B., Reynolds, A. B., Vines, R. R., and Parsons, J. T. (1990) Proc.Natl.Acad.Sci.U.S.A 87, 3328-3332

116. Weed, S. A. and Parsons, J. T. (2001) Oncogene 20, 6418-6434

117. Patel, A. S., Schechter, G. L., Wasilenko, W. J., and Somers, K. D. (1998) Oncogene 16, 3227-3232

118. Wu, H. and Parsons, J. T. (1993) J.Cell Biol. 120, 1417-1426

119. van Damme, H., Brok, H., Schuuring-Scholtes, E., and Schuuring, E. (1997) J.Biol.Chem. 272, 7374-7380

120. Campbell, D. H., Sutherland, R. L., and Daly, R. J. (1999) Cancer Res. 59, 53765385

121. Reynolds, A. B., Kanner, S. B., Wang, H. C., and Parsons, J. T. (1989) Mol.Cell Biol. 9, 3951-3958

122. Qian, Y., Baisden, J. M., Zot, H. G., Van Winkle, W. B., and Flynn, D. C. (2000) Exp.Cell Res. 255, 102-113

123. Qian, Y., Baisden, J. M., Westin, E. H., Guappone, A. C., Koay, T. C., and Flynn, D. C. (1998) Oncogene 16, 2185-2195

124. Kanner, S. B., Reynolds, A. B., Wang, H. C., Vines, R. R., and Parsons, J. T. (1991) EMBO J. 10, 1689-1698

125. Flynn, D. C., Leu, T. H., Reynolds, A. B., and Parsons, J. T. (1993) Mol.Cell Biol. 13, 7892-7900 


\section{Chapter 2}

\section{Determining the effects of phosphorylation on AFAP-110 function.}




\section{Introduction:}

AFAP-110 was identified as a phosphotyrosine protein that coimmunoprecipitates with active Src in vSrc-transformed cells (1). Some time later it was discovered that AFAP-110 forms a stable complex with Src and also is phosphorylated by this tyrosine kinase in in vitro kinase assay (2). Avian form of AFAP-110 was cloned in 1993 (3). Immunofluorescence analysis demonstrated that in cultured cells AFAP-110 co localizes with actin stress fibers as well as with cortical actin matrix. In Srctransformed cells, which have disassembled actin filaments, AFAP-110 co-localizes with actin rosettes or podosomes as well as with the actin underlying dynamic motility structures at the leading edge of the cell such as lamellipodia, filopodia, and membrane ruffles (3).

The domain structure of AFAP-110 indicates that this protein may be positioned to modulate the effects of signaling proteins upon actin cytoskeleton (figure 1). AFAP110 contains several modular domains that mediate its interactions with such signaling proteins as Src and PKC. AFAP-110 forms a stable complex with Src via SH2 and SH3 interactions (4;5); it associates with PKC via amino-terminal PH domain (Baisden and Flynn, unpublished data). At the carboxy terminus of AFAP-110 there are also two actin binding modules, which are responsible for direct interactions of AFAP-110 with actin cytoskeleton (6). AFAP-110 possesses the ability to multimerize via carboxy-terminal leucine zipper motif, although the multimerization is not achieved via classical leucine zipper interactions. In normal cells AFAP-110 exists in a form of multimeric complexes, which range from dimers to hexamers; even larger complexes were observed (7). Deletion of carboxy terminal leucine zipper motif results in ability of AFAP-110 to disassemble actin filaments into rosette-like structures similar to those, which are seen in cells transformed by Src $(6 ; 6)$. AFAP-110, therefore, possesses an intrinsic ability to rearrange actin cytoskeleton.

Recent experiments indicate that AFAP-110 function may be regulated by phosphorylation. Even as early as 1991 it was known that in Src transformed cells AFAP110 is hyperphosphorylated not only on tyrosine, but also on serine and threonine residues (4). That suggested a possibility of Src activating one or several serine/threonine 
kinases responsible for phosphorylation of AFAP-110. One possible candidate of serine/threonine kinase that acts downstream of active Src is protein kinase C. Protein kinase $\mathrm{C}$ family of serine/threonine kinases are well known modulators of cell growth, cell motility and differentiation, also implicated into development and progression of certain cancers (8) . PKC superfamily is divided into three subgroups based on their structure and the nature of activators: conventional, novel and atypical PKC subfamilies. Conventional PKCs are activated by PS, DAG and calcium ions; novel PKCs are activated by PS, and DAG but not calcium; atypical PKCs are activated by PS, but neither DAG nor calcium (9). DAG pharmacological analogs phorbol esters, for example PMA, can also be used to activate conventional and novel PKC isoforms (10). PKC $\alpha$ is known to be activated downstream of active Src (11), therefore it has been important to test whether AFAP-110 would be a substrate and/or binding partner for this serine/threonine kinase.

It has been determined in recent years that AFAP-110 is a substrate for PKC $\alpha$ in vitro, as well as is phosphorylated in PKC-dependent manner in cultured cells. Several $\mathrm{PKC}$ isoforms, including $\mathrm{PKC} \alpha$ are able to associate with AFAP-110 via its amino terminal PH domain (Baisden and Flynn, unpublished data). It was also discovered that PKC-dependent serine/threonine phosphorylation alters AFAP-110 conformation, which in turn results in alterations in AFAP-110 self-association. Phosphorylation by PKC $\alpha$ in vitro enhances actin cross-linking ability of recombinant AFAP-110 (Qian et al, 2002). Electron microscopy demonstrates that non-phosphorylated AFAP-110 cross-links actin filament into a loose meshwork of interconnecting cables, whereas PKC-phosphorylated AFAP-110 arranges actin filaments into a more organized network of short bundles (Qian et al, 2002). Cumulatively, these data indicate that PKC-dependent phosphorylation influences AFAP-110 ability to self-associate and cross-link actin filaments. Therefore, it becomes important to identify phosphorylation sites within AFAP-110 structure that are responsible for serine/threonine phosphorylation-induced changes in AFAP-110 structure and function.

In order to determine the identity of functional phosphorylation sites within AFAP-110 structure we performed phosphotryptic analysis of recombinant AFAP-110 phosphorylated in in vitro PKC kinase assay as well as that of AFAP-110 derived from 
cultured cells either treated with PKC stimulator PMA or co-expressing active form of $\mathrm{Src}\left(\mathrm{Src}^{527 \mathrm{~F}}\right)$. Phosphotryptic mapping analysis demonstrated that $\mathrm{PKC} \alpha$ phosphorylates AFAP-110 on multiple residues as well as confirmed previous data that AFAP-110 is a substrate for $\mathrm{PKC} \alpha$ in vitro. Deletional mutageneses in conjunction with confocal actin filament cross-linking assays were employed to determine which regions of AFAP-110 are most likely to contain functional phosphorylation sites. These experiments indicated that the candidate sites are localized to the region encompassed by amino acids 249-294 of Serine Threonine Kinase Interaction (STK) region. Site directed mutagenesis of putative PKC phosphorylation sites is being employed to alter the candidate serine for alanine residues. More experiments are necessary to determine whether the serine residues within amino acids 249-294 of STK region are the functional phosphorylation sites that regulate AFAP-110 self-association and actin cross-linking properties. 


\section{Materials and methods.}

Reagents: DMEM, BME, PMA, bisindolylmaleimide, phosphatidylserine, and diolein were purchased from Sigma. Recombinant PKC $\alpha$ was purchased from Calbiochem. Recombinant pp60 $60^{\text {c-Src }}$ was supplied by Upstate Biotechnology. AntiAFAP-110 antibodies 4C3 and F1 were generated as previously described (3;12). AntiGST antibody was supplied by Santa Cruz Biotechnology. Gluthathione sepharose beads and PreScission protease were from Amersham Pharmacia Biotech. CalPhos mammalian transfection kit was from Clontech. Lipofectamine 2000 transfection kit and PCR Super Mix High Fidelity kit were from Gibco. Quick Change PCR mutagenesis kit was supplied by Stratagene. General actin buffer BSA01, actin polymerization buffer BSA02, ATP, rhodamine-phalloidin, and rabbit non-muscle actin were supplied by Cytoskeleton. GelCode Blue Stain Reagent was from Pierce.

Cell Culture: Cos-7 cells were maintained in Dulbecco's Modified Eagle's Medium (DMEM) supplemented with 5\% Fetal Calf Serum, 2mM glutamine and 1\% penicillin/streptomycin.

Expression vectors: pCMV/AFAP-110 and pCMV/AFAP-110/Src ${ }^{527 F}$ were described in (5;13). pGEX-6p-1-AFAP-110 were described by Qian et al, 2000 (6).

Primers for deletional mutagenesis: AFAP-110 $10^{\Delta 62-152} 5^{\prime}$ primer was GCAGGTACCTGCTGGCAGGCTGTTG; and the $3^{\prime}$ primer was ATCGGTACCGATGCCAAAATTTGTGCC. AFAP- $110^{\triangle \mathrm{PH} 1} 5^{\prime}$ primer was AAGGGTACCCTTCACCAGATCCATAGAG; the reverse primer was GCTGGTACCAGCAACTGTACGGGCAC. AFAP-110 $0^{\triangle S T K} \quad 5^{\prime}$ primer was TGCGGTACCGCACACATCTTTTATAACC; and the reverse primer was ATCGGTACCGATGTTCCAACATGTGG. AFAP- $110^{\triangle \mathrm{AP} 2} \quad 5^{\prime}$ primer was GAAGGTACCTTCTTCAGCTGACGAGG; and the reverse primer was ATAGGTACCTATGACTATATCGATGTGG. AFAP-110 $10^{\Delta 249-294} \quad 5^{\prime}$ primer was TGCGGTACCGCACACATCTTTTATAACC; and the reverse primer was CACGGTACCGTGTGCAACGGAAAAG. AFAP-110 $10^{\Delta 295-346} \quad 5^{\prime}$ primer was ATCGGTACCGATGTTCCAACATGTGG; and the reverse primer was ACAGGTACCTGTGGTGATGCCATTTTCC. AFAP-110 
TACGGTACCGTACACAAGACAGAGCTG; and the reverse primer was 3' primer used in creating AFAP-110 ${ }^{\Delta 249-294}$ mutant. AFAP-110 $\Delta$ 266-294 5' primer was the same as for AFAP-110 $5^{\Delta 249-294}$ primer; and the $3^{\prime}$ primer was CCAGGTACCTGGAGAACTAGACAATGG.

Deletional mutagenesis: pGEX-6p-1-AFAP-110 ${ }^{\triangle 62-152}$, pGEX-6p-1-AFAP$110^{\Delta \mathrm{PH} 1}$, pGEX-6p-1-AFAP-110 ${ }^{\triangle \mathrm{STK}}$, pGEX-6p-1-AFAP-110 $0^{\Delta \mathrm{PH} 2}$, pGEX-6p-1-AFAP$110^{\Delta 249-294}$, pGEX-6p-1-AFAP-110 $0^{\Delta 295-346}$, pGEX-6p-1-AFAP-110 ${ }^{\Delta 249-265}$, pGEX-6p-1AFAP- $110^{\Delta 266-294}$ were created by PCR amplification with PCR Super mix High Fidelity kit using primers with engineered KpnI restriction site described above (KpnI site underlined). Briefly, $45 \mu \mathrm{l}$ of PCR High Fidelity Mix was mixed with $100 \mathrm{ng}$ of template DNA (pGex-6p-1-110) and primers were added to 200nM final concentration; final volume of reaction was $50 \mu \mathrm{l}$. The reactions were overlaid with $30 \mu \mathrm{l}$ mineral oil and subjected to PCR overnight. PCR machine was programmed according to PCR Super mix High Fidelity supplier recommendations, so the reaction was carried out at 94 degrees for 30 seconds, followed by 35 cycles of 94 degrees for 30 seconds, 55 degrees for 30 seconds, and 68 degrees for 7 minutes and 30 seconds. PCR products were digested with 10 units of KpnI for 2 hours and purified on $0.8 \%$ agarose gel. The DNA was then transferred by electrophoresis to DEAE membrane, which was subjected to 45-minute incubation in 350 $\mu \mathrm{l}$, and consequently 15-minute incubation in $150 \mu \mathrm{l}$ of High Salt DEAE membrane buffer $(10.0 \mathrm{ml} 5 \mathrm{M} \mathrm{NaCl}, 10.0 \mathrm{ml}$ 0.5M EDTA, $1 \mathrm{ml} 1 \mathrm{M}$ Tris, $39 \mathrm{ml}$ MilliQ water) at 65 degrees and then to place DNA into solution. DNA-containing High Salt DEAE membrane buffer $350 \mu \mathrm{l}$ and $150 \mu \mathrm{l}$ portions were combined, and DNA was ethanol precipitated, vacuum dried, and the pellet was dissolved in $16 \mu \mathrm{l}$ of autoclaved MilliQ water. $2 \mu \mathrm{l}$ of 10X ligation buffer (Roche) and 2 units of T4 DNA ligase (Roche) were mixed with the DNA, and the reaction was allowed to proceed at 16 degrees for 16 hours. $3 \mu \mathrm{l}$ of ligation reactions were used to transform E. coli DH5 $\alpha$ competent cells by electroporation. Bacterial cells were then incubated in $1 \mathrm{ml} \mathrm{LB}$ Broth at 37 degrees with shaking for 1 hour; $20 \mu \mathrm{l}$ and $200 \mu \mathrm{l}$ aliquots were plated on 1X Ampicillin LB plates. Cultures from several colonies were inoculated for mini-scale DNA preparation, and the extracted DNA was screened by restriction mapping to determine which colonies contain 
pGEX-6P-1-110 plasmid bearing desired deletion.

Site directed mutagenesis. pCMV/AFAP-110 ${ }^{\mathrm{S186,210A}}$, pCMV/AFAP-

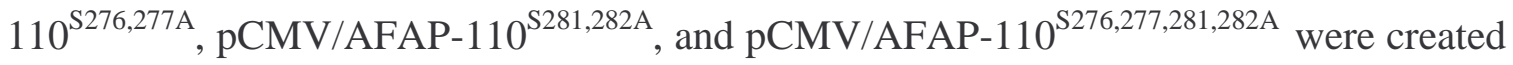
by PCR-based site-directed mutagenesis using primers with nucleotide mismatches containing desired mutation. Briefly, $20 \mathrm{ng}$ of pCMV/AFAP-110 template was mixed with $5 \mathrm{ml}$ of $10 \mathrm{X}$ reaction buffer (Stratagene), $125 \mathrm{ng}$ of each primer, $1 \mathrm{ul}$ of $10 \mathrm{mM}$ dNTP mix (Stratagene), and 2.5 units of Pfu Turbo DNA polymeraze. The volume of PCR mix was brought to $50 \mathrm{ml}$ with HPLC grade autoclaved water. The reactions were overlaid with $30 \mathrm{ml}$ of mineral oil. The ractions were carried out at 95 degrees for 30 seconds, and 18 cycles of 95 degrees at 30 seconds, 55 degrees for 1 minute, and 68 degress for 15 minutes. The reactions were than incubated at 37 degrees for 1 hour with 10 units of DpnI restriction enzyme (Roche) to digest the template. 1 ul of each PCR reaction was added to $50 \mathrm{ul}$ of Epicurian coli XL-1 Blue supercompetent cells and incubated on ice for 30 minutes. The transformation reactions were heat-pulsed for 45 seconds at 42 degrees, and placed on ice for 2 minutes. After that $0.5 \mathrm{ml}$ of NZY-Broth (5 grams of $\mathrm{NZ}$ amine, 2.5 grams of yeast extract, 2.5 grams of $\mathrm{NaCl}$ were diluted in $500 \mathrm{ml}$ of MilliQ water and autoclaved. $6.25 \mathrm{ml}$ of $1 \mathrm{M} \mathrm{MgCl} 2$ and $6.25 \mathrm{ml}$ of $1 \mathrm{M} \mathrm{MgSO} 4$ and 5 $\mathrm{ml}$ of a $2 \mathrm{M}$ filter-sterilized glucose solution were added to the autoclaved broth, and filter-sterilized) preheated to 42 degrees was added to each transformation reaction, and the reactions were incubated at 37 degrees with shaking for 1 hour. After that the reactions were plated onto $2 \mathrm{X}$ Ampicillin LB plates. Cultures from several colonies were inoculated for mini-scale DNA preparation, and the extracted DNA was screened either by restriction mapping or DNA sequencing to determine which colonies contain pCMV/110 plasmid vector bearing desired substitution.

GST-fusion protein induction: Wild type AFAP-110 or mutants in pGEX-6p-1 vector were put into E. coli DH5 $\alpha$ cells. A starter culture was grown at 37 degrees overnight in $50 \mu \mathrm{g} / \mathrm{ml}$ ampicillin LB-Broth media. Starter culture was diluted with fresh $50 \mu \mathrm{g} / \mathrm{ml}$ ampicillin LB broth in a 1:20 ratio and incubated at 37 degrees with shaking for 1 hour. IPTG was added to bacterial culture to $0.5 \mathrm{mM}$ concentration. Cultures were incubated for 5 hours at 30 degrees with shaking. Bacterial pellets were harvested by centrifugation at $6000 \mathrm{rpm}$ for 5 minutes and resuspended in 1\%TritonX MT-PBS (150 
$\mathrm{mM} \mathrm{NaCl}, 16 \mathrm{mM} \mathrm{Na}_{2} \mathrm{HPO}_{4}, 4 \mathrm{mM} \mathrm{NaH} \mathrm{PO}_{4}, 1 \%$ Triton X). Bacterial cell walls were disrupted by sonication, centrifuged at $10000 \mathrm{rpm}$ to separate cell wall debris from lysate. Lysate-containing supernatant was collected and stored at -80-degree freezer until needed.

Immobilization of fusion protein on gluthathione sepharose beads: Gluthathione sepharose beads were washed into $1 \%$ Triton X MT-PBS. GST fusion protein lysates were mixed with bead slurry and incubated for 1 hour at 4 degrees with shaking. After that the bead-fusion protein complexes were washed in $1 \%$ Triton X MTPBS and stored at 4 degree refrigerator for future use.

Cleavage of proteins from GST - gluthathione sepharose beads complexes: Bead-GST-fusion protein complexes were washed into PreScission protease cleavage buffer (50mM Tris, $150 \mathrm{mM} \mathrm{NaCl}, 1 \mathrm{mM}$ EDTA, 1mM DTT). For each $\mathrm{ml}$ of washed Gluthathione Sepharose bed volume 80 units of PreScission protease were mixed with PreScission protease cleavage buffer, and the mixture was added to the beads. Cleavage was allowed to proceed for 16 hours at 4 degrees. Protein-containing supernatant was collected and stored at -20-degree freezer for future use.

Dialysis and concentration of recombinant proteins: Recombinant proteins in PreScission cleavage buffer were placed into dialysis membrane bags and incubated for 24 hours in a dialysis buffer $\left(5 \mathrm{mM}\right.$ Tris, $\left.0.2 \mu \mathrm{M} \mathrm{CaCl}_{2}\right)$ with gentle stirring at 4 degrees. Dialyzed proteins were concentrated using Microcon concentration tubes. Concentration proceeded by sequential centrifugation of $500 \mu \mathrm{l}$ aliquots of dialysed protein samples at $11000 \mathrm{rpm}$ for 10 minutes. The concentrated protein solution was collected by centrifugation at $2000 \mathrm{rpm}$ for 5 minutes. The yield was determined by resolving $1 \mu \mathrm{l}$ aliquots of recombinant protein on a $8 \%$ SDS-PAGE with BSA molecular weight standards followed by staining of gel with GelCode Blue Stain Reagent.

In vitro phosphotryptic mapping: GST-AFAP-110 bound to gluthathione sepharose beads was washed into PKC assay buffer (20 mM Tris, $\mathrm{pH} 7.5,5 \mathrm{mM} \mathrm{MgCl}$, $0.2 \mathrm{mM} \mathrm{CaCl}_{2}, 20 \mu \mathrm{g} / \mathrm{ml}$ phosphatidylserine, $2 \mu \mathrm{g} / \mathrm{ml}$ diolein). $5 \mu \mathrm{g}$ of recombinant $\mathrm{PKC} \alpha$ and $200 \mu \mathrm{Ci}{ }^{32} \mathrm{P}-\gamma$-ATP were added per $1 \mathrm{ml}$ of beads with recombinant protein into the reaction tube, and in-vitro phosphorylation was allowed to proceed for 2 hours at 30degree incubator with shaking. Gluthathione sepharose bead slurry was washed into pre- 
scission protease cleavage buffer, 80 units of PreScission protease were added per $\mathrm{ml}$ of washed Gluthathione Sepharose bed volume, and cleavage proceeded for 16 hours at 4 degrees with shaking. Supernatant, containing ${ }^{32} \mathrm{P}-\gamma$ phosphorylated protein, was collected, and protein was precipitated with $250 \mu \mathrm{l}$ ice cold TCA using $20 \mu \mathrm{g}$ of RNase A as a carrier protein. The pellet was washed with ethanol, air dried, resuspended in $100 \mu \mathrm{l}$ of 2XLSB, boiled for 5 minutes and subjected to $8 \%$ SDS-PAGE. SDS-PAGE with ${ }^{32} \mathrm{P}-\gamma$ phosphorylated protein in it was exposed to film and radioactive band was excised. Radioactively labeled protein was eluted out of acrylamide with two changes of $500 \mu \mathrm{l}$ $50 \mathrm{mM}$ NH4HCO3 with $50 \mu \mathrm{l}$ 2ME and $10 \mu \mathrm{l} 10 \%$ SDS. Radiolabeled protein was TCA precipitated as described above. Immobilized trypsin was washed into 50mM NH4HCO3 buffer and mixed with TCA precipitated radiolabeled protein. Tryptic digestion was allowed to proceed in 37-degree incubator for 16 hours. Phosphotryptic peptide containing supernatant was collected and lyophilized. The pellet was washed and lyophilized twice in milliQ water, resuspended in $6 \mu \mathrm{l}$ buffer $\mathrm{pH}=1.9$ (50 $\mathrm{ml} 88 \%$ formic acid, $156 \mathrm{ml}$ glacial acetic acid, $1794 \mathrm{ml}$ MilliQ water) and loaded on TLC plates. Samples were run via electrophoresis for 1 hour at $1 \mathrm{kVolts}$ in a $\mathrm{pH}=1.9$ buffer in first dimension, then for 16 hours in a chromatography buffer optimized for phosphopeptides (750 ml n-butanol, $607 \mathrm{ml}$ pyridine, $150 \mathrm{ml}$ glacial acetic acid, $600 \mathrm{ml}$ MilliQ water) in the second dimension using the HTLE7000 system, according to manufacturers instructions. TLC plates with two-dimentionally separated phosphotryptic peptides were exposed to phosphorimager cassettes for at least 16 hours. Radioactive spots representative of phosphotryptic peptides were analyzed using phosphorimager.

In vivo phosphotryptic mapping: For PMA treatment, Cos-7 cells were grown to $60 \%$ confluence in $100 \mathrm{~mm}$ culture dishes, transiently transfected with pCMV/AFAP110 or pCMV/AFAP-110/Src ${ }^{527 \mathrm{~F}}$ using CalPhos transfection kit, serum starved overnight in the presence of $2.5 \mathrm{mCi}$ of radioactive orthophosphate, then stimulated with $100 \mathrm{nM}$ PMA for 1 hour. To determine effects of activated Src on AFAP-110, Cos-7 cells were grown to $60 \%$ confluence in $100 \mathrm{~mm}$ culture dishes, transiently transfected with pCMV/AFAP-110/Src ${ }^{527 \mathrm{~F}}$ plasmid and labeled with $2.5 \mathrm{mCi}$ of radioactive orthophosphate. 60-66 hours after transfection cells were washed twice with PBS and lysed with $1 \mathrm{ml}$ RIPA lysis buffer (1\% NP-40, $0.25 \%$ deoxycholate, $150 \mathrm{mM} \mathrm{NaCl}$, 
$50 \mathrm{mM}$ Tris, $\mathrm{pH}=7.5)$ supplemented with protease and phosphatases inhibitors $(50 \mu \mathrm{g} / \mu \mathrm{l}$ aprotinin, 2mM Sodium Vanadate, 2mM PMSF, 2 mM EGTA, $10 \mu \mathrm{g} / \mathrm{ml}$ Leupeptin). 2 $\mu 1$ monoclonal antibody 4C3 was used to immunoprecipitate AFAP-110 from the Cos-7 lysate. $30 \mu \mathrm{l}$ of protein A agarose was used as a secondary antibody to pull down 4C3AFAP-110 complexes. Immunoprecipitates were resuspended in 2X LSB, boiled and subjected to $8 \%$ SDS-PAGE. From this step the experiment proceeded as described in in vitro phosphotryptic mapping protocol.

In vitro PKC kinase assay: $0.4 \mu \mathrm{g}$ of recombinant protein (AFAP-110 or mutant) was mixed with $0.2 \mu \mathrm{g}$ of human recombinant $\mathrm{PKC} \alpha$ in the presence of 2.5 nanomoles ATP in a PKC assay buffer (20 mM Tris, pH 7.5, $5 \mathrm{mM} \mathrm{MgCl}_{2}, 0.2 \mathrm{mM} \mathrm{CaCl} 2,20 \mu \mathrm{g} / \mathrm{ml}$ phosphatidylserine, $2 \mu \mathrm{g} / \mathrm{ml}$ diolein). The reactions were incubated at 30 degrees for 30 minutes.

In vitro Src kinase assay for in vitro phosphotryptic mapping: GST-AFAP110 bound to gluthathione sepharose beads was washed into Src kinase buffer $(100 \mathrm{mM}$ Tris- $\mathrm{HCl}, \mathrm{pH}=7.2,125 \mathrm{mM} \mathrm{MgCl}_{2}, 25 \mathrm{mM} \mathrm{MnCl}_{2}, 2 \mathrm{mM}$ EGTA, $0.25 \mathrm{mM}$ sodium orthovanadate, $2 \mathrm{mM}$ dithiothreitol). 30 units (10 $\mu \mathrm{l})$ of recombinant Src kinase and 200 $\mu \mathrm{Ci}$ of ${ }^{32} \mathrm{P}-\gamma$-ATP were added to the reaction tube already containing gluthathione sepharose beads with GST-AFAP-110 in Src kinase buffer. The phosphorylation reaction was allowed to proceed for 2 hours at 30 degrees with shaking.

Confocal microscopy actin cross-linking assays: Rabbit nonmuscle $\mathrm{G}$ actin was resuspended in general actin buffer BSA01 to concentration $50 \mathrm{ug} / \mathrm{ul}(5 \mathrm{mM}$ Tris, $\mathrm{pH}=8.0$; $0.2 \mathrm{mM} \mathrm{CaCl}_{2}$ ), snap-frozen in liquid nitrogen and kept at -80-degree freezer until needed. $2 \mu \mathrm{M}$ F-actin stock was prepared from $\mathrm{G}$-actin in $5 \mathrm{mM}$ Tris- $\mathrm{HCl} \mathrm{pH} 8.0,0.2 \mathrm{mM}$ $\mathrm{CaCl}_{2}, 0.5 \mathrm{mM} \mathrm{DTT}, 100 \mathrm{mM} \mathrm{MgCl}_{2}$, and 50mM ATP at room temperature for 1 hour. Then F-actin was labeled with rhodamine-phalloidin by incubating F-actin with $0.5 \mu \mathrm{g} / \mu \mathrm{l}$ rhodamine-phalloidin in proportion 9:1 for 3 hours at 4 degrees. Rhodamine-phalloidinlabeled F-actin was mixed with recombinant AFAP-110 or AFAP-110 mutants, either phosphorylated or non-phosphorylated by $\mathrm{PKC}$ in vitro, in $5 \mathrm{mM} \mathrm{MgCl}_{2}, 1 \mathrm{mM}$ EGTA, $2 \mathrm{mM}$ ATP, $50 \mathrm{mM} \mathrm{KCl}$ at room temperature for 30 minutes. After the incubation, reactions were placed on the glass slides, covered with coverslips, sealed and analyzed 
under Zeiss LSM 510 confocal microscope. 


\section{Results.}

Previous data indicates that AFAP-110 is a substrate for PKC in vitro and is phosphorylated on serine and threonine residues in vivo in response to treatment of cultured cells with phorbol ester PMA or co-expression of active Src. Serine/threonine phosphorylation alters AFAP-110 ability to self-associate and enhances its actin crosslinking capability (Baisden and Flynn, unpublished data; Qian et al, 2002, MBC). Therefore it becomes important to identify AFAP-110 phosphorylation sites, which play a pivotal role in regulation of AFAP-110 function.

We started to approach phosphorylation sites identification using phosphotrypticmapping analysis of recombinant AFAP-110 according to the protocol described by Boyle and co-workers (14). Recombinant AFAP-110 was incubated with human recombinant $\mathrm{PKC} \alpha$ in vitro at a molar ratio of 20:1 substrate to enzyme in the presence of radioactive ATP in PKC $\alpha$ kinase buffer containing co-factors for $\mathrm{cPKC}$. Phosphorylated AFAP-110 was then purified on 8\% SDS-PAGE, eluted out of acrylamide and digested with trypsin. Phosphotryptic peptides were subjected to two-dimensional separation on TLC plates, which were then analyzed using phosphorimager.

Phosphotryptic mapping analysis of recombinant AFAP-110 revealed that 14 phosphotryptic fragments are generated in response to AFAP-110 phosphorylation by $\mathrm{PKC} \alpha$ in vitro. This experiment confirmed that AFAP-110 is a substrate for PKC $\alpha$ in vitro and also demonstrated that PKC $\alpha$ phosphorylates AFAP-110 on multiple residues. Figure 2A.

In order to determine whether any of these fragments are generated in response to PKC activation in vivo, Cos-1 cells transiently expressing AFAP-110 were radiolabeled with ${ }^{32} \mathrm{P}$-orthophosphate and subjected to 1 -hour treatment with $100 \mathrm{nM}$ phorbol-12myristate-13-acetate (PMA) to activate PMA-inducible PKC isoforms. Also, Cos-1 cells were transiently co-transfected with AFAP-110 and active form of non-receptor tyrosine kinase $\operatorname{Src}\left(\operatorname{Src}^{527 F}\right)$, which is known to activate $\operatorname{PKC} \alpha(11)$; these cells were also radiolabeled with ${ }^{32} \mathrm{P}$-orthophosphate. AFAP-110 was pulled down from these cells by immunoprecipitation with anti-AFAP-110 antibody 4C3, gel purified, and digested with trypsin. Phosphotryptic peptides were subjected to two-dimensional separation on TLC plates (Figure 2, B and C). Only six phosphotryptic fragments appear on both in vivo 
maps (Figure 2, B and C), four of which are common to both in vivo maps (indicated by arrowheads). Comparison of the three maps (Figure 2, A, B and C) reveals the presence of two common fragments among them (indicated by black arrowheads). Both in vivo maps (B and C) contain two phosphotryptic fragments (indicated by white arrowheads), which are not present on in vitro map (A). These fragments may represent peptides that are actually present on in vitro map, but positioned differently on in vivo maps due to in vivo posttranslational modifications other than phosphorylation, which affect their molecular weight and/or hydrophobicity. Alternatively, these fragments may be generated in response to phosphorylation of AFAP-110 by PKC or other PMA activated serine/threonine kinases on residues, which are not phosphorylated by recombinant $\mathrm{PKC} \alpha$ in vitro. One more explanation of the differences among fragments from in vitro and in vivo maps could be that in vivo derived peptides may also be phosphorylated on tyrosine residues, especially in cells co-expressing active form of Src, which would therefore result in change of their mobility in both dimensions on TLC plates. Neither peptide on maps B nor C represents a phosphotryptic fragment phosphorylated only on tyrosine residues, as no phosphotryptic peptide on maps $\mathrm{B}$ and $\mathrm{C}$ migrates in the same manner as the AFAP-110 tryptic fragment(s) phosphorylated with recombinant Src in vitro (Figure $2 \mathrm{D})$.

Previous data of Qian et al (Qian et al, 2002) indicates that AFAP-110 is an actin cross-linking protein, and that phosphorylation by PKC enhances actin cross-linking properties of AFAP-110. Qian et al used confocal microscopy actin filament crosslinking assays as well as AFAP-110 and actin filament low speed co-sedimentation assays to obtain their data. For confocal actin filament cross-linking assay filamentous actin was prepared in vitro and labeled with rhodamine-phalloidin, and then it was incubated either alone or with non-phosphorylated or phosphorylated AFAP-110. According to Qian et al, in the absence of actin cross-linking protein actin appears uniformly fluorescent, whereas in the presence of non-phosphorylated AFAP-110 actin filament become organized into a pattern of interconnecting fluorescent cables. In the presence of PKC phosphorylated AFAP-110 actin appears in a form of large bright aggregates of fluorescence, which are representative of tightly organized actin filaments, with a dark spaces among them (Qian et al, 2002). These data along with the data from 
actin pelleting assays (Qian et al, 2002) indicates actin cross-linking properties of AFAP110 are regulated by serine/threonine phosphorylation and accentuates the importance of determining the identity of these sites.

PKC consensus site is represented by serine or threonine residue in a position 0 with a basic amino asid(s) lysine or arginine in a position $-4,-3,-2$ and/or $+2,+3,+4$ (15). AFAP-110 contains over twenty putative PKC phosphorylation sites (Table 1).

Table 1

\begin{tabular}{|c|c|c|c|}
\hline $\mathrm{N}$ & $\begin{array}{l}\text { Amino } \\
\text { acid } \\
\text { number }\end{array}$ & $\begin{array}{l}\text { Preceding } \\
\text { fragment }\end{array}$ & $\begin{array}{c}\text { AFAP-110 phosphotryptic fragment containing } \\
\text { putative PKC site(s) }\end{array}$ \\
\hline 1 & $10-25$ & & LFLELLDHEYLTSTVR \\
\hline 2 & $38-42$ & ...NILLR & IQSS $\underline{K}$ \\
\hline 3 & $53-104$ & & ........IPQQWLPPDNGPPPLPTSSLPEGYYEEAVPVSPGK \\
\hline 4 & $186-188$ & LLCY $\underline{K}$ & SS트 \\
\hline 5 & $209-211$ & ...DCSITYIPK & DS $\underline{K}$ \\
\hline 6 & $246-268$ & VIK & DVCSNCTGTVDSDGPLSSSPVHK \\
\hline 7 & $275-299$ & TELEKK & LSSERPSSDGEGAVENGITTVCNGK \\
\hline 8 & $307-309$ & $\underline{\mathrm{RKK}}$ & SS트 \\
\hline 9 & $319-322$ & GTVTK & VTGK \\
\hline 10 & $405-410$ & & HPLTFR \\
\hline 11 & $485-512$ & VISTNPY $\underline{R}$ & GSTANGYACPSGMALHYDDVPCINGSFKK \\
\hline 12 & $515-526$ & & KPPATANGITGK \\
\hline 13 & $642-645$ & LTEV $\underline{K}$ & ESLK \\
\hline
\end{tabular}

Therefore it would not be worthwhile to employ site directed mutagenesis before it has been determined which region of AFAP-110 is most likely to contain functional sites of phosphorylation. In order to determine which regions of AFAP-110 are most likely to contain functional AFAP-110 phosphorylation sites responsible for phosphorylation-dependent change in actin cross-linking ability of this protein PCRbased deletional mutagenesis was performed. GST-tagged AFAP-110 mutants missing amino acids 62-152 (SH3 binding, potential WW, SH2 binding motifs), 153-248 
(PH1domain), 249-346 (Serine threonine kinase interaction region), and 347-450 (PH2 domain) were created (Figure 3).

GST-tagged recombinant AFAP-110 bearing each of these deletions was made in bacteria, purified on gluthathione sepharose beads, and digested from gluthathione sepharose bound GST portion with preScission protease. AFAP-110 was then dialyzed and concentrated on microcon concentrating tubes. Full-length AFAP-110 and deletion mutants were phosphorylated by recombinant $\mathrm{PKC} \alpha$ in vitro, and incubated with rhodamine-phalloidin labeled filamentous actin. The reactions were analyzed by confocal microscopy actin cross-linking assays developed by Qian and colleagues (Qian et al, 2002). In the presence of non-phosphorylated AFAP-110 actin filaments are organized into a network of interconnecting fluorescent filaments (Figure $4 \mathrm{~A}$ and B), whereas confocal microscopy image of actin filaments incubated with PKC-phosphorylated AFAP-110 demonstrates appearance of large bright aggregates of fluorescence representative of tighter cross-linked actin filaments (figure $4 \mathrm{C}$ and D). These data repeated the results of Qian et al (Qian et al, 2002) indicating that phosphorylated AFAP110 cross-links actin filaments much more efficiently than non-phosphorylated. Confocal actin cross-linking assay therefore may be used as an in vitro test for AFAP-110 function. Confocal analysis of PKC $\alpha$-phosphorylated versus non-phosphorylated AFAP-110 mutants demonstrates that three out of four deletions alter actin cross-linking properties of AFAP-110. When AFAP-110 mutant, missing SH3 binding motif, potential WW motif and amino terminal SH2 binding motif (AFAP-110 $162-152$ ), phosphorylated by PKC $\alpha$ in vitro is incubated with rhodamine-labeled filamentous actin, most of the actin filaments appear in a form of network, with few actin aggregates scattered all over slide area (Figure 5).

Deletion of SH3 binding, potential WW, and SH2 binding regions of AFAP-110 therefore reduces PKC ability to enhance actin cross-linking properties of AFAP-110, but does not eliminate it completely. AFAP-110 mutant missing amino terminal PH domain $\left(\mathrm{AFAP}-110^{\triangle \mathrm{PH} 1}\right.$ ) loses the ability to cross-link actin efficiently in response to PKC $\alpha$ phosphorylation (Figure $6 \mathrm{C}$ and D), but the incubation of actin filaments with nonphosphorylated PH1 deletion mutant results in appearance of bright actin aggregates indicative of efficient actin filament cross-linking by this construct (Figure 6 A and B). 
AFAP- $110^{\Delta \mathrm{PH} 1}$ therefore can cross-link actin filaments efficiently in the absence of phosphorylation, in the same manner as PKC phosphorylated full length AFAP-110, however, in response to phosphorylation it can only cross-link filamentous actin into a loose network similar to non-phosphorylated full length AFAP-110.

Rhodamine-labeled actin filaments incubated with phosphorylated AFAP-110 mutant missing serine/threonine kinase interaction region (AFAP-110 ${ }^{\triangle \mathrm{STK}}$ ) appear exactly the same was as F-actin incubated with non-phosphorylated mutant; they are arranged into network of fluorescent fibrils with no bright actin aggregates at all (Figure 7). Phosphorylation by $\mathrm{PKC} \alpha$ fails to enhance actin cross-linking ability of this deletion mutant. The data presented in Figure 7 indicate that the integrity of STK region is important for PKC-phosphorylation-dependent regulation of AFAP-110 function. There are two possible hypotheses as to why AFAP- $110^{\triangle \mathrm{STK}}$ fails to cross-link filamentous actin into a tighter aggregates in response to phosphorylation by PKC $\alpha$. One of them is that AFAP-110 may undergo a conformational change as a result of deletion of amino acids 249-346 in a way that this protein can no longer associate with and/or be phosphorylated by PKC $\alpha$. Another one is that STK region of AFAP-110 contains functional phosphorylation sites within its structure, and it is their disappearance that results in inability of PKC $\alpha$ to alter AFAP- $110^{\triangle \mathrm{STK}}$ actin filament cross-linking properties.

AFAP-110 mutant missing carboxy terminal PH domain (AFAP-110 ${ }^{\triangle \mathrm{PH} 2}$ ) behaves in the same manner as the full length AFAP-110 (Figure 8). Non-phosphorylated AFAP$110^{\mathrm{APH} 2}$ cross-links actin filaments into loosely interconnecting actin cables (Figure $8 \mathrm{~A}$ ). Phosphorylation by PKC $\alpha$ enhances the ability of AFAP- $110^{\triangle \mathrm{PH} 2}$ mutant to efficiently cross-link actin filaments into tighter aggregates (Figure 8 B). Deletion of carboxy terminal PH domain does not seem to have any effect on PKC-phosphorylationdependent ability of AFAP-110 to cross-link actin filaments, and therefore $\mathrm{PH} 2$ domain is hardly likely to contain functional phosphorylation sites.

AFAP- $110^{\triangle \mathrm{STK}}$ completely loses the ability to efficiently cross-link actin in response to phosphorylation by PKC $\alpha$. Therefore STK region of AFAP-110 may contain functional phosphorylation sites within its structure. There are several putative PKC $\alpha$ target sites within this region (Table 1). Before we attempt to change them all at once, 
one by one or in combinations by site-directed mutagenesis, we decided to narrow down the area even further and create two more deletion mutants.

In attempt to discover whether it is a matter of phosphorylation sites, two more deletion mutants were created: GST-tagged AFAP-110 missing amino acids 249-294 (first half of STK region) and amino acids 295-346 (second half of STK region) (Figure 9). These mutants were also expressed in bacterial cells, purified as described above, phosphorylated by $\mathrm{PKC} \alpha$ in vitro and incubated with rhodamine-phalloidin labeled actin filaments and analyzed using confocal microscope.

Actin filaments incubated with PKC-phosphorylated AFAP-110 ${ }^{\Delta 249-294}$ appear as a network of fluorescent cables, same as F-actin incubated with non-phosphorylated AFAP-110 ${ }^{\Delta 249-294}$ mutant or wild type (Figure 10).

PKC-phosphorylated AFAP-110 $0^{\Delta 295-346}$ is able to cross-link actin into a large bright fluorescent aggregates in a same manner as PKC phosphorylated full length AFAP-110, whereas non-phosphorylated AFAP-110 ${ }^{\Delta 295-346}$ behaves exactly as the full length AFAP-110 (Figure 11). These data suggest that the integrity if the amino-terminal half of STK region is the most important for PKC-dependent regulation of AFAP-110 actin cross-linking ability. The first half of STK region therefore may contain the phosphorylation sites crucial for the regulation of AFAP-110 function by serine/threonine phosphorylation. In an attempt to further narrow down the AFAP-110 region containing functional serine/threonine phosphorylation sites, two more deletion mutants were created by PCR-based deletional mutagenesis.

These AFAP-110 mutants miss either amino acids 249-265 (first quarter of STK region) or amino acids 266-294 (second quarter of STK region) (Figure 12). GST-tagged AFAP-110 $0^{\Delta 249-265}$ and AFAP-110 $0^{\Delta 266-294}$ were expressed in bacterial cells, purified, cleaved off GST portion, dialyzed, concentrated and phosphorylated by $\mathrm{PKC} \alpha$ in vitro. Rhodamine labeled actin filaments were incubated with PKC phosphorylated versus nonphosphorylated these mutants. Results of this experiment are shown in figures 13 and 14 . Non-phosphorylated AFAP-110 $0^{\Delta 249-265}$ and AFAP-110 ${ }^{\Delta 266-294}$ cross-link actin in the same manner as non-phosphorylated full length AFAP-110 (Figures 13 and 14, panels A). Actin filaments incubated with phosphorylated forms of these mutants mostly organized into network of fluorescent bundles with very few bright aggregates of more 
tightly cross-linked actin (Figure 13 and 14, panels B). There are fewer of these aggregates in case of PKC-phosphorylated AFAP-110 ${ }^{\Delta 266-294}$ (Figure 14 B) rather than in case of PKC-phosphorylated AFAP-110 ${ }^{\Delta 249-265}$ (Figure 13 B). These data suggest that more important functional phosphorylation sites are localized to amino acids 266-294 within STK region. Incomplete loss of AFAP-110 ${ }^{\Delta 266-294}$ to efficiently cross link actin upon PKC phosphorylation suggests that multiple phosphorylation sites may be responsible for this, and some of them may be localized to amino acids 249-265. There are four serine residues within second quarter of STK region - S276, 277, 281 and 282. They all fall into definition of PKC phosphorylation sites. They will be mutated to alanine residues in pairs or all at once, and various experiments will be performed to determine whether these are the functional phosphorylation sites. 


\section{Discussion.}

AFAP-110 is a multidomain adaptor protein, which was discovered as a Srcassociated tyrosine phosphorylated protein (2). AFAP-110 domain structure suggests that this protein can be positioned to alter actin cytoskeleton in response to cellular signals. Indeed, AFAP-110 binds Src directly via SH2- and SH3 binding motifs, and also interacts with PKC via its amino-terminal PH domain; AFAP-110 has the ability to bind actin directly via its carboxy-terminally located actin binding modules (16). AFAP-110 also has the ability to self-associate via leucine zipper interactions; gel filtration analysis of cellular AFAP-110 demonstrated that in normal cells AFAP-110 is present mostly in the form of large complexes like tetramers, pentamers or hexamers or even larger ones. In response to co-expression with active Src it exists predominantly in a form of dimers (7). AFAP-110 has an intrinsic ability to remodel actin cytoskeleton as the deletion of leucine zipper motif enables this protein to cause disorganization of actin stress fibers into actin rosettes similar to ones often seen in cells expressing active Src; AFAP-110 ${ }^{\Delta l z i p}$ also induces lamellipodia and filopodia formation (6). Previous data have shown that AFAP110 may be regulated by serine/threonine phosphorylation in response to activation of cellular kinases Src and PKC. AFAP-110 is a substrate for PKC $\alpha$ in vitro and is phosphorylated in response to PKC activation in vivo (Baisden and Flynn, unpublished data). Serine/threonine phosphorylation is thought to cause alterations in AFAP-110 conformation, which are responsible for changes in its multimerization status. Recently it was determined that large multimeric complexes formed by non-phosphorylated AFAP110 are thought to cross-link actin filaments in a loose manner, promoting assembly of a meshwork of cross-linked actin filaments, whereas AFAP-110 dimers formed by serine/threonine phosphorylated protein arrange actin filaments into more dense structures which can be described as a networks of short tight actin bundles (Qian et al, accepted). Activation of cellular kinase PKC promotes actin stress fibers disassembly but in the same time induces actin filament organization into a meshwork of cross-linked short bundles, which act as a skeleton for lamellipodia. AFAP-110 is a protein that may act as a PKC effector responsible for those changes, and its ability to rearrange actin is regulated by serine/threonine phosphorylation. Therefore it became important to identify phosphorylation sites within AFAP-110 structure that are responsible for changes in 
AFAP-110 conformation, self-association status and actin cross-linking ability of this protein.

Fist of all, AFAP-110 was subjected to phosphotryptic mapping analysis. Phosphotryptic map of in vitro PKC phosphorylated recombinant AFAP-110 reveals presence of fourteen spots which indicate that PKC phosphorylates AFAP-110 on multiple residues and also confirms data of Baisden and Flynn that AFAP-110 is a substrate for PKC in vitro. Phosphotryptic maps of in-vivo derived AFAP-110 purified from cultured cells either treated with PMA or co-expressed with active Src demonstrate lesser number of phosphotryptic fragments but nonetheless confirm that AFAP-110 is phosphorylated in vivo in PKC dependent manner. Each in vivo map reveals the presence of six fragments total, four of which coincide between the two in vivo maps suggesting that most of the fragments on in vivo map of AFAP-110 over expressed with active Src are serine/threonine phosphorylated fragments. Two fragments (indicated by black arrowheads on figure 2) are common between the in vivo maps and the recombinant AFAP-110 phosphorylated by PKC in vitro map suggesting that those two fragments must be phosphorylated by $\mathrm{PKC}$ in vivo. There are fragments present on in vivo phosphotryptic maps, which are absent from in vitro phosphotryptic map; their different mobility in both dimensions may be explained by the presence of posttranslational modifications other than phosphorylation in AFAP-110 purified from mammalian cells and/or by the fact that those fragments are phosphorylated on tyrosine residues as well.

Phosphotryptic mapping, although a useful technique, cannot provide us with an answer which serine/threonine residues within AFAP-110 structure are phosphorylated in response to PKC activation. When we analyze AFAP-110 amino acid sequence, we find that AFAP-110 contains over twenty potential PKC phosphorylation sites (table 1). It would not be rational to try to change all these serine or threonine residues one by one or in combinations until we know which regions of AFAP-110 are most likely to contain functional phosphorylation sites. In order to identify the region(s) of AFAP-110 containing functional serine/threonine phosphorylation sites we have decided to use deletional mutagenesis in conjunction with an actin filament cross-linking assays as a test for AFAP-110 function developed by Yong Qian (described in Qian et al, accepted).

At first, four deletion mutants missing either amino-terminally located SH3- 
binding, potential WW-binding and SH2- binding motifs, amino terminal $\mathrm{PH}$ domain, STK region or carboxy-terminal PH domain were created and tested for the ability to cross-link filamentous actin in response to PKC phosphorylation in vitro. AFAP-110 mutant missing amino-terminally located SH3- binding, potential WW-binding and $\mathrm{SH} 2$ binding motifs (AFAP-110 ${ }^{\Delta 62-152}$ ) demonstrated a partial loss of ability to cross-link actin efficiently in response to PKC phosphorylation in vitro, but not the complete inability to cross-link actin filaments into the tight aggregates (figure 5), whereas AFAP-110 mutant missing carboxy-terminal PH domain (AFAP-110 ${ }^{\triangle \mathrm{PH} 2}$ ) behaved in the same manner as the full length AFAP-110, displaying an increase in actin cross-linking ability upon PKC $\alpha$-phosphorylation. AFAP- $110^{\triangle \mathrm{PH} 1}$ mutant on the other hand displayed a peculiar behavior. In the absence of $\mathrm{PKC} \alpha$ phosphorylation this mutant cross-linked actin filaments as efficiently as $\mathrm{PKC} \alpha$ phosphorylated wild type AFAP-110, whereas phosphorylated AFAP- $110^{\triangle \mathrm{PH} 1}$ could only loosely cross-link filamentous actin in a manner resembling that of wild type non-phosphorylated AFAP-110, and did not bring actin filaments into tight aggregates. This behavior of PH1 deletion mutant may be explained by the fact that amino terminal PH domain participates in AFAP-110 selfassociation. PH1 is known to interact with carboxy terminal leucine zipper motif; these interactions are thought to stabilize AFAP-110 multimerization (Qian et al, accepted). Deletion of carboxy terminal leucine zipper motif results in ability of AFAP-110 to efficiently cross-link actin without $\mathrm{PKC} \alpha$ phosphorylation in confocal actin filament cross-linking assays (Qian et al, accepted). It has been determined by Qian and colleagues that full length AFAP-110 exists in a form of nanomers in actin buffer, whereas AFAP-110 missing leucine zipper motif is found only in a form of trimers (Qian et al, accepted). Therefore we hypothesize that deletion of amino terminal PH domain of AFAP-110 results in a loss of an opposing binding site for leucine zipper motif, therefore AFAP-110 may not have been able to form multimers larger than dimers or trimers, and so the changed state of multimerization may have been responsible for the ability of AFAP- $110^{\triangle \mathrm{PH} 1}$ to cross-link actin filaments efficiently on its own. Surprisingly, PKC $\alpha$ phosphorylation of AFAP-110 ${ }^{\Delta \mathrm{PH} 1}$ mutant down-regulates its actin cross-linking ability. We do not know why that occurs, it may be that phosphorylation of AFAP- $110^{\triangle \mathrm{PH} 1}$ 
mutant induces a conformational change in this protein so that it can no longer form dimers or trimers, AFAP-110 may only exist in a form of monomers or conversely, phosphorylation of this particular mutant may alter its conformation in a way that formation of larger complexes becomes possible. Additional experiments are needed to determine multimerization status of AFAP- $110^{\triangle \mathrm{PH} 1}$ in $\mathrm{PKC} \alpha$-phosphorylated versus nonphosphorylated states.

AFAP- $110^{\Delta \mathrm{STK}}$ mutant demonstrated a complete loss of PKC $\alpha$ - induced ability to cross-link actin filaments efficiently into tight aggregates. This mutant, whether phosphorylated or non-phosphorylated, could only loosely cross-link actin filaments in a manner identical to that of non-phosphorylated wild type AFAP-110. There are two possible explanations why this has happened: one of them is that STK region contains pivotal PKC phosphorylation sites responsible for AFAP-110 regulation in response to serine/threonine phosphorylation; another explanation may be that the deletion of STK region caused a change in AFAP-110 conformation so AFAP- $110^{\Delta \mathrm{STK}}$ mutant could no longer associate with and/or be phosphorylated by $\mathrm{PKC} \alpha$. There is a strong indication that AFAP-110 inability to efficiently cross-link actin in response to phosphorylation occurs due to the first reason because STK region contains nine serine and threonine residues which fall into definition of PKC consensus sites (table 1, fragments 6-9).

In order to narrow down the area of investigation further two more AFAP-110 deletion mutants were created - missing either first or second half of STK region, called AFAP-110 $0^{\Delta 249-294}$ and AFAP-110 ${ }^{\Delta 295-346}$, missing six and three potential PKC phosphorylation sites, respectively. Both mutants were tested in confocal in vitro actin filament cross-linking assays to determine the effects of each deletion on the ability of PKC $\alpha$ to enhance actin filament cross-linking properties of AFAP-110. AFAP-110 $1249-294$ behaved exactly as AFAP- $110^{\triangle \mathrm{STK}}$ - in other words it failed completely to cross-link filamentous actin efficiently in response to $\mathrm{PKC} \alpha$ phosphorylation, whereas actin filaments cross-linking ability of AFAP-110 $0^{\Delta 295-346}$ was enhanced in response to PKC $\alpha$ phosphorylation in the same manner as in case of the full length AFAP-110. Therefore we conclude that the amino terminal half of serine threonine kinase interaction domain of AFAP-110 is the region the integrity of which is important for PKC-dependent regulation of AFAP-110 function, and that the functional phosphorylation sites are most likely to 
reside within this region. There are six potential PKC phosphorylation sites within amino acids 249-294; so in order to narrow down the area even further two more deletion mutants were made- AFAP-110 missing either first quarter (AFAP-110 ${ }^{\Delta 249-265}$ ) or second quarter (AFAP-110 ${ }^{\Delta 266-294}$ ) of STK region. These mutants were tested for their ability to cross-link actin with or without $\mathrm{PKC} \alpha$ phosphorylation in confocal actin cross-linking assays. The results of the first experiment have shown that both mutants demonstrate partial loss of ability to efficiently cross-link actin upon PKC $\alpha$ phosphorylation (figures 13 and 14). Confocal data is qualitative rather than quantitative, but our rough estimate is the ability of AFAP-110 to display enhanced actin filament cross-linking upon phosphorylation is diminished up to 90 per cent whereas the ability of AFAP-110 to display enhanced actin filament cross-linking upon phosphorylation is diminished only up to 50 or 60 per cent. These experiments must be repeated in order to confirm the accuracy of the first experiment described here. Nonetheless, the data of confocal actin cross-linking assays performed with AFAP-110 deletion mutants described above points out that phosphorylation sites playing role in regulation of AFAP-110 function must reside within amino acids 266-294 of STK region. Serine residues 276,277,281 and 282 are the strongest candidates to be PKC $\alpha$ functional phosphorylation sites. AFAP-110 point mutants having either first or second pair of these serines changed to alanines have already been created in our lab as well as AFAP-110 mutant, which has all four of these serine residues mutated to alanines. These mutants are going to be tested in confocal actin cross-linking assays in order to determine whether they would fail to cross-link filamentous actin efficiently in response to $\mathrm{PKC} \alpha$ phosphorylation in vitro, and also these mutants along with described above AFAP-110 deletion mutants will be expressed in cultured cells to determine whether their expression would block actin cytoskeleton reorganization and motility structure formation induced in response to $\mathrm{PKC}$ activation. 
Figures and legends

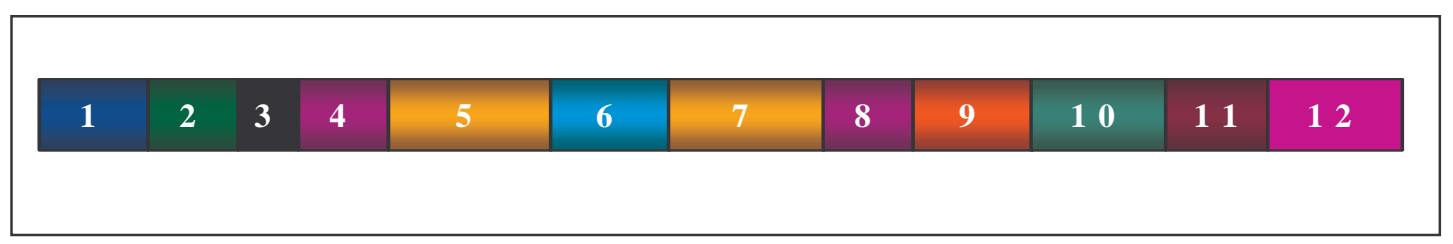

\section{Figure 1. AFAP-110 domain structure}

1- Amino terminus containing putative Nuclear Export $\underline{\text { Sequence }}$ (NES)

2- $\quad$ SH3 binding motif

3- $\quad$ Putative WW binding motif

4, 8 - SH2 binding motifs

5, 7 - Pleckstrin Homology (PH) domains

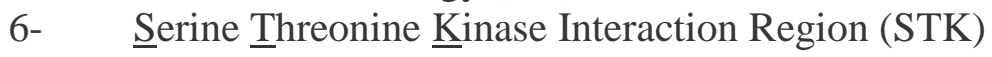

9- Coil/turn region, unknown function.

10- Leucine zipper motif

11- Actin binding regions

12- Carboxy terminus, unknown function. 


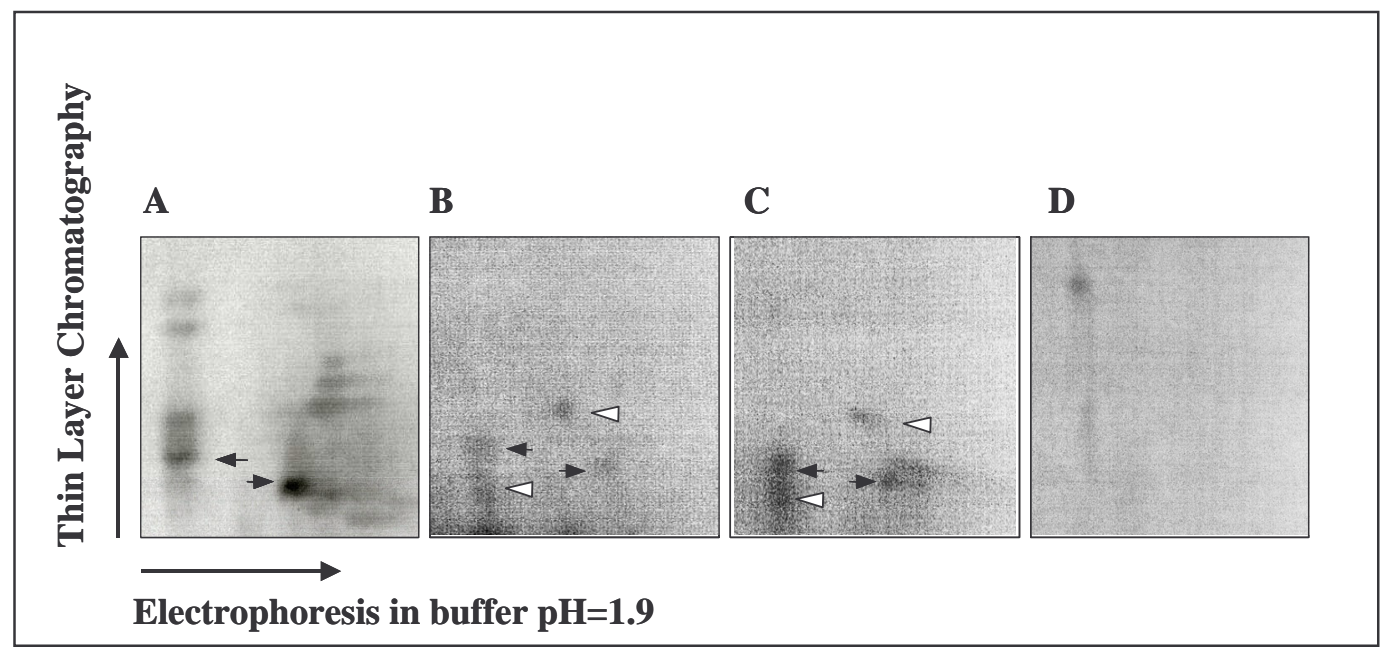

\section{Figure 2. Results of phosphotryptic mapping analysis of AFAP-110.}

A. Recombinant AFAP-110 was phosphorylated with recombinant $\mathrm{PKC} \alpha$ in vitro in the presence of radiolabeled ATP in a PKC kinase buffer; phosphorylated protein was gelpurified, eluted out of polyacrylamide and subjected to digestion with followed by two-dimensional separation of phosphotryptic peptides on a Thin Layer Chromatography (TLC) plate.

B. Cos-1 cells transiently transfected with AFAP-110 were labeled with radioactive orthophosphate for 16 hours and treated with 100nM PMA for 60 minutes prior to cell lysis. AFAP-110 was immunoprecipitated from these cell lysates, gel-purified, eluted out of polyacrylamide and subjected to digestion with trypsin followed by two-dimensional separation of phosphotryptic peptides on a TLC plate.

C. Cos- 1 cells were transiently co-transfected with AFAP-110 and active Src (Src527F), and labeled with radioactive orthophosphate for 16 hours prior to cell lysis. AFAP-110 was immunoprecipitated from these cell lysates, gel-purified, eluted out of polyacrylamide and subjected to digestion with trypsin followed by two-dimensional separation of phosphotryptic peptides on a TLC plate.

D. Recombinant AFAP-110 was phosphorylated with recombinant Src kinase in vitro in the presence of radiolabeled ATP in an Src kinase buffer; phosphorylated protein was gel-purified, eluted out of polyacrylamide and subjected to a digestion with trypsin followed by two-dimensional separation of phosphotryptic peptides on a TLC plate. 


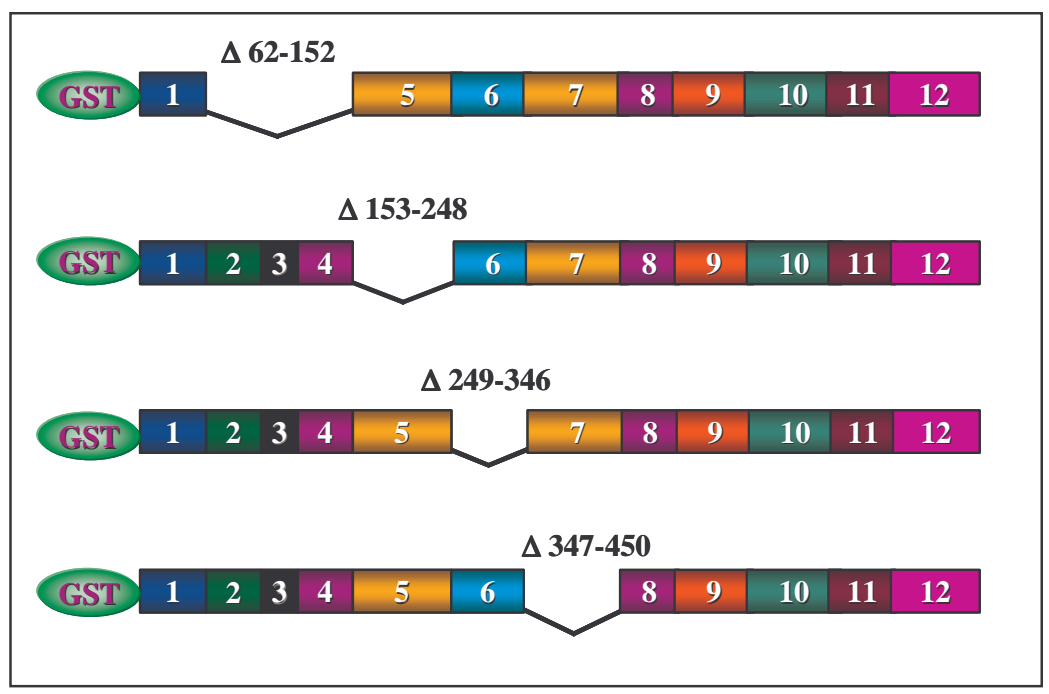

Figure 3. First set of AFAP-110 deletion mutants. Schematic representation of the four GST-tagged AFAP-110 deletion mutants missing either SH3 binding motif, potential WW binding motif and amino-terminal SH2 binding motif altogether (represented by amino acids 62-152), or amino terminal PH domain (represented by amino acids 153248), or STK region (represented by amino acids 246-346), or carboxy terminal PH domain (represented by amino acids 347-450). 


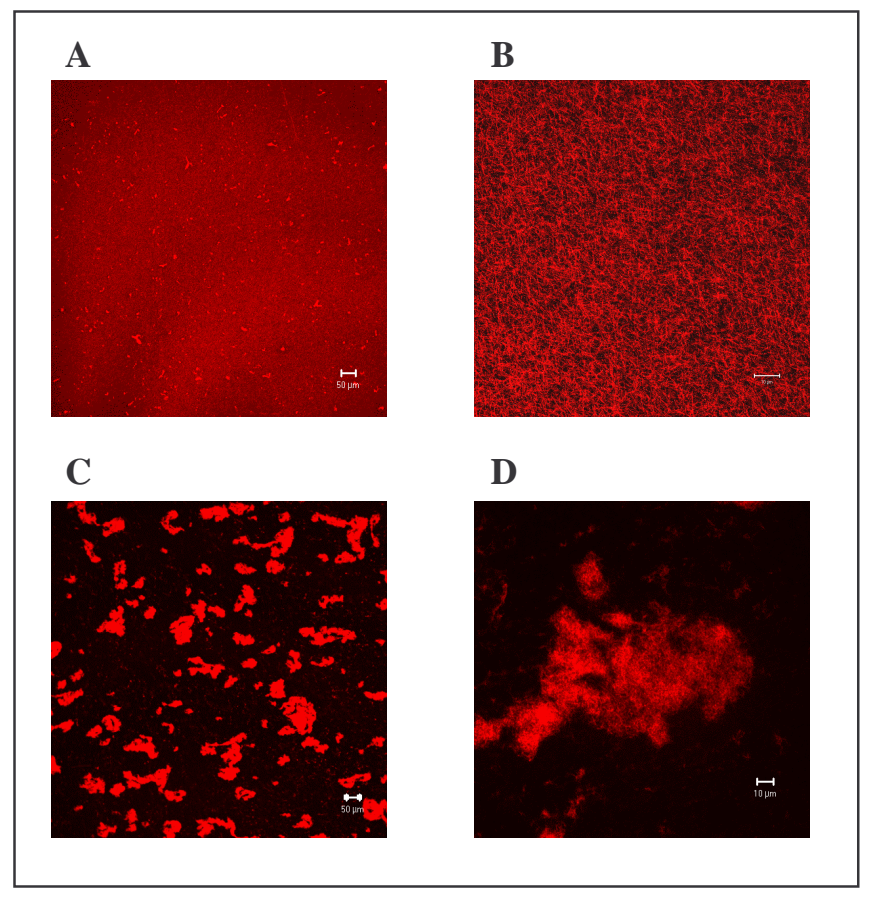

Figure 4. Confocal actin filament cross-linking assay with full length AFAP-110. Rhodamine-labeled filamentous actin was incubated with either non-phosphorylated (A and $\mathrm{B}$ ) or PKC $\alpha$ - phosphorylated (C and $\mathrm{D})$ recombinant AFAP-110 in the actin polymerization buffer. The reactions were plated on microscope slides, covered with coverslips and analyzed using confocal microscope. Panels $\mathrm{A}$ and $\mathrm{C}$ represent 10X magnification; panels B and D - 63X magnification. 


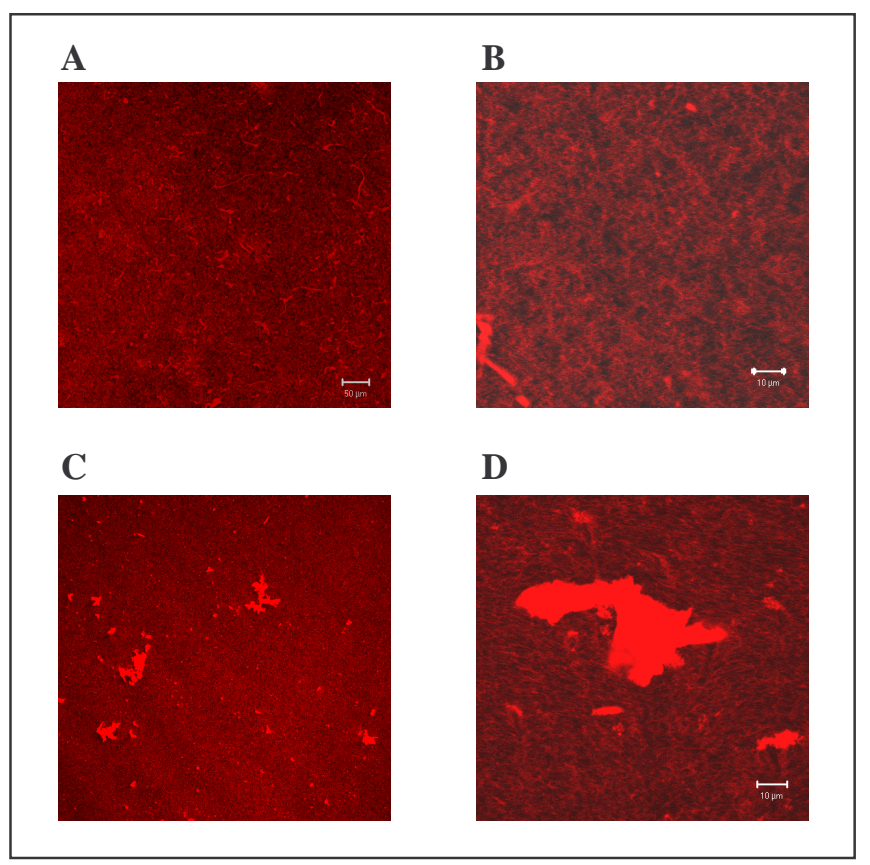

Figure 5. Confocal actin filament cross-linking assay with AFAP-110 ${ }^{\Delta 62-152}$. Rhodamine-labeled filamentous actin was incubated with either non-phosphorylated (A and $\mathrm{B}$ ) or PKC $\alpha$-phosphorylated (C and D) recombinant AFAP-110 ${ }^{\Delta 62-152}$ in the actin polymerization buffer. The reactions were plated on microscope slides, covered with coverslips and analyzed using confocal microscope. Panels $\mathrm{A}$ and $\mathrm{C}$ represent 10X magnification; panels $\mathrm{B}$ and $\mathrm{D}-63 \mathrm{X}$ magnification. 


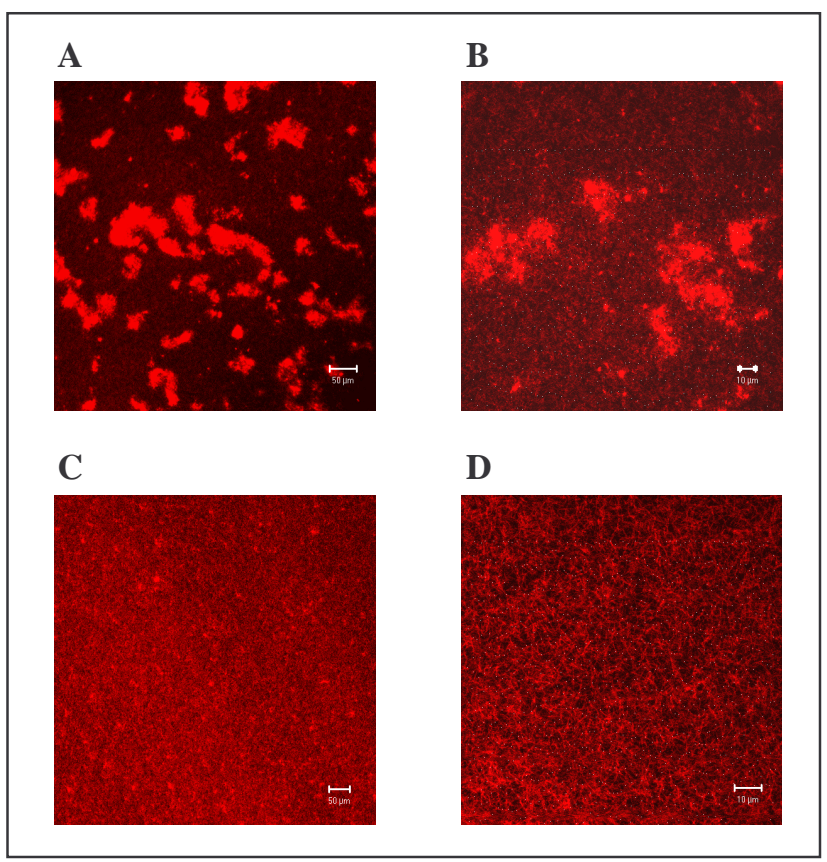

Figure 6. Confocal actin filament cross-linking assay with AFAP-110 ${ }^{\Delta \mathrm{PH} 1}$. Rhodamine-labeled filamentous actin was incubated with either non-phosphorylated (A and $\mathrm{B}$ ) or PKC $\alpha$-phosphorylated (C and D) recombinant AFAP-110 ${ }^{\Delta 62-152}$ in the actin polymerization buffer. The reactions were plated on microscope slides, covered with coverslips and analyzed using confocal microscope. Panels $\mathrm{A}$ and $\mathrm{C}$ represent 10X magnification; panels B and D - 63X magnification. 


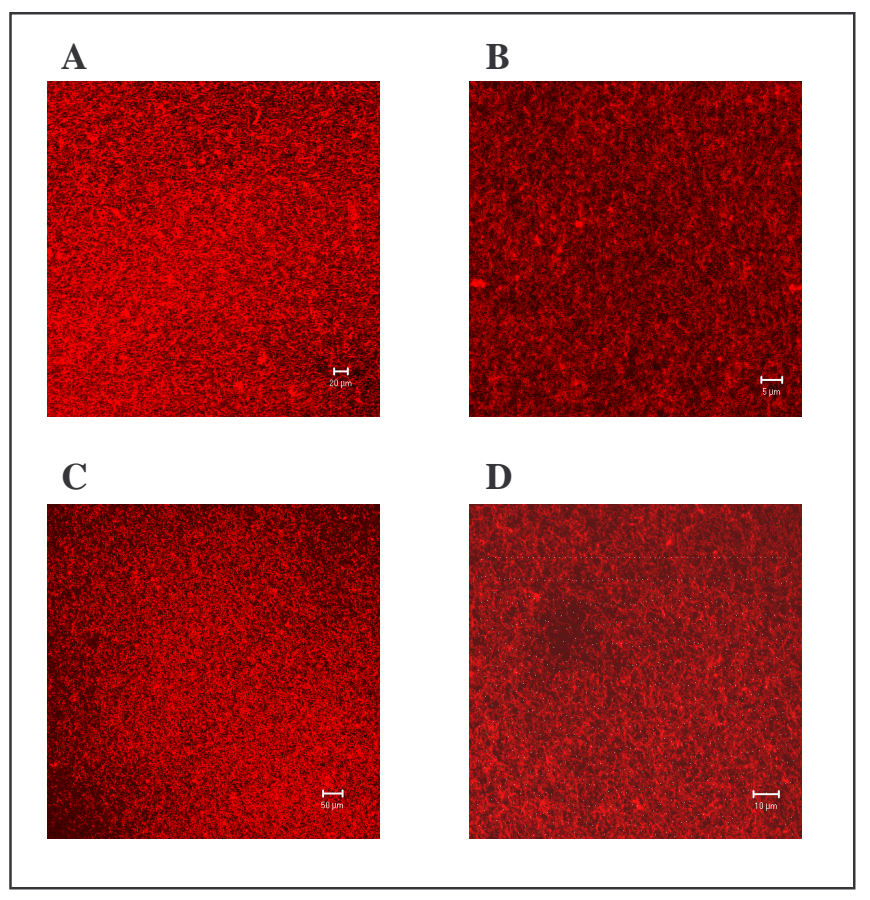

Figure 7. Confocal actin filament cross-linking assay with AFAP-110 ${ }^{\Delta S T}$. Rhodamine-labeled filamentous actin was incubated with either non-phosphorylated (A and $\mathrm{B}$ ) or PKC $\alpha$-phosphorylated $(\mathrm{C}$ and $\mathrm{D})$ recombinant AFAP- $110^{\Delta \mathrm{STK}}$ in the actin polymerization buffer. The reactions were plated on microscope slides, covered with coverslips and analyzed using confocal microscope. Panels $\mathrm{A}$ and $\mathrm{C}$ represent 10X magnification; panels $\mathrm{B}$ and $\mathrm{D}-63 \mathrm{X}$ magnification. 


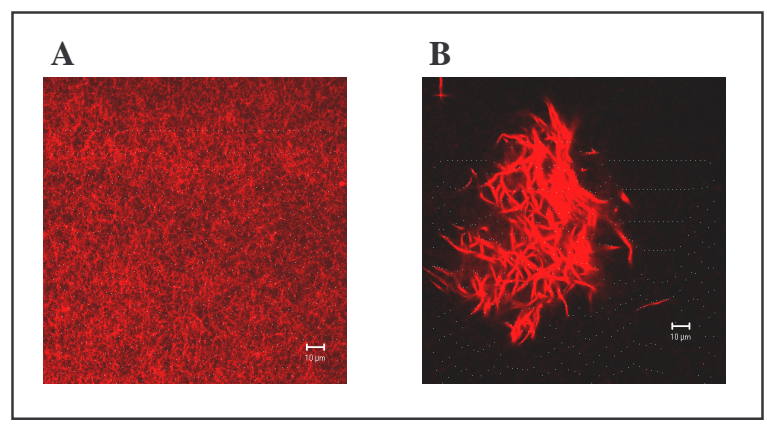

Figure 8. Confocal actin filament cross-linking assay with AFAP-110 ${ }^{\triangle \mathrm{PH} 2}$. Rhodamine-labeled actin filaments were incubated with either non-phosphorylated (A) or PKC $\alpha$-phosphorylated (B) recombinant AFAP- $110^{\triangle \mathrm{PH} 2}$ in the actin polymerization buffer. The reactions were plated on microscope slides, covered with coverslips and analyzed using confocal microscope at $63 \mathrm{X}$ magnification. 


\begin{tabular}{|c|c|c|c|c|c|c|}
\hline \multicolumn{7}{|c|}{$\Delta 249-294$} \\
\hline & 2 & & 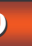 & 10 & 11 & 12 \\
\hline \multicolumn{7}{|c|}{$\Delta$ 295-346 } \\
\hline & 2 & 3 & ) & 10 & 11 & 12 \\
\hline
\end{tabular}

Figure 9. Second set of AFAP-110 deletion mutants. Schematic representation of the two GST-tagged AFAP-110 deletion mutants missing either first (represented by amino acids 249-294) or second (represented by amino acids 295-346) half of STK region. 


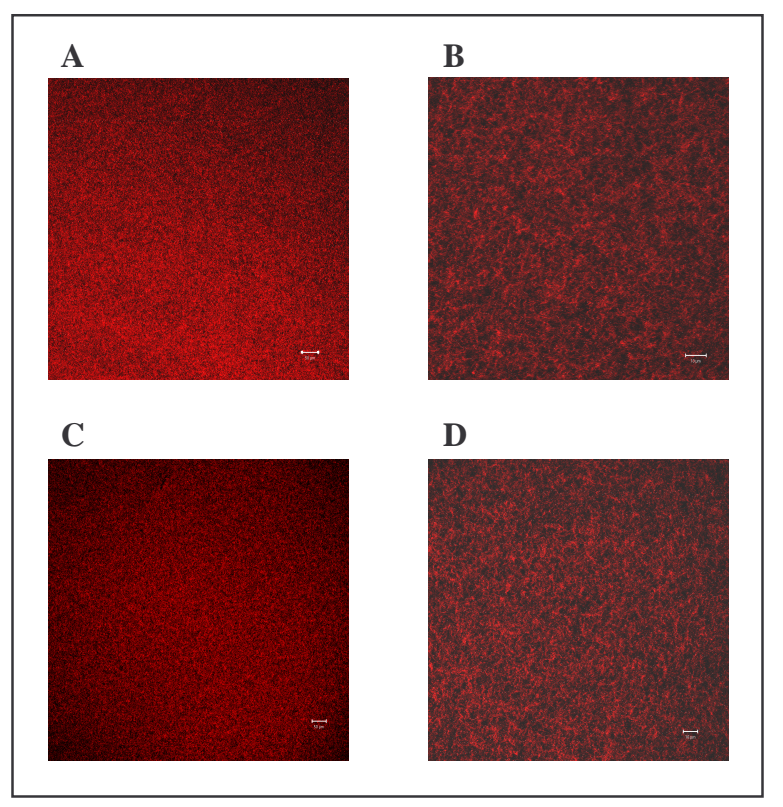

Figure 10. Confocal actin filament cross-linking assay with AFAP-110 ${ }^{\Delta 24-294}$. Rhodamine-labeled filamentous actin was incubated with either non-phosphorylated (A and B) or PKC $\alpha$-phosphorylated (C and D) recombinant AFAP-110 ${ }^{\Delta 249-294}$ in the actin polymerization buffer. The reactions were plated on microscope slides, covered with coverslips and analyzed using confocal microscope. Panels A and C represent 10X magnification; panels B and D - 63X magnification. 


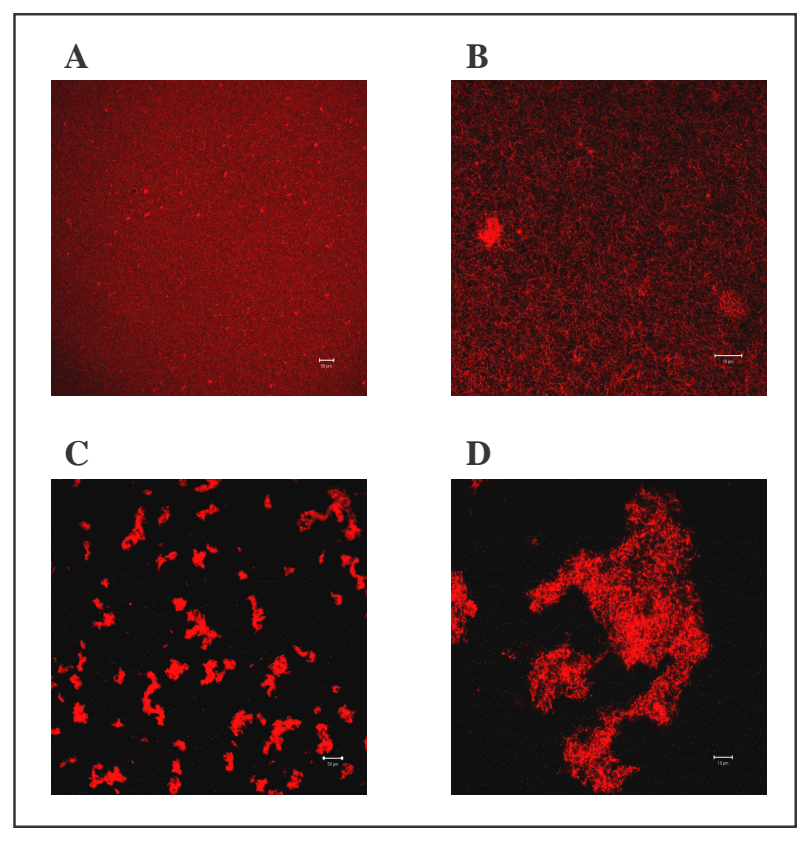

Figure 11. Confocal actin filament cross-linking assay with AFAP-110 ${ }^{\Delta 295-346}$. Rhodamine-labeled filamentous actin was incubated with either non-phosphorylated (A and $\mathrm{B}$ ) or PKC $\alpha$-phosphorylated (C and D) recombinant AFAP-110 ${ }^{\Delta 295-346}$ in the actin polymerization buffer. The reactions were plated on microscope slides, covered with coverslips and analyzed using confocal microscope. Panels A and C represent 10X magnification; panels B and D - 63X magnification. 


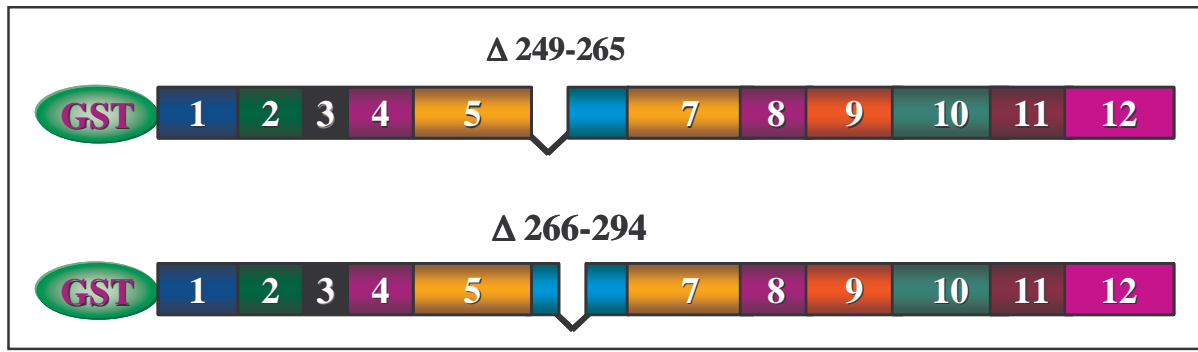

Figure 12. Third set of AFAP-110 deletion mutants. Schematic representation of the two GST-tagged AFAP-110 deletion mutants missing either first (represented by amino acids 249-265) or second (represented by amino acids 266-294) quarter of STK region. 


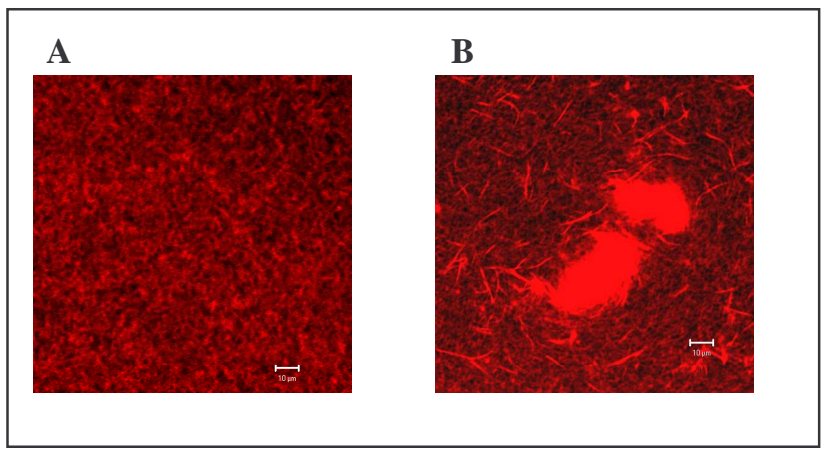

Figure 13. Confocal actin filament cross-linking assay with AFAP-110 ${ }^{\Delta 49-265}$. Rhodamine-labeled filamentous actin was incubated with either non-phosphorylated (A) or PKC $\alpha$-phosphorylated (B) recombinant AFAP-110 $0^{\Delta 249-265}$ in the actin polymerization buffer. The reactions were plated on microscope slides, covered with coverslips and analyzed using confocal microscope at $40 \mathrm{X}$ magnification. 


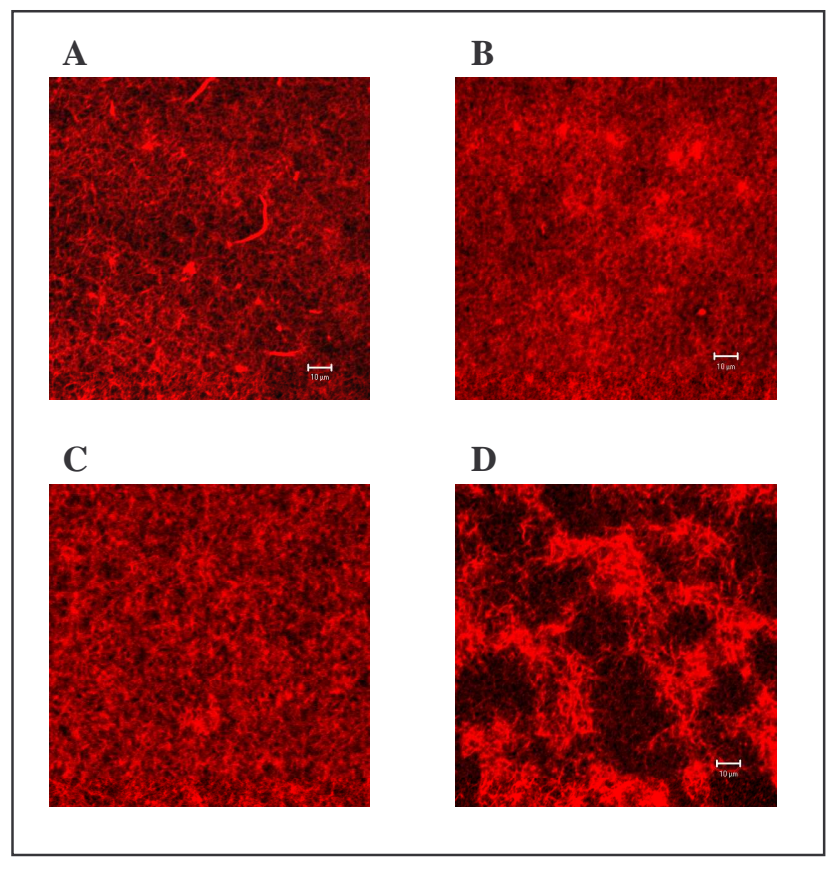

Figure 14. Confocal actin filament cross-linking assay with AFAP-110 ${ }^{\Delta 26-294}$. Rhodamine-labeled filamentous actin was incubated with either non-phosphorylated (A and $\mathrm{B}$ ) or PKC $\alpha$-phosphorylated (C and D) recombinant AFAP-110 2 266-294 in the actin polymerization buffer. The reactions were plated on microscope slides, covered with coverslips and analyzed using confocal microscope. All panels represent 40X magnification. 


\section{References}

1. Reynolds, A. B., Roesel, D. J., Kanner, S. B., and Parsons, J. T. (1989) Mol.Cell Biol. 9, 629-638

2. Reynolds, A. B., Kanner, S. B., Wang, H. C., and Parsons, J. T. (1989) Mol.Cell Biol. 9, 3951-3958

3. Flynn, D. C., Leu, T. H., Reynolds, A. B., and Parsons, J. T. (1993) Mol.Cell Biol. 13, 7892-7900

4. Kanner, S. B., Reynolds, A. B., Wang, H. C., Vines, R. R., and Parsons, J. T. (1991) EMBO J. 10, 1689-1698

5. Guappone, A. C. and Flynn, D. C. (1997) Mol.Cell Biochem. 175, 243-252

6. Qian, Y., Baisden, J. M., Zot, H. G., Van Winkle, W. B., and Flynn, D. C. (2000) Exp.Cell Res. 255, 102-113

7. Qian, Y., Baisden, J. M., Westin, E. H., Guappone, A. C., Koay, T. C., and Flynn, D. C. (1998) Oncogene 16, 2185-2195

8. Musashi, M., Ota, S., and Shiroshita, N. (2000) Int.J.Hematol. 72, 12-19

9. Liu, W. S. and Heckman, C. A. (1998) Cell Signal. 10, 529-542

10. Ways, K. J., Chou, E., and King, G. L. (2000) Trends Pharmacol.Sci. 21, 181-187

11. Zang, Q., Frankel, P., and Foster, D. A. (1995) Cell Growth Differ. 6, 1367-1373

12. Qian, Y., Guappone, A. C., Baisden, J. M., Hill, M. W., Summy, J. M., and Flynn, D. C. (1999) Hybridoma 18, 167-175

13. Guappone, A. C., Weimer, T., and Flynn, D. C. (1998) Mol.Carcinog. 22, 110-119

14. Boyle, W. J., van der, G. P., and Hunter, T. (1991) Methods Enzymol. 201, 110-149

15. Nishikawa, K., Toker, A., Johannes, F. J., Songyang, Z., and Cantley, L. C. (1997) J.Biol.Chem. 272, 952-960

16. Baisden, J. M., Qian, Y., Zot, H. G., and Flynn, D. C. (2001) Oncogene 20, 64356447 


\section{Chapter 3}

\section{Determining whether 14-3-3 is a binding partner for AFAP-110}




\section{Introduction.}

14-3-3 proteins represent a group of small acidic proteins with isoelectric point 4.5 and molecular weight around $30 \mathrm{kDa}$. These proteins are expressed ubiquitously and are known to be present in all species of vertebrates, invertebrates, plants, and fungi (14). 14-3-3 family of proteins includes seven unique isoforms name by Greek letters according to their elution order after reverse-phase high-performance liquid chromatography: $\beta / \alpha, \zeta / \delta, \eta, \gamma, \tau, \sigma$ and $\varepsilon(2 ; 5 ; 6) .14-3-3$ proteins are highly conserved among each other and across different species although they do have differences in some regions (5). All 14-3-3 proteins have the ability to dimerize; they can form both homo- and heterodimers in vitro and in vivo (4;7). Dimerization occurs via hydrophobic interactions between highly conserved residues within amino-terminal parts of the molecules $(2 ; 5 ; 6)$. Carboxy-termini of two molecules brought together by dimerization create ligand binding amphipathic groove (8;9). Highly conserved residues form the inner surface of the binding groove, whereas variable residues create the outer surface. This groove may bind either two different molecules or bring together different regions of the same protein allowing 14-3-3 to act as scaffolds or allosteric regulators $(8 ; 10))$. The variant residues of the outer surface of the groove may also provide specific binding surfaces for different proteins (5). 14-3-3 proteins binding groove is specific for either one of the two well-defined structural motifs on target proteins. First of them contains phosphoserine (or phosphothreonine) in the center with arginine, serine and proline in positions $-3,-2$, and +2 , respectively. Second one is defined as a short amino acid sequence containing phosphoserine/phosphothreonine in the center with arginine, aromatic residue, basic residue and proline at positions $-4,-2,-1,+2$ respectively (6;9;11). Some 14-3-3 binding sequences are known to contain lysine instead of arginine in -3 or -4 position respective to phosphoserine/phosphothreonine (Dr. Gury Tzivion, personal communication). 14-3-3 dimers could bind to several phosphoserine-containing motifs on one protein or bring several target proteins together as a consequence of binding to conserved motifs found on different proteins. 14-3-3 dimers also may act as molecular links between proteins bound to the conserved groove and ones associated with variable outer surface, therefore performing a role of scaffolds that regulate specific

protein-protein interactions (8). 14-3-3 proteins have been implicated in regulation of 
serine/threonine kinases such Raf and PKC (12-14). 14-3-3 proteins bind Raf and certain PKC isoforms directly and therefore serve to facilitate interactions between these signaling proteins (10). Raf is a key protein kinase in mitogen activated protein kinase (MAPK) cascade. Raf acts downstream of growth factor receptor and Src-family nonreceptor tyrosine kinases, and Ras, and upstream of MAPK kinase to transmit developmental and proliferative signals. 14-3-3 associates with Raf in vivo regardless of Raf subcellular localization or activation status (15). Overexpression of 14-3-3 proteins has been shown to contribute to Raf activation, although it is clear that 14-3-3 proteins unable to activate Raf by themselves (15). Some other reports stated that the nature of 14-3-3 influence on Raf-1 is inhibitory $(16 ; 17)$. The data on Raf-14-3-3 interaction accumulated up-to-date suggests the following model of Raf-14-3-3 interaction: Raf has three 14-3-3 binding sequences in its structure. 14-3-3 is bound to cytosolic Raf at amino-terminal and carboxy terminal binding sites; this association serves to keep Raf in inactive although activatable state. Upon Raf activation by Ras the former undergoes translocation to membrane. 14-3-3 protein is displaced from the amino terminal binding site on Raf, but it still associates with the carboxy terminal 14-3-3 binding site. Yet unidentified kinase come along and phosphorylate the serine in the center of intermediate 14-3-3 binding site of Raf and 14-3-3 binds to it, stabilizing Raf in active state $(9 ; 14)$. 14-3-3 therefore has a dual role in Raf regulation. 14-3-3 proteins also have been shown to be both PKC substrates and regulatory proteins $(12 ; 18)$. At first it was believed that 14-3-3 had inhibitory influence on PKC, this conclusion came mostly from the fact that PKC inhibitors from brain belong to 14-3-3 family of proteins (19;20). At least three possible mechanism of inhibitory influence of 14-3-3 upon PKC have been suggested. 14-3-3 proteins have been found to contain a stretch of amino acid residues similar to PKC pseudosubstrate sequence, which lead to one possible explanation of their inhibitory influence on PKC. Another possible mechanism of PKC inhibition by 14-3-3 proteins arose from the fact that 14-3-3 contains a stretch of amino acid identical to those seen in receptors for activated $\mathrm{C}$ kinase (RACKs), whose function is to bring active PKC to membrane and cytoskeletal structures. 14-3-3 interaction with active PKC therefore thought to interfere with its translocation to membrane and therefore inhibit its function $(2 ; 5)$. One more possible mechanism came from the observation that 14-3-3 bind to 
cysteine rich domain of PKC which is responsible for interaction with DAG (5). It was postulated that 14-3-3 binding to PKC prevents its activation by DAG (5). Experiments conducted by other groups contradict the belief that 14-3-3 inhibit PKC. Studies by Acs et al and van der Hoeven et al revealed positive influence of 14-3-3 on PKC activity $(12 ; 21)$. The nature of 14-3-3 influence on PKC activity is controversial but nonetheless it is apparent that 14-3-3 interacts with PKC. Some 14-3-3 proteins have been shown to bind phospholipids; this fact suggests that 14-3-3 family facilitate PKC association with cell membrane (7). 14-3-3 may bind to Raf and PKC at the same time, therefore bringing Raf to proximity with PKC to ensure phosphorylation of the former by the latter $(6 ; 10 ; 22)$. Recent reports indicate that $14-3-3$ proteins may be involved in regulation of cytoskeleton organization. 14-3-3 $\beta$ and $\gamma$ isoforms have been reported to associate with actin and be implicated into rearrangements of cortical actin network (23). Expression of dominant negative 14-3-3 analogs in yeast result in disruption of actin cables (24).

Numerous reports on 14-3-3 that have appeared in recent years indicate that 14-33 proteins act as molecular scaffolds regulating function of signaling proteins by either changing thei conformation or by assembling them into multiplayer signaling complexes. 14-3-3 proteins also appear to play a role in cytoskeletal remodeling. Discovering whether 14-3-3 is a binding partner for AFAP-110 may shed light on revealing the new insight on the mode of AFAP-110 regulation. 


\section{Materials and methods.}

Expression vectors: pCMV/AFAP-110 and pCMV/AFAP-110/Src ${ }^{527 F}$ were

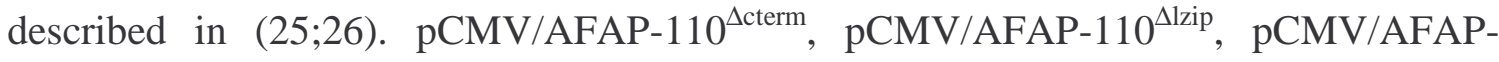
$110^{\Delta 44}, \mathrm{pCMV} / A F A P-110^{\Delta \mathrm{Sfu}}$, pGEX-6p-1-AFAP-110 were described in Qian et al, accepted. pEBG-GST-14-3-3 and pEBG-GST-CT-14-3-3 were kindly provided by Dr. Gury Tzivion.

\section{Primers for site directed mutagenesis:}

S548A(+): AGCGCACAGCAGCCAATGCAGAACAG

S548A(-): CTGTTCTGCATTGGCLTGCTGTGCGCT

S569A(+): AGAGGTTACAGGCCAAGGAAGAGGAAC

S569A(-): GTTCCTCTTCCTTGGCCTGTAACCTCT

Site directed mutagenesis: pCMV/AFAP- $110^{\text {S548a }}$ and pCMV/AFAP- $110^{\text {S569a }}$

were created by PCR-based site-directed mutagenesis using primers with nucleotide mismatches containing desired mutation. Briefly, $20 \mathrm{ng}$ of pCMV/AFAP-110 template was mixed with $5 \mathrm{ml}$ of $10 \mathrm{X}$ reaction buffer (Stratagene), $125 \mathrm{ng}$ of each primer, $1 \mathrm{ul}$ of $10 \mathrm{mM}$ dNTP mix (Stratagene), and 2.5 units of Pfu Turbo DNA polymeraze. The volume of PCR mix was brought to $50 \mathrm{ml}$ with HPLC grade autoclaved water. The reactions were overlaid with $30 \mathrm{ml}$ of mineral oil. The ractions were carried out at 95 degrees for 30 seconds, and 18 cycles of 95 degrees at 30 seconds, 55 degrees for 1 minute, and 68 degress for 15 minutes. The reactions were than incubated at 37 degrees for 1 hour with 10 units of DpnI restriction enzyme (Roche) to digest the template. $1 \mathrm{ul}$ of each PCR reaction was added to 50 ul of Epicurian coli XL-1 Blue supercompetent cells and incubated on ice for 30 minutes. The transformation reactions were heat-pulsed for 45 seconds at 42 degrees, and placed on ice for 2 minutes. After that $0.5 \mathrm{ml}$ of NZYBroth (5 grams of NZ amine, 2.5 grams of yeast extract, 2.5 grams of $\mathrm{NaCl}$ were diluted in $500 \mathrm{ml}$ of MilliQ water and autoclaved. $6.25 \mathrm{ml}$ of $1 \mathrm{M} \mathrm{MgCl} 2$ and $6.25 \mathrm{ml}$ of $1 \mathrm{M}$ MgSO 4 and $5 \mathrm{ml}$ of a $2 \mathrm{M}$ filter-sterilized glucose solution were added to the autoclaved broth, and filter-sterilized) preheated to 42 degrees was added to each transformation reaction, and the reactions were incubated at 37 degrees with shaking for 1 hour. After that the reactions were plated onto $2 \mathrm{X}$ Ampicillin LB plates. Cultures from several colonies were inoculated for mini-scale DNA preparation, and the extracted DNA was 
screened either by restriction mapping or DNA sequencing to determine which colonies contain pCMV/110 plasmid vector bearing desired substitution.

Cell culture and transient transfections: Cos-1 cells were maintained in Dulbecco's Modified Eagle's Medium (DMEM) supplemented with 5\% Fetal Calf Serum, 2mM glutamine and 1\% penicillin/streptomycin. Cos-1 cells for AFAP-110/14-33 association experiment were transiently co-transfected with AFAP-110 and 14-3-3 constructs using either Modified Calcium Phosphate-mediated Transfection Procedure or lipofectamine 2000 transfection kit. For Modified Calcium Phosphate-mediated Transfection Procedure, cells were grown to $60 \%$ confluence. $20 \mu \mathrm{g}$ plasmid DNA for single transfection or $15 \mu \mathrm{g}$ of each plasmid for co-transfection were mixed with $0.5 \mathrm{ml}$ of $0.25 \mathrm{M} \mathrm{CaCl}_{2}$. $0.5 \mathrm{ml}$ of 2X BES-buffered saline (50mM BES, 280mM NaCl, $1.5 \mathrm{mM}$ $\mathrm{Na}_{2} \mathrm{HPO}_{4} \times 2 \mathrm{H}_{2} \mathrm{O}$ ) was added to DNA dissolved in $0.25 \mathrm{M} \mathrm{CaCl} 2$, and the mixtures were incubated for 20 minutes at room temperature to allow complex formation. After that the mixtures were added to Cos cells in a drop wise manner. Cells were then placed into $3 \%$ $\mathrm{CO} 2$ incubator for 16 hours, after which the medium was replaced with fresh growth medium and cells were allowed to reach confluence. They were lysed at 60-66 hours after transfection in 1x RIPA lysis buffer (1\% NP-40, $0.25 \%$ deoxycholate, $150 \mathrm{mM}$ $\mathrm{NaCl}, 50 \mathrm{mM}$ Tris, $\mathrm{pH}=7.5$ supplemented with protease and phosphatases inhibitors 50 $\mu \mathrm{g} / \mu \mathrm{l}$ aprotinin, 2mM Sodium Vanadate, 2mM PMSF, $2 \mathrm{mM}$ EGTA, $10 \mu \mathrm{g} / \mathrm{ml}$ Leupeptin). For transfection with lipofectamine2000 reagent Cos-1 cells were grown to $60 \%$ confluence on $10 \mathrm{~mm}$ cell culture dishes, washed with DMEM supplemented with $2 \mathrm{mM}$ glutamine and overlaid with $6 \mathrm{ml} \mathrm{Cos}-1$ culture medium containing $2 \mu \mathrm{g}$ of 14-3-3 plasmid construct, $3 \mu \mathrm{g}$ of AFAP-110 plasmid construct, and $25 \mu$ lipofectamine reagent. In 12-14 hours $6 \mathrm{ml}$ of DMEM supplemented with $20 \%$ fetal calf serum, $2 \mathrm{mM}$ glutamine, and $1 \%$ penicillin/streptomycin was added to the cells being transfected. Cells were incubated in this medium for 8-10 hours. Then the media containing the DNA/lipofectamine mixture was removed and transfected cells were overlaid with $10 \mathrm{ml}$ of Cos-7 growth media. Cells were lysed at 36 hours after transfection in either NP-40 Lysis Buffer (1\% NP-40, 150mM NaCl, 50mM Tris, $\mathrm{pH}=7.5)$ supplemented with protease and phosphatases inhibitors $(50 \mu \mathrm{g} / \mu \mathrm{l}$ aprotinin, $2 \mathrm{mM}$ Sodium Vanadate, $2 \mathrm{mM}$ PMSF, 2 mM EGTA, $10 \mu \mathrm{g} / \mathrm{ml}$ Leupeptin)) or 1XRIPA lysis buffer plus inhibitors. 
Gluthathione sepharose affinity absorption: GS beads were washed 4 times into 1X RIPA lysis buffer. $30 \mu \mathrm{l}$ of washed beads were added into $1 \mathrm{ml}$ of Cos cell lysates co-expressing full length or amino-terminally truncated GST tagged 14-3-3 and either wild type or mutant AFAP-110. Pull down reactions were incubated for 2 hours at 4 degrees with shaking and spun down in tabletop centrifuge; beads were washed twice in 1XRIPA and once in 1XTBS, resuspended in 2XLSB, boiled for 5 minutes, and subjected to $10 \%$ SDS-PAGE followed by Western transfer to PVDF membrane and immunoblotting with AFAP-110 reactive antibodies (either 4C3 or F1). In order to determine GST-14-3-3 expression levels PVDF membranes were stripped for 30 minutes in stripping buffer (3.5 $\mathrm{ml}$ 2-ME, $100 \mathrm{ml} \mathrm{10 \%} \mathrm{SDS,} 15.6 \mathrm{ml} 1 \mathrm{M}$ Tris, $\mathrm{pH}=6.7,380.85 \mathrm{ml}$ milliQ water), at 50 degrees with shaking, washed in TBS-T, blocked in 3\% milk and stained with anti GST antibody. Pull downs were normalized to GST-14-3-3 expression levels.

Immunoprecipitation: $2 \mu$ polyclonal antibody $\mathrm{F} 1$ was added to $1 \mathrm{ml}$ of Cos-1 cell lysates and the reactions were incubated for 1.5 hours at 4 degrees with shaking. After that $30 \mu \mathrm{l}$ of protein A agarose was added to immunoprecipitation reaction as a secondary antibody to pull down F1-AFAP-110 complexes; the reactions were incubated for 1.5 hours at 4 degrees with shaking. Complexes were then washed twice with 1XRIPA and once with 1XTBS, resuspended in 2XLSB, boiled, and subjected to SDSPAGE followed by transfer to PVDF membrane for western blotting analysis. 


\section{Results.}

14-3-3 proteins comprise a family of small acidic adaptor proteins, which recognize consensus sites RSXpS/TXP or RXSXpS/TXP. In order for 14-3-3 proteins to bind to its target serine or threonine in a position 0 in the center of 14-3-3 binding site must be phosphorylated, and arginine (or lysine) in -3 or -4 position must be present for 14-3-3 binding to occur, whereas $\mathrm{S}$ in -2 position and $\mathrm{P}$ in +2 position may be substituted by any other residue (27).

AFAP-110 contains twelve potential 14-3-3 binding sequences in its structure (table 1). Amino acids stretches 528-534, 45-550 and 660-666 represent the most valid candidates to be 14-3-3 binding sites (Dr. Gury Tzivion, personal communication).

Table 1

\begin{tabular}{|c|c|c|}
\hline Number & Amino acids & Potential 14-3-3 binding sequences \\
\hline 1 & $37-43$ & $\underline{\text { RIQSSKG }}$ \\
\hline 2 & $279-284$ & $\underline{\text { RPSSDG }}$ \\
\hline 3 & $304-310$ & $\underline{\text { KKKSSST }}$ \\
\hline 4 & $333-339$ & $\underline{\text { RVISTNP }}$ \\
\hline 5 & $476-482$ & $\underline{\text { RTLNSQP }}$ \\
\hline 6 & $528-534$ & $\underline{\text { KPESVS }}$ \\
\hline 7 & $536-541$ & $\underline{\text { RTASNA }}$ \\
\hline 8 & $545-550$ & $\underline{\text { KRLQSKE }}$ \\
\hline 9 & $565-571$ & $\underline{\text { KSGTSSP }}$ \\
\hline 10 & $660-666$ & $\underline{\text { KHRTLE }}$ \\
\hline 11 & $672-677$ & $\underline{\text { RPPSSNN }}$ \\
\hline 12 & $703-709$ & \\
\hline
\end{tabular}

Table 2

\begin{tabular}{|c|c|c|}
\hline $\begin{array}{c}\text { AFAP-110 mutants } \\
\text { used in co-expression } \\
\text { with 14-3-3 }\end{array}$ & $\begin{array}{c}\text { Amino acid stretch } \\
\text { missing }\end{array}$ & $\begin{array}{c}\text { Potential 14-3-3 } \\
\text { sequence(s) missing }\end{array}$ \\
\hline AFAP-110 $\Delta$ cterm & $553-729$ & $9-12$ \\
\hline AFAP-110 $\Delta 44$ & $593-729$ & $10-12$ \\
\hline AFAP-110 $10^{\Delta \text { zip }}$ & $554-592$ & $5-12$ \\
\hline AFAP-110 $\mathrm{Sfu}$ & $417-723$ & $2-4$ \\
\hline AFAP-110 $\Delta 146-343$ & $146-343$ & \\
\hline
\end{tabular}


AFAP-110 was immunoprecipitated from Cos-1 cell lysates over expressing AFAP-110 and subjected to western blotting analysis with anti phospho 14-3-3 binding motif antibody. Anti phospho 14-3-3 binding motif antibody was immunoreactive with AFAP-110 derived from Cos cell lysates, either non-treated or subjected to 15 minute PMA treatment to induce cellular PMA responsive PKC isoforms or co-expressing active Src (Figure 1). These data indicate that, first of all, AFAP-110 may contain one or several 14-3-3 binding sequences and second of all, as the antibody is phospho-specific, suggest that serine/threonine residues in the middle of 14-3-3 binding sequences must be constitutively phosphorylated. This experiment was repeated three times.

When we established that AFAP-110 contains 14-3-3 binding sites, we decided to find out whether 14-3-3 associated with AFAP-110 in vivo. In order to answer this question GST-14-3-3 was co-expressed in Cos cells with AFAP-110. Cells were lysed, and $30 \mu \mathrm{l}$ of gluthathione sepharose beads were used to pull down GST-14-3-3. The beads-GST-14-3-3 complexes were boiled and subjected to SDS-PAGE, followed by western transfer and staining with anti-AFAP-110 antibody. A 110-kDa band was visualized on that blot indicating that AFAP-110 associated with 14-3-3 (figure 2). This experiment was repeated three times.

Next question was to find which region(s) of AFAP-110 is/are responsible for its association with 14-3-3. It was proposed to co-express GST-14-3-3 with either one of several existing AFAP-110 deletion mutants missing one or more potential 14-3-3 binding sequences (table 2). The mutant that would fail to associate with 14-3-3 would therefore be missing sequence(s) facilitating 14-3-3 association with AFAP-110, and would also suggest the possibility of direct interactions between 14-3-3 and AFAP-110.

First of all, GST-14-3-3 was co-expressed with either full length AFAP110 or truncated version of it missing amino acids 553-729 (AFAP-110 ${ }^{\Delta \text { cterm }}$ ). AFAP$110^{\Delta \text { cterm }}$ lacks five carboxy-terminally located potential 14-3-3 binding sequences. The pull down experiments demonstrated that full length AFAP-110 associates with 14-3-3 whereas carboxy terminally truncated AFAP-110 fails to associate with 14-3-3 (figure 3). This experiment was repeated twice.

When we established that AFAP-110 contains 14-3-3 binding sites, we decided to find out whether 14-3-3 associated with AFAP-110 in vivo. In order to answer this 
question GST-14-3-3 was co-expressed in Cos-1 cells with AFAP-110. Cells were lysed, and $30 \mu \mathrm{l}$ of gluthathione sepharose beads were used to affinity absorb GST-14-3-3 from the cell lysates. Affinity absorptions were normalized to GST-14-3-3 expression levels. The beads-GST-14-3-3 complexes were then washed twice in lysis buffer and once in 1XTBS buffer, resuspended in 2XLSB, boiled and subjected to SDS-PAGE, followed by western transfer and staining with anti-AFAP-110 antibody (F1 or 4C3). A 110-kDa band was visualized on the blot indicating that AFAP-110 associated with 14-3-3 in vivo (figure 2 - representative of the three experiments).

Next question was to find which region(s) of AFAP-110 responsible for interaction with 14-3-3. Analysis of amino acid sequence of AFAP-110 reveals the presence of twelve candidate 14-3-3 target sequences within its structure (table 1). In order to determine which sequences facilitate AFAP-110 association with 14-3-3 in vivo it was proposed to co-express GST-14-3-3 with either one of several existing AFAP-110 deletion mutants missing one or more potential 14-3-3 binding sequences (table 2). The mutant(s) that would fail to associate with 14-3-3 would therefore be missing sequence(s) facilitating 14-3-3 association with AFAP-110, and would also suggest the possibility of direct interactions between 14-3-3 and AFAP-110. First of all, GST-143-3 was co-expressed with either full length AFAP-110 or truncated version of it missing amino acids 553-729 (AFAP-110 ${ }^{\Delta \text { cterm }}$ ). AFAP-110 ${ }^{\Delta \text { cterm }}$ lacks four carboxy-terminally located potential 14-3-3 binding sequences. The pull down experiments demonstrated that full length AFAP-110 associates with 14-3-3 whereas carboxy terminally truncated AFAP-110 fails to associate with 14-3-3 (figure 3). This experiment was repeated twice.

We included into our following experiments gluthathione sepharose pull down from cell lysates over expressing GST-Cterm-14-3-3 with full length AFAP-110 as soon as we received pEBG-GST-Cterm-14-3-3 plasmid from our collaborator Dr. Gury Tzivion. 14-3-3 mutants containing amino-terminal truncation fail to dimerize, and therefore in most cases they fail to bind to target proteins for full length 14-3-3. If GSTCterm-14-3-3 would associate with AFAP-110 as well as GST-14-3-3, we would conclude that AFAP-110 might be one of those few 14-3-3 target proteins, which contain high affinity 14-3-3 binding sequences. If GST-Cterm-14-3-3 would fail to associate with AFAP-110, we would therefore be able to use it as a negative control in our pull 
down experiments. Our experiments indicated that GST-Cterm-14-3-3 associates with AFAP-110 much weaker than full length 14-3-3 (figures 5,6,7). The presence of background band in our experiments may be explained by the dimerization between $\mathrm{N}$ terminal GST-tags; although GST-facilitated dimerization is much weaker and cannot by any means compensate for absence of N-terminal helices of 14-3-3.

The failure of GST-14-3-3 to pull down AFAP-110 ${ }^{\Delta \text { cterm }}$ suggested that the carboxy terminal potential 14-3-3 binding sequences of AFAP-110 play an important role in 14-3-3-AFAP-110 interactions. The deletion of amino acids 553-729 results in disappearance of four carboxy terminal potential 14-3-3 binding sequences (table 2) and a possible disruption of potential 14-3-3 binding sequence represented by amino acids 545-550; this sequence is which is one of the three strongest candidates to be the 14-3-3 interaction site on AFAP-110 (Dr. Gury Tzivion, personal communication). Therefore we have decided to test whether amino acids 545-550 represent 14-3-3 binding site, responsible for 14-3-3 association with AFAP-110. In order to determine that serine 548 was changed to alanine; this amino acid substitution results in inability of this potential 14-3-3 binding sequence to be phosphorylated and therefore this site can no longer facilitate AFAP-110 interactions with 14-3-3. Serine residue 569 in the middle of the neighboring amino acid stretch 565-571 was also changed to alanine, and either one of the two site-directed mutants were co-expressed with GST-14-3-3 in cultured cells. In order to test whether either one or both of these mutants would fail to associate with 143-3 we pull down GST-14-3-3 from the cell lysates and performed western blotting analysis with anti-AFAP-110 antibody 4C3 (Fugure4). This experiment indicated that AFAP-110 $0^{\text {s548a }}$ mutant associates with AFAP-110 weaker than either wild type or AFAP$110^{\mathrm{s} 569 \mathrm{a}}$ mutant (figure 5). Surprisingly, this experiment has shown that AFAP110deltacterm, included as a negative control for AFAP-110 association with 14-3-3, associates with 14-3-3 better than full length AFAP-110 and any other AFAP-110 mutant included into this assay (figure 5). This contradicts the earlier data, which indicate that AFAP-110delta cterm cannot associate with 14-3-3. Since then we performed more experiments to determine whether c-terminally truncated AFAP-110 fails to associate with 14-3-3. Three out of seven gluthathione sepharose pull down assays indicate that AFAP-110delta cterm fails to associate with GST-14-3-3 (figure 3 - 
representative of two experiments, figure5), whereas four out of seven experiments demonstrate that AFAP-110 delta cterm associates with 14-3-3 better than wild type (figures 4,6,7,8). We also performed gluthathione sepharose pull down assays from the cell lysates over expressing GST-14-3-3 (or even GST-Cterm-14-3-3) with wild type AFAP-110 or AFAP-110 deletion mutants missing one or several prospective 14-3-3 binding sequences (table 2). We failed to get consistent results with these mutants as well. For example, in figure 5 we see that AFAP-110 ${ }^{\Delta \text { lzip }}$ associates with GST-14-3-3 better than AFAP-110 full length and any other mutant, and that even GST-Cterm-14-3-3 strongly interacts with AFAP-110 ${ }^{\text {Llzip }}$, whereas the very next experiment indicates just the opposite - that AFAP-110 ${ }^{\text {Lzip }}$ fails to associate with 14-3-3 (figure 6). The same can be said about interactions of GST-14-3-3 with any other AFAP-110 deletion mutant used in these assays shown in figures 5 through 7. Therefore we have decided to drop this project at this point. We have determined that 14-3-3 and AFAP-110 associate in vivo, although it is still unclear whether this association is direct or indirect. It remains to be determined which sequence(s) within AFAP-110 structure facilitate AFAP-110 interaction with 14-3-3 in vivo. 


\section{Discussion.}

14-3-3 proteins comprise a group of small acidic proteins, which act as adaptor proteins in living cells; due to their ability to form dimers they can regulate function of signaling proteins by either changing their conformation or bringing several different proteins into multi-protein signaling complexes (27). 14-3-3 proteins are expressed ubiquitously, and are known to bind to over sixty cellular proteins via well-defined target motifs RSXpS/TXP or RXSXpS/TXP containing phosphorylated serine or threonine residue in the middle thereby regulating their function (28). In this work we tried to determine whether actin filament associated protein AFAP-110 is a binding partner for 14-3-3. AFAP-110 is an actin filament cross-linking protein with an intrinsic ability to remodel actin in response to Src/PKC signaling; 14-3-3 association with AFAP-110 could link AFAP-110 to Raf-MAPK cascade or stabilize AFAP-110 interactions with PKC in the same manner as 14-3-3 brings PKC and Raf together into close proximity.

Western blotting analysis of AFAP-110 with anti-14-3-3 binding site antibody suggested that AFAP-110 is a possible binding partner for 14-3-3 (Figure 1). Gluthathione sepharose pull down assays from cell lysates co-expressing GST-tagged 14-3-3 and AFAP-110 indicate the possibility of in vivo association of these two proteins. Analysis of amino acid sequence of AFAP-110 demonstrates that there are twelve prospective 14-3-3 binding sequences within AFAP-110 structure (table1). In order to determine which sequences facilitate AFAP-110 association with 14-3-3 in vivo we co-expressed GST-14-3-3 with either full length AFAP-110 or either one of five AFAP-110 deletion mutants (table 2). We were trying to determine which deletion would result in inability of AFAP-110 to associate with 14-3-3; AFAP-110 mutant, which would fail to associate with GST-14-3-3, would therefore miss 14-3-3 binding site(s) responsible for 14-3-3 interactions with AFAP-110. Inability of a deletion mutant to associate with 14-3-3 would suggest the possibility of direct interaction between AFAP110 and 14-3-3. At first the data was indicating that AFAP- $110^{\Delta \text { cterm }}$ fails to associate with 14-3-3, and we thought that one of the four carboxy-terminal potential14-3-3 binding sequences of AFAP-110 facilitate interactions with 14-3-3. It was also possible that the carboxy-terminal truncation of AFAP-110 alters a strong potential 14-3-3 interaction site delineated by amino acids 545-550, so the AFAP-110 mutant that has 
serine in the middle of this site substituted by alanine residue was created to test the importance of this particular sequence in AFAP-110 interactions with 14-3-3. We also made another site-directed mutant of AFAP-110 by substitution of serine residue (s569) in the middle of neighboring prospective 14-3-3 binding sequence delineated by amino acids 565-571. This is the most amino terminal of four potential 14-3-3 binding sites, which are completely missing in AFAP $-110^{\Delta \text { cterm }}$. We decided to compare effects of these two amino acid substitutions on AFAP-110 associations with 14-3-3. GST-14-3-3 pull down assays have shown that neither one of these mutants fail to associate with 143-3 although GST-14-3-3 associates with AFAP-110 ${ }^{\text {s548a }}$ weaker than with either wild type AFAP-110 or AFAP-110 ${ }^{\mathrm{s569a}}$. Therefore, amino acids 545-550 may represent one of the pivotal 14-3-3 interaction sequences within AFAP-110 structure, but certainly not the only one. More experiments are required to determine the significance of this particular sequence in AFAP-110-14-3-3 interactions.

Further experiments have demonstrated that AFAP-110 delta cterm interacts with GST-14-3-3 better than full length AFAP-110, which did not agree with the previous data. In order to determine whether AFAP- $110^{\Delta \text { cterm }}$ associates with $14-3-3$ better or worse than full length AFAP-110 more gluthathione sepharose affinity absorptions of GST-14-3-3 from cell lysates co-expressing GST-14-3-3 and AFAP-110 or AFAP$110^{\Delta \text { cterm }}$ or any other existing AFAP-110 deletion mutants were performed. The results were controversial for all the deletion mutants used in these experiments; for example, in case of GST-14-3-3 and AFAP-110 ${ }^{\Delta \text { cterm }}$ co-expressions the results of the three pull down assays inducate failure of AFAP-110 cterm to associate with 14-3-3 whereas the results of four pull down assays demonstrate that AFAP-110 $10^{\Delta \text { cterm }}$ associates with 14-3-3 much better than full length AFAP-110. It is uncertain at this point whether the loss of cterminus, or deletion of leucine zipper or any other region of AFAP-110 (table 2) has positive or negative effect on ability of AFAP-110 to associate with 14-3-3 in vivo. The controversy of results of our pull down experiments may be explained by the differences in phosphorylation level of AFAP-110 at the time when the cells were lysed, as it is known that 14-3-3 binding is phosphorylation dependent; serine/threonine phosphorylation is also known to induce conformational change of AFAP-110, therefore the variations in phosphorylation levels and conformation of AFAP-110 at the time of 
cell lysis may be responsible for the lack of consistency in our pull down assays. 14-3-3 proteins are known to interact with over 60 binding partners in living cells (28), and the binding of 14-3-3 proteins to their targets does not always occur via interactions of inner surface of 14-3-3 binding groove with phosphoserine-containing consensus sites RSXpS/TXP or RXSXpS/TXP. For example, 14-3-3 is known to bind to adaptor protein IRS-1 in phosphospecific manner despite the fact that IRS-1 contains no 14-3-3 binding consensus sequences such as RSXpS/TXP or RXSXpS/TXP (27). In some cases the interaction with target protein may occur on the outer surface of 14-3-3 binding groove (9). In the latter case it is unknown which sequences on target proteins facilitate its interactions with 14-3-3, and 14-3-3 binding in this case is likely to be phosphorylationindependent.

In conclusion it can be said that our experiments indicated that AFAP-110 associates with 14-3-3 in vivo, although it still remains unclear whether this association is direct or facilitated by one or more of 60 14-3-3 binding partners. In order to determine whether AFAP-110 interacts with 14-3-3 directly we would need to perform affinity absorption of purified AFAP-110 with purified 14-3-3 and vice versa; for this experiment we would need both proteins to be purified from mammalian cells, so they would be in proper conformation and contain proper post-translational modifications, which will most likely be absent in proteins expressed in bacterial cells. We do not have all the necessary equipment to perform this kind of experiment at this time, so this project must be postponed until this kind of equipment is available. 
Figures and legends.

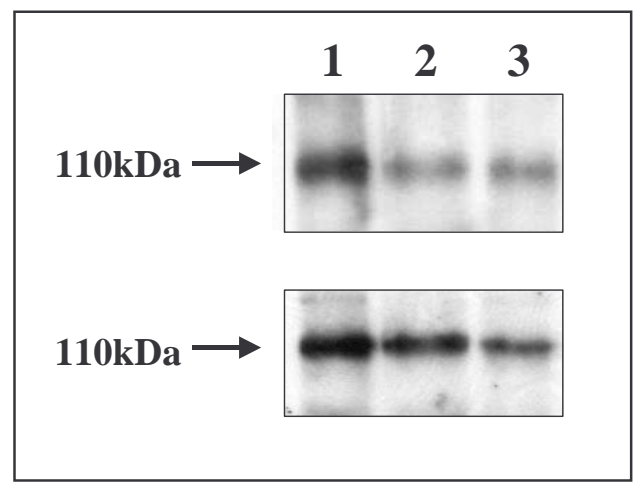

Figure 1. Cos-1 cells were transiently transfected with AFAP-110 with no treatment (lane 1), AFAP-110 with Src $^{527 F}$ (lane2), or AFAP-110 along treated with 100nM PMA for 1 hour (lane3). AFAP-110 was immunoprecipitated from these cells and subjected to SDS-PAGE followed by Western transfer and staining with anti 14-3-3 binding site antibody (upper panel). Blot was stripped and reprobed with 4C3 antibody to determine AFAP-110 expression levels (lower panel). 


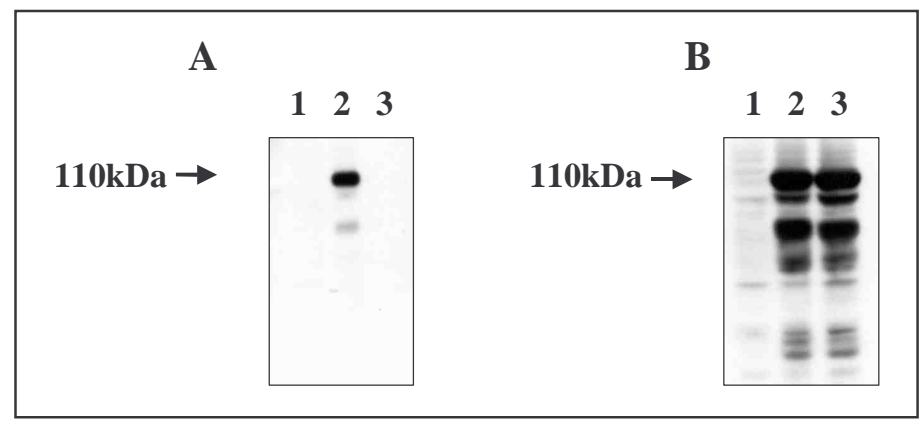

Figure 2. Cos-1 cells were transiently transfected with either GST-14-3-3 alone or AFAP-110 alone (lanes 1 and 3 respectively in both panels) or co-transfected with both GST-14-3-3 and AFAP-110 (lane 2 in both panels). A. GST-14-3-3 was pulled down from cell lysates with gluthathione sepharose beads and subjected to SDS-PAGE followed by western blotting with F1 antibody. Pull down assay was normalized to GST14-3-3 levels. B. AFAP-110 expression levels in cells lysates used in panel A. 


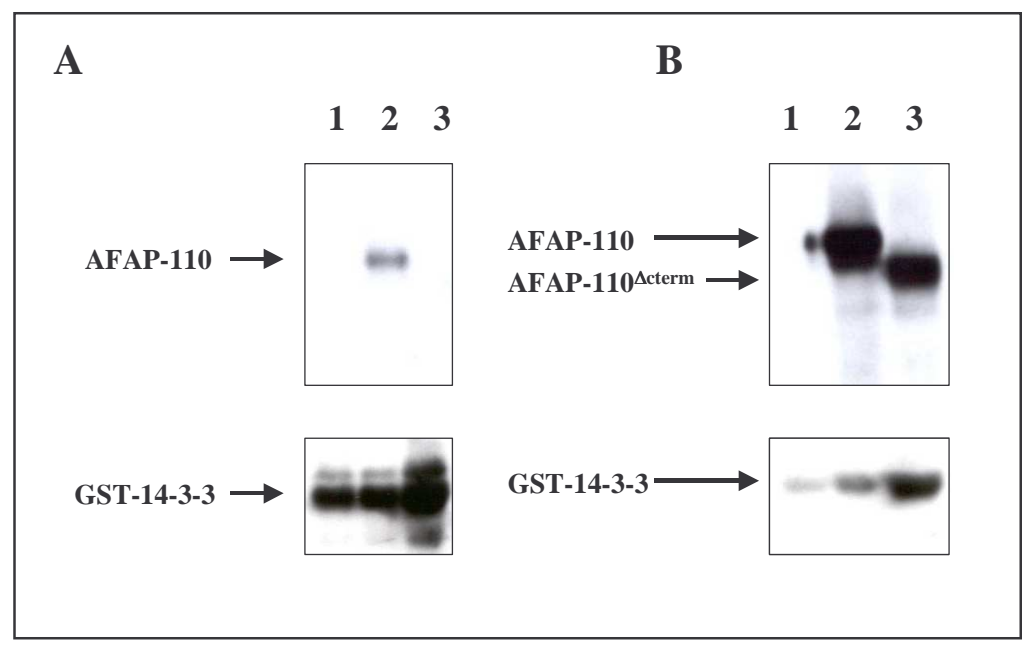

Figure 3. Cos-1 cells were transiently transfected with either GST-14-3-3 alone (lane 1 in both panels) or co-transfected with GST-14-3-3 with either full length AFAP-110 (lane 2 in both panels) or AFAP-110 ${ }^{\text {cterm }}$ (lane 3 in both panels). GST-14-3-3 was pulled down from cell lysates with gluthathione sepharose beads and subjected to SDS-PAGE followed by western blotting with anti-AFAP-110 antibody F1. Pull down assay was normalized to GST-14-3-3 levels. B. AFAP-110 expression levels in cells lysates used in panel A. 


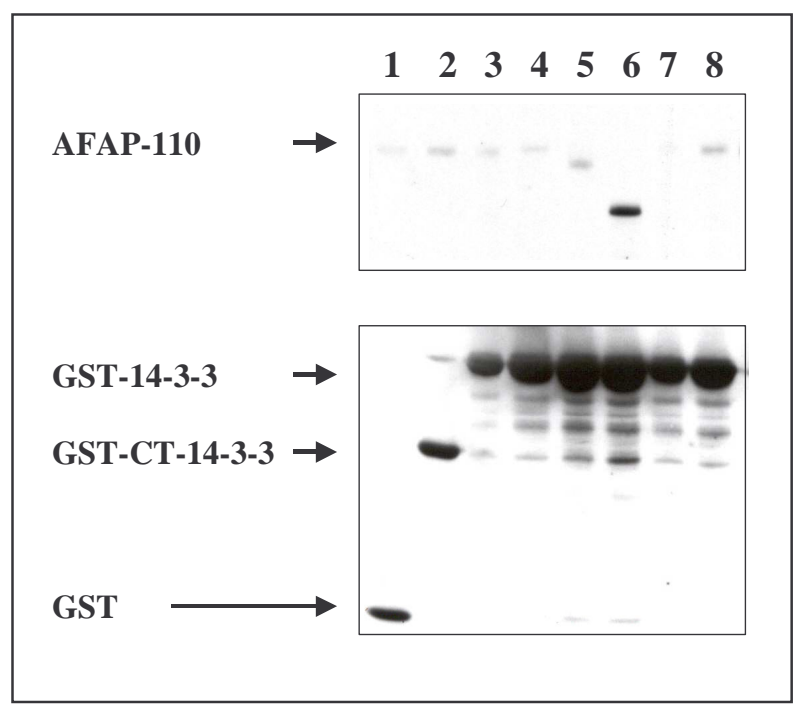

Figure 4. Upper panel - F1 blot of gluthathione sepharose pull down of GST-14-3-3 from Cos- 1 cell lysates co-expressing 1 - GST and full length AFAP-110, 2- GST-CT-14-3-3 and full length AFAP-110, 3- GST-14-3-3 and full length AFAP-110, 4- GST-14-3-3 and

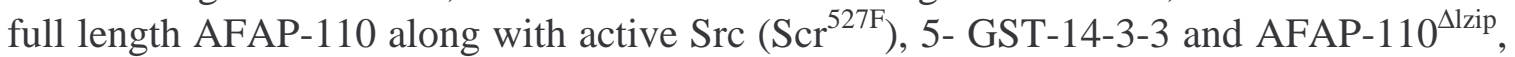
6- GST-14-3-3 and AFAP-110 ${ }^{\text {cterm }}, 7-G S T-14-3-3$ and AFAP-110 ${ }^{\text {s548a }}$, 8- GST-14-3-3 and AFAP-110 ${ }^{\mathrm{s} 569 \mathrm{a}}$. Lower panel represents GST, GST-CT-14-3-3 and GST-14-3-3 levels to which the pull down assays were normalized. 


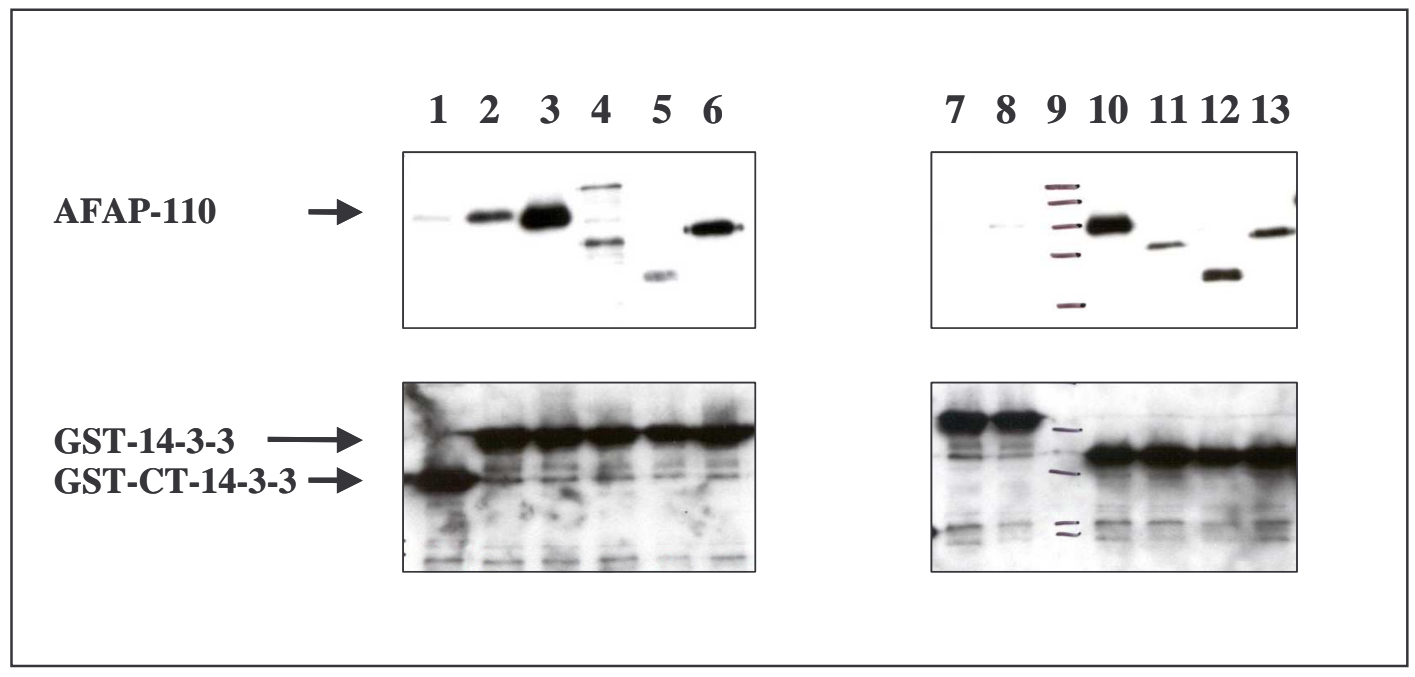

Figure 5. Upper panels - 4C3 blot of gluthathione sepharose pull down of GST-14-3-3 from Cos-1 cell lysates co-expressing 1 - GST-CT-14-3-3 and full length AFAP-110, 2GST-14-3-3 and full length AFAP-110, 3- GST-14-3-3 and AFAP-110 ${ }^{\text {lzip }}$, 4- GST-14-33 and AFAP-110 ${ }^{\Delta \text { cterm }}, 5-$ GST-14-3-3 and AFAP-110 ${ }^{\text {Sfu } \Delta}, 6-$ GST-14-3-3 and AFAP$110^{\Delta 44}, 7-$ GST-14-3-3 and AFAP-110 ${ }^{\text {s548a }}, 8-$ GST-14-3-3 and full length AFAP-110 along with active Src (Scr $\left.{ }^{527 F}\right)$, 9- rainbow weight markers, 10- GST-CT-14-3-3 and AFAP-110 ${ }^{\Delta l z i p}, 11-$ GST-CT-14-3-3 and AFAP-110 ${ }^{\Delta \text { cterm }}$, 12- GST-CT-14-3-3 and AFAP-110 ${ }^{\text {Sfu } \Delta}$, 13- GST-CT-14-3-3 and AFAP-110 ${ }^{\Delta 44}$. Lower panels represent GST-143-3 and GST-CT-14-3-3 levels to which the pull down assays were normalized. 


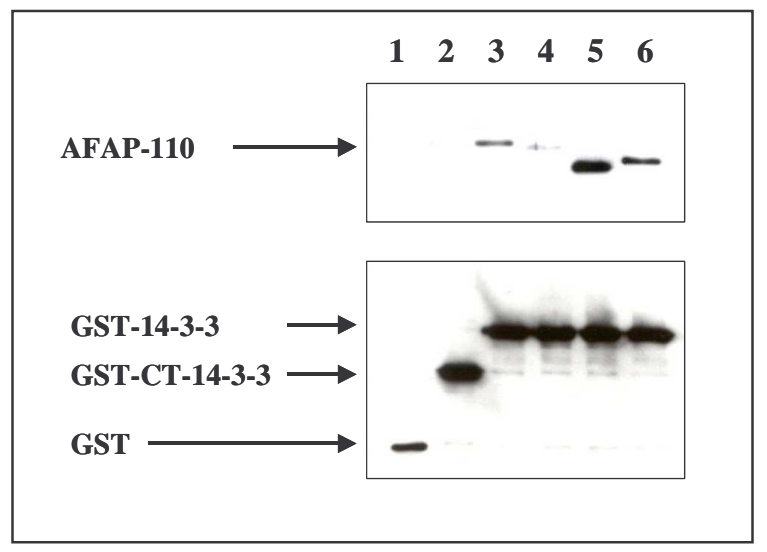

Figure 6. Upper panel - 4C3 blot of gluthathione sepharose affinity absorption of GST14-3-3 from Cos-1 cell lysates co-expressing 1 - GST and full length AFAP-110, 2GST-CT-14-3-3 and full length AFAP-110, 3- GST-14-3-3 and full length AFAP-110, 4GST-14-3-3 and AFAP-110 ${ }^{\Delta \text { zip }}, 5-$ GST-14-3-3 and AFAP-110 ${ }^{\Delta \text { cterm }}$, 6- GST-14-3-3 and AFAP- $110^{\Delta 44}$. Lower panels represent GST, GST-14-3-3 or GST-CT-14-3-3 levels to which the affinity absorption assays were normalized. 


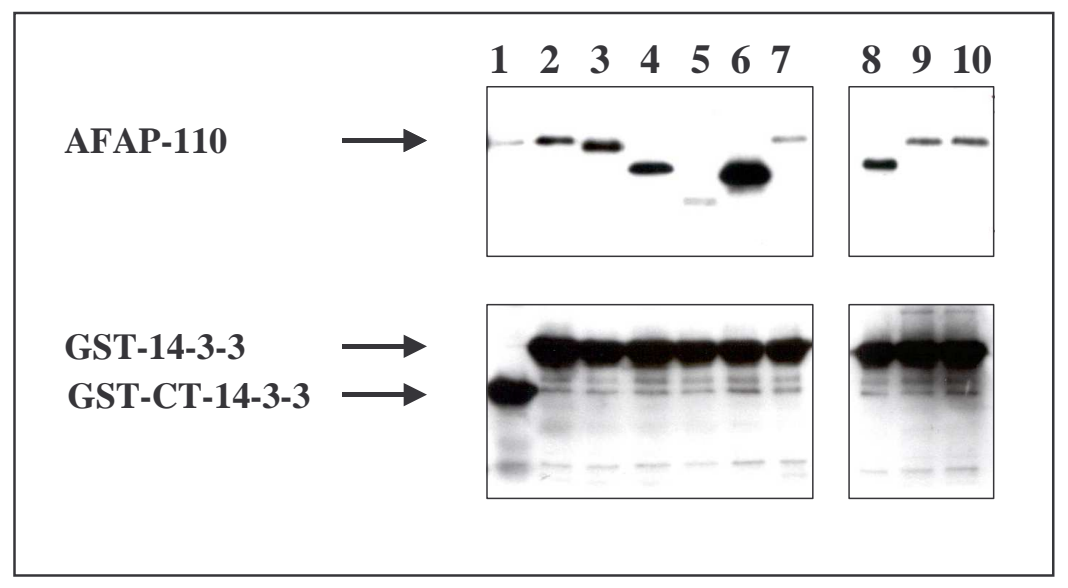

Figure 7. Upper panel - 4C3 blot of gluthathione sepharose affinity absorption of GST14-3-3 from Cos-1 cell lysates co-expressing: 1 - GST-CT-14-3-3 and full length AFAP110, 2- GST-14-3-3 and full length AFAP-110, 3- GST-14-3-3 and AFAP-110 ${ }^{\text {Llzip }}$, 4GST-14-3-3 and AFAP-110 ${ }^{\Delta \text { cterm }}, 5-$ GST-14-3-3 and AFAP-110 ${ }^{\text {Sfu } \Delta}$, 6- GST-14-3-3 and AFAP-110 $\Delta 146-343,7$ - GST-14-3-3 and AFAP-110 ${ }^{\text {s548a }}, 8-$ GST-14-3-3 and AFAP$110^{\Delta 44}, 9-$ GST-14-3-3 and AFAP-110 ${ }^{5569 a}, 10-$ GST-14-3-3 and full length AFAP-110 along with active $\mathrm{Src}\left(\mathrm{Scr}^{527 F}\right)$. Lower panels represent GST-14-3-3 and GST-CT-14-3-3 levels to which the affinity absorption assays were normalized. 


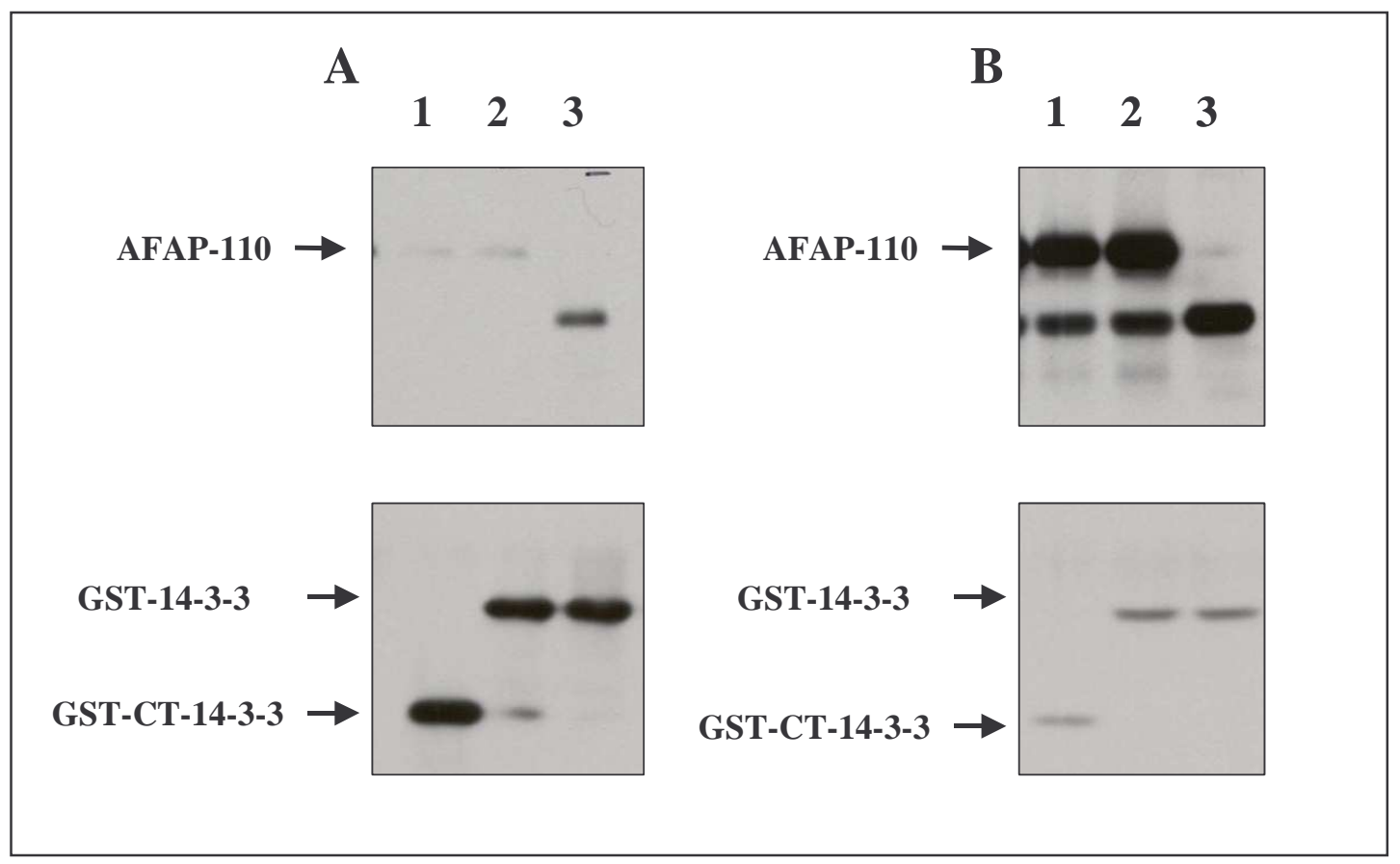

Figure 8. Cos cells were co-transfected with GST-CT-14-3-3 and AFAP-110 (lanes 1), GST-14-3-3 and AFAP-110 (lanes2) or GST-14-3-3 and AFAP-110 ${ }^{\Delta \text { cterm }}$. A. Western blots of gluthathione sepharose affinity absorption of GST-CT-14-3-3 or GST-14-3-3 from Cos cell lysates. Upper panel represents 4C3 western blot; lower panel shows the same blot as in upper panel striped and reprobed with anti-GST antibody to visualize CT14-3-3 and 14-3-3 levels. B. Western blot for expression levels of AFAP-110 (upper panel, 4C3 antibody staining) and GST-CT-14-3-3 and GST-14-3-3 (lower panel, antiGST antibody staining). 


\section{References}

1. Morrison, D. (1994) Science 266, 56-57

2. Aitken, A., Jones, D., Soneji, Y., and Howell, S. (1995) Biochem.Soc.Trans. 23, 605-611

3. Burbelo, P. D. and Hall, A. (1995) Curr.Biol. 5, $95-96$

4. Baldin, V. (2000) Prog. Cell Cycle Res. 4, 49-60

5. Reuther, G. W. and Pendergast, A. M. (1996) Vitam.Horm. 52, 149-175

6. Skoulakis, E. M. and Davis, R. L. (1998) Mol.Neurobiol. 16, 269-284

7. Jones, D. H., Ley, S., and Aitken, A. (1995) FEBS Lett. 368, 55-58

8. Marais, R. and Marshall, C. (1995) Structure. 3, 751-753

9. Fu, H., Subramanian, R. R., and Masters, S. C. (2000) Annu.Rev.Pharmacol.Toxicol. 40, 617-647

10. Van Der Hoeven, P. C., Van Der Wal, J. C., Ruurs, P., Van Dijk, M. C., and Van Blitterswijk, J. (2000) Biochem.J. 345 Pt 2, 297-306

11. Hausser, A., Storz, P., Link, G., Stoll, H., Liu, Y. C., Altman, A., Pfizenmaier, K., and Johannes, F. J. (1999) J.Biol.Chem. 274, 9258-9264

12. Acs, P., Szallasi, Z., Kazanietz, M. G., and Blumberg, P. M. (1995) Biochem.Biophys.Res.Commun. 216, 103-109

13. Aitken, A., Jones, D., Soneji, Y., and Howell, S. (1995) Biochem.Soc.Trans. 23, 605-611

14. Tzivion, G., Luo, Z., and Avruch, J. (1998) Nature 394, 88-92

15. Freed, E., McCormick, F., and Ruggieri, R. (1994) Cold Spring Harb.Symp.Quant.Biol. 59, 187-193

16. Rommel, C., Radziwill, G., Lovric, J., Noeldeke, J., Heinicke, T., Jones, D., Aitken, A., and Moelling, K. (1996) Oncogene 12, 609-619

17. Clark, G. J., Drugan, J. K., Rossman, K. L., Carpenter, J. W., Rogers-Graham, K., Fu, H., Der, C. J., and Campbell, S. L. (1997) J.Biol.Chem. 272, 20990-20993

18. Robinson, K., Jones, D., Patel, Y., Martin, H., Madrazo, J., Martin, S., Howell, S., Elmore, M., Finnen, M. J., and Aitken, A. (1994) Biochem.J. 299 ( Pt 3), 853-861 
19. Toker, A., Ellis, C. A., Sellers, L. A., and Aitken, A. (1990) Eur.J.Biochem. 191, 421-429

20. Aitken, A., Howell, S., Jones, D., Madrazo, J., Martin, H., Patel, Y., and Robinson, K. (1995) Mol.Cell Biochem. 149-150, 41-49

21. Van Der Hoeven, P. C., Van Der Wal, J. C., Ruurs, P., Van Dijk, M. C., and Van Blitterswijk, J. (2000) Biochem.J. 345 Pt 2, 297-306

22. Bax, B. and Jhoti, H. (1995) Curr.Biol. 5, 1119-1121

23. Roth, D. and Burgoyne, R. D. (1995) FEBS Lett. 374, 77-81

24. Roth, D., Birkenfeld, J., and Betz, H. (1999) FEBS Lett. 460, 411-416

25. Guappone, A. C. and Flynn, D. C. (1997) Mol.Cell Biochem. 175, 243-252

26. Guappone, A. C., Weimer, T., and Flynn, D. C. (1998) Mol.Carcinog. 22, 110-119

27. Tzivion, G. and Avruch, J. (2002) J.Biol.Chem. 277, 3061-3064

28. Tzivion, G., Shen, Y. H., and Zhu, J. (2001) Oncogone 6331-6338 
Chapter 4

\section{General discussion}


AFAP-110 was discovered in late eighties as a protein that associates with active Src in v-Src-transformed chicken embryo fibroblast cells (1). AFAP-110 co-localizes with actin stress fibers as well as cortical actin cytoskeleton in normal cells and with actin rosettes in Src transformed cells. As AFAP-110 is hyperphosphorylated in response to co-expression with active Src and also has the ability to associate with this non-receptor tyrosine kinase, it was proposed that AFAP-110 might be an effector protein for Src that remodels actin cytoskeleton in response to Src activation by extracellular stimuli (2).

AFAP-110 contains several protein-protein interaction modules, which enable this protein to bind to other proteins such as filamentous actin and cellular kinases Src and PKC. AFAP-110 also possesses the ability to multimerize via carboxy-terminal leucine zipper motif. The deletion of carboxy terminal leucine zipper motif enables AFAP-110 to disorganize actin cytoskeleton resulting in a phenotype resembling the consequences of active Src over expression characterized by actin filament repositioning into actin rosettes. AFAP-110 therefore possesses an intrinsic ability to remodel actin cytoskeleton.

In recent years it has been determined that AFAP-110 is an actin cross-linking protein, and that actin cross-linking ability of AFAP-110 is regulated by serine/threonine phosphorylation (Qian et al, accepted). AFAP-110 actin cross-linking properties are dependent on its multimerization status; non-phosphorylated AFAP-110 is thought to exist in a form of large multimeric complexes cross-linking filamentous actin into a lattice of loosely interconnecting actin fibers whereas phosphorylated AFAP-110 is thought to exist only in a form of dimers and cross-link actin filaments into a network of short bundles (Qian et al, accepted). AFAP-110 ability to self-associate is regulated by serine/threonine phosphorylation in PKC dependent manner (Baisden and Flynn, unpublished data). Therefore it became important to identify serine and threonine residues within AFAP-110 structure phosphorylation of which induces changes in AFAP110 conformation resulting in altered mode of self-association and consequently in enhancement of actin cross-linking properties of AFAP-110. Identification of functional phosphorylation sites of AFAP-110 was an objective of the first project, described in chapter 2 of this thesis.

Firstly, we performed phosphotryptic-mapping analysis of AFAP-110 either recombinant phosphorylated by $\mathrm{PKC} \alpha$ in vitro or AFAP-110 derived from radio labeled 
cultured cells either expressing active Src or treated with PKC activator PMA. We determined that $\mathrm{PKC} \alpha$ phosphorylates AFAP-110 on multiple residues in vitro and also that two of the fragments on the maps of in vivo derived AFAP-110 are likely to be products of PKC dependent phosphorylation in vivo.

Secondly, we performed PCR-based deletional mutagenesis to determine which domains of AFAP-110 are the most likely to contain functional phosphorylation sites as the analysis of AFAP-110 amino acid sequence revealed over twenty PKC consensus phosphorylation sequences. Confocal actin filament cross-linking assays developed by Qian and colleagues (Qian et al, accepted) were used as a test for AFAP-110 phosphorylation-regulated function. Wild type AFAP-110 cross-links actin filaments into loose lattices when non-phosphorylated, but, once it is phosphorylated, this protein arranges actin filaments into more efficiently cross-linked actin filament aggregates. In our experiments with AFAP-110 deletion mutants we were looking whether any of them would fail to display increase in actin cross-linking efficiency upon phosphorylation. Such a mutant was found; it is an AFAP-110 deletion mutant missing amino acids 249346 comprising $\underline{\text { Serine }}$ Threonine Kinase Interaction (STK) region.

There are nine prospective PKC phosphorylation sites within STK region, therefore two more deletional mutants were created, each missing either first (amino acids 249-294) or second half (amino acids 295-346) of STK region. The deletion of amino terminal half of STK region abrogated PKC $\alpha$-dependent increase in actin filament cross-linking efficiency of AFAP-110, whereas the deletion of carboxy-terminal half of STK region did not have any effect on PKC $\alpha$-dependent increase in actin filament crosslinking efficiency of AFAP-110. Therefore we draw a conclusion that functional phosphorylation sites of AFAP-110 must reside within amino acid stretch 249-294. There are six candidate sites in this region; therefore we created two more deletion mutants missing either first (amino acids 249-265) or second (amino acids 266-294) quarter of STK region to narrow down to the region containing not more than four potential sites. Our data suggests that four serine residues within amino acid stretch 266-294 are the most likely candidates to be functional PKC phosphorylation sites responsible for phosphorylation-regulated AFAP-110 function. These residues are being altered by sitedirected mutagenesis either all at once or in pairs. Future experiments will determine 
whether some or all of these serine residues are AFAP-110 functional phosphorylation sites. Phosphotryptic mapping analysis will determine if these serine residues are phosphorylated in vitro versus in vivo. The mutants will also be tested in in vitro actin filament cross-linking assays to determine whether a loss of all the four serine residues or either serine pair would result in inability of PKC $\alpha$ to enhance actin cross-linking properties of AFAP-110. These mutants will also be expressed in cultured cells to determine whether any of them would block the effects of active PKC on actin cytoskeleton.

The objective of the second project described in chapter three was to determine whether AFAP-110 is a binding partner for 14-3-3. 14-3-3 proteins are a family of small acidic proteins originally discovered as brain proteins in 1967 (Moore and Perez, 1967). By now it is known that these proteins are expressed ubiquitously and are common to every known organism studied up to date. They have no catalytic function of their own but nevertheless play an important role in cellular signal transduction pathways because of their ability to act as scaffolds and/or allosteric regulators for signaling proteins due to their ability to form dimers (3). 14-3-3 proteins dimerize via interaction between their amino terminal parts and bind to target proteins via highly conserved carboxy terminally located binding grooves, which are know to recognize specific target sequences in phosphorylation-dependent manner. These target sequences usually have phosphorylated serine or threonine in the middle, position 0 , with basic amino acid in position -3 or -4 and proline in position +2 . The basic amino acid in -4 or -3 position in most case is arginine but sometimes it can be substituted by lysine. Basic amino acid in position -4 or -3 as well as phosphorylation of serine/threonine in position 0 are required for 14-3-3 binding to occur, whereas proline in position +2 is preferred but no absolutely required. There are certain preferences in other positions surrounding the central phosphorylated serine/threonine but neither of them as crucial as the presence of basic residue in position -4 or -3 or requirement for phosphorylation of the central serine/threonine. Binding groove of 14-3-3 proteins in fact was the first serine/threonine phosphorylation-binding domain discovered and nowadays it remains the best-studied phospho-serine/threonine binding module. 
14-3-3 binds a wide variety of proteins participating in different cellular pathways, among which are serine/threonine kinases Raf, PKC and Bcr, cellular adaptor proteins IRS-1, Gab1, and p66Shc, apoptotic protein Bad, cdc25C phosphatase and others $(4 ; 5)$ We proposed to determine whether AFAP-110 would be a binding partment for 143-3.

First of all, by Western blotting analysis of cellular AFAP-110 with phosphospecific anti-14-3-3 binding site antibody we determined that AFAP-110 contains 14-3-3 binding sequence(s). By the next experiment demonstrated that 14-3-3 and AFAP-110 are associated in vivo, although it remained unknown whether the two proteins bind to each other directly or via some other cellular adaptor. Analysis of AFAP-110 amino acid sequence revealed the presence of twelve potential 14-3-3 binding sequences in its structure, three of which were better candidates comparing to the remaining nine according to Dr. Gury Tzivion (personal communication).

When we have shown that AFAP-110 associates with 14-3-3 in vivo, we have decided to find out which regions of AFAP-110 make this interaction possible. It was decided to co-express different AFAP-110 deletion mutant missing one or several potential 14-3-3 binding sequences in order to determine which deletion if any results in abrogation of AFAP-110 association with 14-3-3. The mutant that would fail to associate with 14-3-3 in vivo would do so either because it lacks important 14-3-3 binding site(s) or simply because deletion of a certain region results in altered AFAP-110 conformation so that 14-3-3 can no longer associate with AFAP-110. Once such a mutant was found, we would have used PCR-based site directed mutagenesis to substitute serine/threonine residue(s) in the middle of important 14-3-3 binding site(s) to alanines to determine whether AFAP-110 inability to associate with 14-3-3 is a result of disappearance of pivotal 14-3-3 binding sequence or merely the consequence of conformational change. If we would find that the disappearance of 14-3-3 binding site(s) as a result of deletion or site directed mutation is responsible for abrogation of 14-3-3 association with 14-3-3, we would have, first of all, found which 14-3-3 binding sequences within AFAP-110 structure make 14-3-3-AFAP-110 interactions possible, and, would get a strong suggestion that 14-3-3 binds AFAP-110 directly. 
Either one out of several AFAP-110 deletion mutants were co-expressed with GST-14-3-3 in cultured cells, and gluthathione sepharose affinity absorption of GST-143-3 followed by western blotting with anti-AFAP-110 antibodies were performed in order to determine which AFAP-110 mutant fails to associate with 14-3-3. Neither of AFAP110 deletion mutants used in our experiments consistently failed to associate with 14-3-3. This may occur due to a number of reasons. First of all, association of AFAP-110 with 14-3-3 may be indirect, and there is a third, yet unidentified protein that facilitated AFAP-110 interactions with 14-3-3. Second of all, 14-3-3 does not always bind to well defined RSXpSXP or RXXXpSXP sequences. 14-3-3 is known to bind in phosphorylation-dependent manner to proteins such as IRS-1, vimentin, Wee1, and IGFI, although neither of these proteins contains either one of well-defined 14-3-3 binding sequences (Tzivion and Avruch, 2001). 14-3-3 may also bind to target proteins via variable outer surface of binding groove.

Thus, we have determined that AFAP-110 associates with full length 14-3-3 in vivo, whereas association of monomeric 14-3-3 with AFAP-110 is very weak, almost at the background level. It still remains to be determined whether AFAP-110 and 14-3-3 associate directly and, if yes, whether 14-3-3 interactions with AFAP-110 are phosphorylation dependent and facilitated by any of the twelve conventional sequences defined as RSXpSXP or RXXXpSXP. 


\section{References}

1. Reynolds, A. B., Roesel, D. J., Kanner, S. B., and Parsons, J. T. (1989) Mol.Cell Biol. 9, 629-638

2. Baisden, J. M., Qian, Y., Zot, H. G., and Flynn, D. C. (2001) Oncogene 20, 64356447

3. Tzivion, G. and Avruch, J. (2002) J.Biol.Chem. 277, 3061-3064

4. Fu, H., Subramanian, R. R., and Masters, S. C. (2000) Annu.Rev.Pharmacol.Toxicol. 40, 617-647

5. Tzivion, G., Shen, Y. H., and Zhu, J. (2001) Oncogone 6331-6338 


\title{
Curriculum vitae
}

\author{
Lidia N Cherezova, M.S. (anticipated May, 2002)
}

\section{Personal and Professional}

\section{Personal}

Home: 5029 148-th Ave N.E. Apt K207 Bellevue, WA 98007

Tel: (425)-881-9665

Work: 2822 MBR Cancer Center, West Virginia University, Morgantown, WV 26506-9300

Tel: (304)-293-0501

Email: lcherezova@hotmail.com

Citizenship: Russian

\section{Education}

1998-present: West Virginia University, Department of Microbiology, Immunology and Cell Biology, M.S.

GPA: 4.0

Thesis: Determining the effects of phosphorylation on AFAP-110 function

Thesis advisor: Dr. Daniel C. Flynn

1991-1996: Novosibirsk State University, Department of Natural Sciences, Biology, Baccalaureate Degree (Physiology)

GPA: 3.5

Thesis advisors: Dr. Biol. Sci, Professor M.S. Vinogradova;

Dr. Biol. Sci I.M. Korostyshevskaya;

Dr. Biol. Sci E.I. Ryabchikova.

Thesis title: "Morphological and functional features of cardiomiocytes of heterothermic animals in different seasonal and physiological states".

\section{Professional}

\section{Research:}

1998-present: Graduate research in the laboratory of Dr. Daniel C.Flynn, Department of Microbiology, Immunology and Cell Biology, West Virginia University.

1994-1996: Undergraduate research in the laboratories of Dr. Biol Sci, Professor M. S. Vinogradova, Deparment of Natural Sciences, Chair of Physiology, Novosibirsk State University; Dr. Biol. Sci I. M. Korostyshevskaya, Institute of Physiology, Novosibirsk; Dr. Biol. Sci E. I. Ryabchikova, State Research Center of Virology and Biotechnology "Vector", Koltsovo. 


\title{
Supervision:
}

Summer, 2001: supervisor to an undergraduate student for two summer semesters.

\section{Teaching:}

1998-2000: Teaching assistant for two semesters of Parasitology Labs for Medical Technology students, one semester of Microbiology Labs for Dental Students.

\section{Laboratory techniques:}

1. Tissue culture.

2. Transient transfection of cultured mammalian cells.

3. Immunoprecipitation.

4. Western blotting analysis.

5. Agarose and polyacrylamide gels.

6. DNA and RNA purification.

7. DNA restriction digestion and sub-cloning.

8. Small and large-scale DNA preparation.

9. PCR-based site-directed and deletional mutagenesis.

10. Immunofluorescence.

11. Confocal microscopy.

12. ${ }^{32} \mathrm{P}$-orthophosphate labeling of cultured mammalian cells.

13. Phosphoaminoacid analysis.

14. Phosphotryptic mapping analysis.

15. GST-fusion protein induction.

16. In vitro $\mathrm{PKC}$ phosphorylation of recombinant proteins.

17. In vitro actin cross-linking assays.

18. Chicken embryo fibroblast plating.

19. Chicken embryo fibroblast synchronization in the different phases of the cell cycle.

20. Cell fractionation.

20. Taking and processing hibernating animal (ground squirrel) heart atrium samples for further analysis using electron microscopy.

\section{Honors and awards}

Third prize in XXXV International Scientific Students Conference "Student and Progress in Science and Technology” organized by Novosibirsk State University.

\author{
Abstracts \\ L.Cherezova, J.M. Baisden, H.G. Zot, Y. Qian, and D.C. Flynn. Phosphorylation of \\ AFAP-110 regulates its ability to alter actin cytoskeleton. ASCB meeting, San \\ Francisco. December 9-13, 2000. \\ L. Cherezova, Y. Qian, J.M. Baisden, H.G. Zot, and D.C. Flynn. PKC induces actin \\ bundling ability of AFAP-110. AACR meeting, San Fransisco. April 6-10, 2002.
}




\section{Publications}

L. Cherezova, A.S. Gatesman, and D.C. Flynn. The effects of phosphorylation on adaptor protein function. 2002 Frontiers in bioscience 7: D164-D203.

Qian Y., J.M. Baisden, L. Cherezova, Justin M Summy ${ }^{1}$, A. Guappone-Koay, X. Shi, T. Mast, J. Pustula, H.G. Zot, Nayef Mazloum, Marietta Y Lee ${ }^{4}$, and D.C. Flynn. PKC phosphorylation increases the ability of AFAP-110 to cross-link actin filaments. Mol. Biol. Cell. Accepted.

J.M. Baisden, A S. Gatesman, L. Cherezova, B.-H. Jiang, and D.C. Flynn. The intrinsic ability of AFAP-110 to alter actin filament integrity is linked with its ability to also activate cellular tyrosine kinases. 2001 Oncogene 20 (45): 6607-6616

M.S. Vinogradova, L.N. Cherezova, I.M. Korostyshevskaya, and L.V. Kolesnikova. Cardiomyocytes of a Heterothermic Animal in Various Physiological States. September 1998. Bulletin of experimental biology and medicine. Vol. 126, Number 9, p. 957.

\section{Relevant graduate coursework}

1. Graduate Microbiology and Immunology, including Immunology, Virology and Bacteriology (two semesters), Department of Microbiology, Immunology, and Cell Biology, West Virginia University.

2. Cell and Molecular Biochemistry (two semesters), Department of Biochemistry, West Virginia University.

3. Graduate Seminar (seven semesters), Department of Microbiology, Immunology, and Cell Biology, West Virginia University.

4. Introduction to Molecular Modeling (one semester), School of Pharmacy, West Virginia University.

5. Yeast as a Model Eukaryote (one semester), Department of Microbiology, Immunology, and Cell Biology, West Virginia University.

\section{Computer skills}

Word, Excel, Adobe Photoshop, Power Point, Stratagene Eagle Eye.

\section{Society membership}

American Society for Cell Biology (ASCB): Student member. 